\title{
Transcrição do Inventário formado por Lorenzo Infante Boticário em la Ciudad de Córdoba de los bienes medicinales, Julio de $1772^{1}$
}

\author{
Eliane Cristina Deckmann Fleck \\ Roberto Poletto
}

Recibido: 17 de junio de 2013

Evaluado: 14 de julio de 2013

\section{Apresentação}

Se na América portuguesa, os jesuítas se encontravam instalados desde 1549 e já contavam com colégios em Piratininga, Salvador, Rio de Janeiro e Olinda, nas regiões da América espanhola, os missionários da Companhia de Jesus ingressariam somente a partir de 1568. Se consideramos, especificamente, a entrada de religiosos desta ordem em Córdoba de la nueva Andalucia, fundada, em 1573, pelo espanhol Jerônimo Luiz de Cabrera, então Vice-rei do Peru e governador do Tucuman, ela se deu somente quatorze anos depois, em 1587, sendo que tiveram que aguardar por mais doze anos para erguer a primeira casa da Companhia de Jesus em terreno cedido pelo cabildo da cidade. Nas últimas décadas do século XVI e nas duas primeiras do século XVII, Córdoba de la nueva Andalucía era

Una fortaleza, vários molinos y brazos del río (...) El fuerte era 'un ancón de tierra que empezaba a correr desde una barranca de el río Suquía, de donde se sacó la tierra para formar las tapias del fuerte, que [...] se reducía a una empalizada, o cerco de palos gruesos hincados en tierra (...) Así pues (...) no era más que el lecho del río, con pocos árboles aislados y grupos de piedra y arena con poco pasto ${ }^{2}$.

Um ano antes da chegada dos jesuítas à Córdoba, em outubro de 1586, havia sido decretada a ereção de uma capela, que veio a ser concluída somente em 1589. Os colonos haviam se empenhado "en edificar un templo y dar gracias a Dios e para este fim, juntaron las piedar bolas que hallaban en el río, disponiéndolas una sobre otra, en forma más o menos desordenada, y uniéndolas por medio de una mezcla de cal y arena." Tempos depois, com alguma dificuldade "lograron encontrar palos de suficiente longitud y resistencia como pra armar un techo de tijeras que cubrieron de barro y paja" ${ }^{3}$.

\footnotetext{
${ }^{1}$ Este documento encontra-se no Archivo Histórico de la Universidad Nacional de Córdoba, Argentina. Documentos de la Junta de Temporalidades de Córdoba. Caja 10, legajo 2, n 27, fólios 4533r - 4628 r.

${ }^{2}$ Gracia, 2006, Tomo II: 123.

${ }^{3}$ Ibíd: 123-124.
} 
Dez anos depois, em 1599, essa ermida passaria a ser propriedade da Companhia de Jesus, que buscou "medios para mejorar las construcciones", já que a capela "no tenía suficiente espacio para contener los fieles" e sua forma interior "no permitía la aplicación de adornos que faltaban en una iglesia"4. Neste mesmo local - "la manzana de la ermita" -, anos mais tarde, seriam construídos a igreja e o colégio, que, por decisão do Padre Provincial Diego de Torres Bollo, passou, em 1610, a denominar-se Colégio Máximo de la Compañía de Jesús, que, por autorização do Papa Gregório XV e do Rei espanhol Felipe III, em 1621, foi elevado à Universidade de Córdoba, oferecendo cursos de Artes e Teologia. Na verdade, após um período em que as atividades de formação foram transferidas para Santiago do Chile, o colégio jesuíta retomaria suas atividades em Córdoba, em 1614, contando com o inestimável apoio da Diocese de Córdoba, em especial, do Bispo Hernando de Trejo y Sanabria.

Neste mesmo período, a Companhia de Jesus passou a ampliar sua atuação junto às populações indígenas, o que pode ser atestado no número de reduções que foram instaladas, tais como as de São Miguel, São Cosme e Damião, São José, Santo Tomás, dos Apóstolos, São Carlos, Santos Mártires, Candelária, Santo Inácio e de Corpus. Enquanto alguns padres dirigiam-se ao "campo de las misiones”, em Córdoba - no colégio - permaneciam os noviços, os estudantes, os enfermos e um reduzido número de padres que encarregavam-se de ensinar e de ler - "según costumbre de la Compañía"- e confirmando a "muy vasta red de comunicación entre misioneros" - as notícias sobre as "conquistas espirituales (...) que acabavan con frecuencia en el martírio" 5 . Se em 1609, o Provincial Diego de Torres referiu-se à Córdoba como "el corazón de las três gobernaciones", em 1644, o Provincial Francisco Lupercio de Zurbano se referiria ao Colégio jesuítico de Córdoba como "el primero y mas frecuentado de nuestra província y es la Atenas de nuestros escolares”, o que parece confirmar a importante - e estratégica - função desempenhada pelo colégio instalado na “nueva Andalucía”.

Sabe-se que os colégios da Companhia de Jesus na América foram, por excelência, espaços de formação da Ordem e também de intensa produção e circulação de conhecimentos, contribuindo de forma decisiva para a cultura científica na América do período, como atestam as bibliotecas e as boticas que os jesuítas instalaram junto a eles. Ao manterem "sus propias farmacias tanto para abastecer la orden con medicina como para el servicio de la población local", os colégios da Companhia de Jesus "cooperaban entre ellas y formaban una red farmacéutica por todo el mundo"6. Muitos destes conhecimentos - relativos a receitas de medicamentos e a práticas terapêuticas foram compartilhados através da intensa correspondência que os missionários mantiveram entre si ou das cópias de matérias médicas e receituários que fizeram circular entre as reduções, as estâncias e os colégios das Províncias Jesuíticas na América e aqueles instalados na Europa e também no Oriente.

A manutenção de boticas nos colégios, reduções e estâncias mantidas pela Companhia de Jesus - e, especialmente, do valioso patrimônio que armazenavam -, tanto na América espanhola, quanto na portuguesa, podem ser comprovados nos inventários que delas foram feitos após a expulsão da Ordem dos domínios coloniais ibéricos na segunda metade dos século XVIII. Nestes inventários, aparecem

\footnotetext{
${ }^{4}$ Ibid.

${ }^{5}$ Ibid, Tomo II:15-16.

${ }^{6}$ Meier, 2011.
} 
relacionados ungüentos, óleos, purgas e vomitórios originários de diferentes regiões do Império espanhol e da Europa, apontando para a circulação - ou para o comércio - de medicamentos e plantas medicinais, numa troca de experiências que ultrapassava aquela que era feita, exclusivamente, por intermédio da rede epistolar mantida entre membros da Ordem jesuíta. Além de remédios, as boticas jesuíticas contavam ainda com instrumentos cirúrgicos, livros - impressos e manuscritos - e receituários, que foram também taxados pelos inventariantes designados.

Os jesuítas foram expulsos do território americano, em cumprimento ao Decreto de 27 de fevereiro de 1767, no qual Carlos III estabelecia: "He venido en mandar se extrañen de todos mis dominios de España e Índias, islas Filipinas y demás adyacentes a los religiosos de la Compañía, así sacerdotes como coadjutores o legos (...) y que se ocupen todas las temporalidades de la Compañía en mis domínios."7 A decisão de expulsar a Companhia de Jesus se inseria em um contexto mais amplo de reformas que viriam a ser realizadas tanto no império português, como no hispânico, e que visavam aumentar o controle do poder real sobre os domínios ultramarinos, tendo por base um conjunto de idéias pautadas na Ilustração. Em ambos os reinos, governados por déspotas esclarecidos - d. José I, em Portugal, e Carlos III, na Espanha, - objetivava-se redimensionar o papel do aparelho eclesiástico, subordinando-o ao Estado.

Em Córdoba del Tucumán, a execução da ordem real foi cumprida em 12 de julho de 1767, pelo Sargento Mayor do Batalhão de Voluntários da Infantaria espanhola de Buenos Aires, Fernando Fabro, que foi designado Teniente de Rey junto ao Auditor de Guerra Don Antonio Aldao. Dois dias depois foi autorizada a taxação dos bens das propriedades urbanas e das estâncias dos jesuítas em Córdoba, enquanto os 130 religiosos - padres, irmãos e noviços -, viriam a ser acomodados em 38 carretas e enviados para Buenos Aires na noite de 22 de julho. Em fevereiro de 1768 terá início o inventário da botica do Colégio de Córdoba, que, numa primeira etapa, se estenderá até maio de 1768, sendo retomado novamente em outubro de 1771 e concluído em março de 1772.

O inventário da botica do Colégio de Córdoba revelará que, além de preparados à base de nitro-ácido e amoníaco, como os 'vinos', e das águas - como a rosada, de melissa e de canela -, os boticários jesuítas contavam também com polvos extraídos de plantas medicinais americanas, como o da ipecacuanha ${ }^{8}$, além de livros especializados, como Concilari Médici a professariis, de Lazari Riveri (1679); Pharmacopea médicochymica, de Schrödera Hoffmannana (1687) e Medicina Ilustrada, de Francisco Suarez de Rivera (1725). Mais do que informações sobre os medicamentos utilizados pelos boticários jesuítas, o inventário oferece aos pesquisadores evidências tanto da aplicação e da circulação de conhecimentos europeus de Medicina e de Farmácia, quanto de experimentalismos e apropriações de saberes nativos, que podem ser constatados nos tratados de botânica médica e nos receituários escritos por irmãos e padres da Companhia de Jesus na primeira metade do século XVIII.

Na continuidade, apresentamos a transcrição - acrescida de comentários em notas de rodapé - do "Inventário formado por Lorenzo Infante Boticário em la Ciudad de Córdoba de los bienes medicinales, de julio de 1772”, que integra os Documentos de la Junta de Temporalidades de Córdoba, e que pode ser consultado no Archivo

\footnotetext{
${ }^{7}$ Colección Providencias..., 1767-1784.

${ }^{8}$ Page; Vera de Flachs, 2010: 123.
} 
Histórico de la Universidad Nacional de Córdoba, na cidade do mesmo nome. A transcrição e análise deste inventário atende a um dos objetivos previstos pelo projeto de pesquisa "Sobre o papel desempenhado pelos colégios e fazendas da Companhia de Jesus: um estudo comparado entre o Colégio do Rio de Janeiro e o Colégio de Córdoba - século XVIII”, submetido ao Edital Ciências Humanas, Sociais e Sociais Aplicadas Chamada MCTI/CNPq/MEC/CAPES № 07/2011.

\section{Inventário formado por Lorenzo Infante Boticário em la Ciudad de Córdoba de los bienes medicinales, Julio de $1772^{9}$}

Fólio 4533r.

\section{Para los años de $1771 / 1772^{10}$}

Inventário formado por Lorenzo Infante Boticário da Botica de S. M. (Su Majestade) na cidade de Córdoba por ordem do senhor tenente de Pveya D.n (dom) Fernando Fabro, para dar conta ao ex. mo (excelentíssimo) Senhor dom Fran. ${ }^{\text {co }}$ (Francisco) de Bucareli Governador, e capitão Geral destas Províncias; dos bens Medicinais que em dha oficina e estoque nela se encontram, com expressão de quantidade, e valor, assistindo o médico dom Ygn. ${ }^{\circ}$ Tolosa começado em Y.10 de Fevereiro de $1768 .^{11}$

\begin{tabular}{|l|l|l|}
\hline Águas & Botica & Pesos ..... R. ${ }^{\mathrm{S}}$ \\
\hline $\begin{array}{l}\text { Escorcionera (Escorcioneira } \text { ga. }^{12} \text { ) } \\
\text { hispanica] }\end{array}$ & 1 Libra à 4 R.s & D000.....4s \\
\hline Chicoria (Chicória ga.) [gênero Cichorium] & 1 Libra à 4 R.s & D000.....4s \\
\hline Cardo Santo [ Cnicus benedictus] & 1 Libra à 4 R.s & D00.....4s \\
\hline $\begin{array}{l}\text { Berdolaga (Beldroega ga.) [várias espécies das } \\
\text { famílias Aizoaceae, Urticaceae e Portulacaceae] }\end{array}$ & 1 Libra à 4 R.s & D000.....4s \\
\hline
\end{tabular}

9 Esclarecemos que os fármacos arrolados no Inventário foram organizados em tabelas, visando à facilitação da análise e à inclusão de notas explicativas. As plantas e os compostos químicos relacionados pelos inventariantes foram, na medida do possível, identificadas com o nome científico e sua composição inserida ao lado das denominações originalmente por eles empregadas. Os utensílios utilizados para o preparo dos medicamentos foram mantidos como na relação original.

${ }^{10}$ Carimbos na parte superior esquerda da folha.

${ }^{11}$ Dois profissionais com conhecimentos técnicos foram responsabilizados pelo inventário da botica do Colégio de Córdoba no ano de 1768. O boticário Lorenzo Infante deveria proceder ao levantamento “dos bens Medicinais que em dha oficina e estoque nela se encontram, com expressão de quantidade, e valor [...]” (AHUNC, caja 10, legajo 2, n. 27, Fólio 4533r.) Enquanto o médico Ygnacio de Tolosa teria como principal função "asistir”, ou seja, supervisionar e conferir o trabalho do boticário. A distinção hierárquica entre as profissões ligadas às artes de curar no período, com os médicos ocupando o topo da pirâmide, fica evidenciada nas atribuições que foram dadas a Lorenzo Infante e a Ygnacio de Tolosa. Cabe, no entanto, ressaltar que no inventário do ano de 1771-72, o boticário Lorenzo Ynfante também será chamado de médico.

12 Empregamos as seguintes abreviaturas ao longo da transcrição: Grafia Atual: ga; Português: pt; Variação na Grafia: vg. 


\begin{tabular}{|c|c|c|}
\hline Borraja (borragem pt.) [Borago officinalis] & 1 Libra à 4 R.s & $\mathrm{D} 000 \ldots . .4 \mathrm{~s}$ \\
\hline Tumaria [fumaria offiicinalis] ${ }^{13}$ & 1 Libra à 4 R.s & $\mathrm{D} 00 \ldots . . .4 \mathrm{~s}$ \\
\hline $\begin{array}{l}\text { Labendula (lavendula ga.) (lavanda pt.) [gênero } \\
\text { lavandula] }\end{array}$ & 2 Libra à 6 R.s & $\mathrm{D} 001 \ldots . . .4 \mathrm{~s}$ \\
\hline Torongil (melissa pt.) [melissa officinalis] & 6 Libra à 4 R.s & D003 \\
\hline Hinojo (funcho pt.) [Foeniculum vulgare] ${ }^{14}$ & 3 Libra à 4 R.s & D001......4s \\
\hline & & D009 \\
\hline
\end{tabular}

Fólio 4533v.

Suma anterior ......D009

\begin{tabular}{|l|l|l|}
\hline (ilegível) ar ${ }^{15}$ & 2 Libra à 4 R.s & D001... \\
\hline $\begin{array}{l}\text { Hierva Buena (hortelã- verde pt.) [Mentha } \\
\text { spicata] }\end{array}$ & 4 Libra à 4 R.s & D002 \\
\hline $\begin{array}{l}\text { Lanten (língua de ovelha pt.) [Plantago } \\
\text { lanceolata] }\end{array}$ & 2 Libra à 4 R.s & D001 \\
\hline Rosas [genêro rosa] & 4 Libra à 6 R.s & D003 \\
\hline $\begin{array}{l}\text { Manzanilla (camomila pt.) [várias plantas da } \\
\text { família Asteraceae] }\end{array}$ & 2 Libra à 6 R.s & D001....4s \\
\hline Ruda (arruda pt.) [Ruta graveolens L.] & 4 Libra à 4 R.s & D002 \\
\hline Cal (cal) & 3 Libra à 4 R.s & D001....4s \\
\hline Suero de leche (soro de leite pt.) & 5 Libra à 6 R.s & D003....6s \\
\hline $\begin{array}{l}\text { De Canela bloja (canela pt.) [Cinnamomum } \\
\text { zeylanicum] }\end{array}$ & 3 Libra à 8 R.s & D003 \\
\hline $\begin{array}{l}\text { De Peonia Comp. }{ }^{\text {a }} \text { (Peônia pt.) [plantas gênero } \\
\text { Paeonia] }\end{array}$ & 1 Libra à 8 R.s & D001 \\
\hline Estephana & 1 Libra à 8 R.s & D001 \\
\hline Vendula Comp. ${ }^{\text {a18 }}$ & 4 Libra à 8 R.s & D004 \\
\hline
\end{tabular}

Vinhos

\begin{tabular}{|l|l|l|}
\hline Mellepedes (millepedes pt.) & \multicolumn{1}{|c|}{ 19 Libra à 8 R.s } & D000....6 \\
\hline Emetico (emético) & 2 Libra à 8 R.s & D002 \\
\hline
\end{tabular}

${ }^{13}$ Acreditamos que se trate da fumaria.

14 "Para hacer esta agua se toma v. gr. una libra de simiente de hinojo quebrantada, y se pone á infundir en un alambique con doce libras de agua y ocho onzas de alcohol por espacio de doce horas; despues se procede á la destilacion con un fuego lento y suave, hasta que hayan salido seis libras.” In: Gregorio, 1803: 80-81.

${ }^{15} \mathrm{O}$ fólio 4533v. se encontra amassada no campo superior esquerdo.

16 "Para hacerla se toma una libra de cal viva, y se echa en una tinaja que tenga veinte libras de agua clara de fuente, meneando mientras la ebulicion; en casando el hervor, y despues que se haya reposado por algun corto tiempo, se sacará por inclinacion, y se trasladará a una redoma exactamente cerrada, la qual nunca se deberá destapar quando se vaya á hacer uso de ella, sino que mas bien deberia tener una canilla dicha redoma para despacharla, y estar ademas en parte obscura.” (Gregorio, 1803: 82).

17 "Esta agua debe hacer con el vino, precediendo un dia de infusion en el mismo alambique" (Gregorio, 1803: 80).

${ }^{18}$ Acreditamos que refira-se à lavanda.

19 "Insecto [...] são aquelles, que tocandolhes com o dedo, se fazem tão redondos, como húa conta” (Bluteau, 1728: 488). 


\begin{tabular}{|l|l|l|}
\hline Caliviado & 1 Libra à 6 R.s & D000....6 \\
\hline Vinagre destilado & 2 Libra à 12 R.s & D003 \\
\hline Vinagre escilitico & 3 Libra à 8 R.s & D003 \\
\hline
\end{tabular}

Ungüentos

\begin{tabular}{|c|c|c|}
\hline Blanco (branco pt.) & 2 Libra à 12 R.s & D006 \\
\hline Blanco alcanforado (branco canforado) ${ }^{20}$ & 4 Libra à 14 R.s & D007 \\
\hline Minio [Tetróxido de chumbo $\left.2 \mathrm{PbO} \cdot \mathrm{PbO}_{2}\right]^{21}$ & $1 / 2$ onça à $1 / 2$ R.s & $\mathrm{D} 000 \ldots . .2$ \\
\hline \multicolumn{3}{|l|}{ Tusia No sirve } \\
\hline Aragon $^{22}$ & $1 / 2$ libra à 12 R.s & D002.....2 \\
\hline Marsiàton & 1/2 onça em 1 R.s & D000.....1 \\
\hline Sarna $^{23}$ & 1/2 libra à 12 R.s & D002.....2 \\
\hline Althea (malvavisco pt.) [Malvaviscus arboreus] & 3 libras à 12 R.s & D004.....4 \\
\hline Sacarias & 1 libra à 12 R.s & D001....4 \\
\hline Amarillo (Amarelo pt.) & $1 / 2$ libra à 12 R.s & D000.....2 \\
\hline Calabaza (abóbora pt.) [gênero curcubita] & 4 onças em 4 R.s & D000.....4 \\
\hline Mercurio comp. $^{0}$ (composto) & 2 Libra à $4 \mathrm{P}^{8}$ & D008 \\
\hline De la condessa (da condessa) ${ }^{24}$ & 2 onças em 6 R.s & D000.....6 \\
\hline Litargiro (litargírio pt.) [óxido de chumbo PbO] & 1/2 libra à 12 R.s & $\mathrm{D} 002 \ldots . .2$ \\
\hline \multirow[t]{2}{*}{ Saturno } & 1 onça em 1 R.s & D000.....1 \\
\hline & & D081 \\
\hline
\end{tabular}

Suma anterior.

Fólio 4534r.

\begin{tabular}{|l|l|l|}
\multicolumn{4}{|l}{ Suma anterior.................. D081 } \\
\hline Basalicon $^{25}$ & 1 libra à 12 R.s & D001....4 \\
\hline Plomo (chumbo) [símbolo Pb] & 1 libra à 12 R.s & D001....4 \\
\hline Rosado & 2 onças em 2 R.s & D000....2 \\
\hline Rosado Sandalino ${ }^{26}$ & $1 / 2$ libra em 2 p. & D002 \\
\hline $\begin{array}{l}\text { Altanita (matricária pt.)[algumas plantas da tribu } \\
\text { Anthemideae] }\end{array}$ & $1 / 2$ onça em 3 R.s & D000....3 \\
\hline Balsamo alceó. & 1 libra em 2 P.s 2 R.s & D002....2 \\
\hline $\begin{array}{l}\text { De Pimenta (pimenta) [várias espécies no gênero } \\
\text { pimenta) }\end{array}$ & 1 libra à 12 R.s & D001....4 \\
\hline Nervino & & \\
\hline Naphe No sirve & & \\
\hline Laurel (loureiro pt.) [laurus nobilis] & 4 onças em 4 R.s & D000....4 \\
\hline
\end{tabular}

\footnotetext{
${ }^{20}$ Preparado feito à base de cânfora.

21 “azarcón/ el plomo que calcinado adquiere color rojo.” Mistura do plomo II com plomo IV. In: Picatoste, 1887: 717.

${ }^{22}$ Acreditamos que se refira a um ungüento originário da região de Aragão na Espanha.

${ }^{23}$ Acreditamos que se refira a algum medicamento específico empregado contra sarna.

${ }^{24}$ Feito à base de quina. Sobre o tema ver mais em Ortiz Crespo, 1994: 130-136.

25 "Unguento Amarillo" (Picatoste, 1887: 151)

${ }^{26}$ Feito à base de sândalo.

${ }^{27}$ Nervino: “Unguento hecho, de aceites y enjundias.” (Picatoste, 1887: 749).
} 
Trementina (terebintina pt.) ${ }^{28}$

6 libras à 8 R.s

D006

Lamedores $^{29}$

\begin{tabular}{|c|c|c|}
\hline $\begin{array}{l}\text { Azederas (azedeira ou língua de vaca pt.) } \\
\text { [Rumex acetosa] }\end{array}$ & 1 libra à 12 R.s & D001.....4 \\
\hline Ajenjos (Absinto pt.) [Artemisia absinthium] & 1 libra à 12 R.s & D001....4 \\
\hline Membrillos (Marmelo) [Cydonia oblonga] & 1 libra à 12 R.s & D001.....4 \\
\hline Agraz $^{30}$ & 3 libras à 12 R.s & D001.....4 \\
\hline Althea & 1 libra à 12 R.s & D001....4 \\
\hline Borraja & 3 libras à 12 R.s & D004.....4 \\
\hline Escorzonera & 2 libras à 12 R.s & D003....6 \\
\hline Emetico (emético pt.) & 3 libras à 3 P.s & D009 \\
\hline $\begin{array}{l}\text { Corteza de Naranja (Casca de Laranja pt.) } \\
\text { [Citrus } \times \text { sinensis] }\end{array}$ & 3 libras à 12 R.s & D004.....4 \\
\hline Miel Rosada (Mel Rosada pt.) & 3 libras à 12 R.s & D004.....4 \\
\hline Corteza de Sidra (cidra pt.) [Citrus medica] & 3 libras à 12 R.s & D004.....4 \\
\hline Obreo & 4 onças em 4 R.s & D001 \\
\hline $\begin{array}{l}\text { Chicoria e ruibarvo (ruibarbo pt.) [Rheum } \\
\text { palmatum L.] }\end{array}$ & 3 libras à 3 P.s & D009 \\
\hline Opio $^{31}$ & 3 libras à 12 R.s & D004.....4 \\
\hline De cinco raízes & 3 libras à 12 R.s & D004.....4 \\
\hline De Kerma & 3 libras à 3 P.s & D009 \\
\hline $\begin{array}{l}\text { Culantrillo (Avenca pt.) [várias plantas do } \\
\text { gênero Adiantum] }\end{array}$ & $1 / 2$ libra em 6 r.s & D000.....6 \\
\hline Violeta [várias plantas família das violáceas] & $1 / 2$ libra em 6 r.s & D000....6 \\
\hline $\begin{array}{l}\text { Orozu (Orozuz ga.) (alcaçuz pt.) [Glycyrrhiza } \\
\text { glabra] }\end{array}$ & $1 / 2$ libra em 6 r.s & D000.....6 \\
\hline Hierva Buena & 3 libras à 12 R.s & D004.....4 \\
\hline & & D173.....3 \\
\hline
\end{tabular}

Suma anterior.

Fólio 4534v.

\begin{tabular}{|l|l|l|}
\hline Limón (Limão pt.) [citrus limon] & 4 onças em 4 R.s & D000....4 \\
\hline $\begin{array}{l}\text { Adormidera Blanca (papoula pt.) [vários gêneros } \\
\text { da família das Papaveraceae] }\end{array}$ & 3 libras à 12 R.s & D004.....4 \\
\hline Amapolas (Papoilas) [papoula pt.] & 3 libras à 12 R.s & D004....4 \\
\hline
\end{tabular}

\footnotetext{
${ }^{28}$ Feita da destilação da resina de coníferas.

29 “Composición de vários simples con azúcar.” (Picatoste, 1887: 640).

30 “La uva sin madurar/ zumo que se saca de ella." (Picatoste, 1887: 43).

${ }^{31}$ Opio: "He o licor, que por incisaõ destila das cabeças das dormideyras, quando chegaõ a madurecer [...] A summa frialdade do opio tira o sentido às partes, \& por isso adormece a dor. (Querem outros que o opio seja quente, \& que faça dormir, como o vinho, que com sumos cálidos causa sono.) He taõ poderoso, que dificilmente o póde alterar o nosso calor natural, \& dizem que três grãos de opio bastão para matar o homem mais robusto. Porém tenho lido que houve quem tomou trinta e seis grãos dele sem dano. Aos que tomão opio lhes sobrevem hum sono profundíssimo, \& juntamente lhes transpira por todo o corpo o cheyro do opio." (Bluteau, 1728: 88).
} 


\begin{tabular}{|c|c|c|}
\hline $\begin{array}{l}\text { Moras (Amoras pt.) [diversas plantas gênero } \\
\text { rubus] }\end{array}$ & 3 libras à 18 R.s & D006....6 \\
\hline Rosa Solutivo & $1 / 2$ libra em 12 r.s & D001.....4 \\
\hline Rosa seca & $21 / 2$ libras à 12 R.s & D003....6 \\
\hline Persico & 3 libras à 8 P.s & D009 \\
\hline Zumo de Granada (Suco de Granada pt.) ${ }^{32}$ & 3 libras à 12 R.s & D004.....4 \\
\hline Escordio [teocrium scorodonia] & 3 libras à 12 R.s & D004.....4 \\
\hline Berdolaga & $31 / 2$ libras à 12 R.s & D005.....2 \\
\hline Oximiel Siclitico [Mel com Vinagre pt.] & 3 libras à 12 R.s & D004.....4 \\
\hline Coclearea [Cochlearia officianalis L.] & 2 libras à 18 R.s & $\mathrm{D} 004 \ldots . . .4$ \\
\hline Oximiel simple & 1/2 libra em 6 R.s & D000....6 \\
\hline
\end{tabular}

Azeites

\begin{tabular}{|c|c|c|}
\hline $\begin{array}{l}\text { Almendoras dulces (almendras ga.) (amêndoas } \\
\text { doces pt.) [árvore da família das Rosaceae] }\end{array}$ & 3 libras à 18 R.s & D006.....6 \\
\hline Agripa & 3 libras à 8 R.s & D003 \\
\hline Eneldo (endro pt.) [Anethum graveolens] & 2 libras à 6 R.s & D001....4 \\
\hline Aparicio $^{34}$ & 2 1/2 libras à 2 P.s & D005 \\
\hline $\begin{array}{l}\begin{array}{l}\text { Balsamina } \\
\text { balsamina }\end{array} \\
\text { (beijo- de- frade }\end{array}$ & 1 libras à 8 R.s & D001 \\
\hline \multicolumn{3}{|l|}{ Alcaparra No sirve [Capparis spinosa] } \\
\hline Mansanilla & 4 onças em 2 R.s & D000....2 \\
\hline Azafran (Açafrão pt.) [crocus sativus] & 4 onças em 4 R.s & $\mathrm{D} 000 \ldots . . .4$ \\
\hline $\begin{array}{l}\text { Euforvio (Euforbio ga.) (Eufórbio pt.) [planta da } \\
\text { família das euforbiáceas] }\end{array}$ & 4 onças em 4 R.s & D000....4 \\
\hline Laurel $^{36}$ & 3 libras à 8 R.s & D003 \\
\hline lombrizes (lombrices ga.) (minhoca pt.) & 1 libras à 8 R.s & D001 \\
\hline De Ypericion [Hypericum perforatum] & 1 libra em 2 P.s & D002 \\
\hline $\begin{array}{lllll}\begin{array}{l}\text { Linaza } \\
\text { usitatissimum }]^{37}\end{array} & \text { pt.) } & \text { [semente } & \text { da } & \text { Linum } \\
\end{array}$ & 2 libras à 12 R.s & D003 \\
\hline
\end{tabular}

\footnotetext{
32 Acreditamos que se refira à região de Granada na Espanha.

33 "Para extraerle se frotan las almendras em um saco de cáñamo áspero, para quitarlas la epidermis, que es muy leñosa, y presta color al aceyte; [...] de cada libra de almendras se sacan regularmente seis onzas de aceyte.” (Gregorio, 1803: 9).

34 Localizamos uma Apologia do dito azeite na Universidade de Sevilha. Ver mais em http://fondosdigitales.us.es/fondos/libros/1300/1/apologia-del-azeite-de-aparicio-a-los-cirujanos-destaciudad-de-seuilla/ Acesso em 15/04/2013.

35 Planta africana euforbiácea con un tallo carnoso, espinas cónicas y muy duras, sin hojas, y de la cual, por presión, se extrae un zumo muy acre que al secarse da una sustancia resinosa usada en medicina como purgante. In: http://www.wordreference.com/definicion/euforbio Acesso: 18/04/13

36 "Este aceyte es muy graso, de color verde, y muy aromático: el modo de extraere consiste en machacar las bayas de laurel recientes y medio secas, y hervirlas despues en mucha cantidad de agua: estando el cocimiento frio se recoge el aceyte que nada por encima del agua, separándole por medio de un filtro." (Gregorio, 1803: 11).

37 "de cada libras de simiente de Lino bien molida y pistada se sacan regularmente ocho onzas de aceyte.” (Gregorio, 1803: 10).
} 


\begin{tabular}{|l|l|l|}
\hline $\begin{array}{l}\text { Azuzena blanca (Azucena ga.) (açucena pt.) [lilium } \\
\text { candidum] }\end{array}$ & 3 libras à 8 R.s & D003 \\
\hline Araian (Arrayán ga.) No sirve ${ }^{38}$ & & \\
\hline Olivo (Oliva pt.) [Olea europaea] & 5 libras em 2 R.s & D002....4 \\
\hline & & D260....7 \\
\hline
\end{tabular}

Fólio 4535r.

Suma anterior.

. D260...7

\begin{tabular}{|c|c|c|}
\hline Rosado & 3 libras à 8 R.s & D003 \\
\hline Ruda & 1 libra à 8 R.s & D001 \\
\hline Espica & 3 libras à 16 R.s & D006 \\
\hline Escorpion (Escorpião pt.) & 3 libras à 16 R.s & D006 \\
\hline Zorro (Raposa pt.) & 1 libra à 12 R.s & D001....4 \\
\hline Yema de Huebo (Gema de Ovo) ${ }^{39}$ & 4 onças em 3 P.s & D003 \\
\hline Matiolo ${ }^{40}$ & 4 onças em 4 pesos & D004 \\
\hline Piedra Blanca (Pedra Branca pt.) & 5 onças em 8 R.s & D005 \\
\hline Piedra Ruvia (Piedra Rubia ga.) & 2 onças em 2 P.s & D002 \\
\hline
\end{tabular}

Essencíales $^{41}$

\begin{tabular}{|c|c|c|}
\hline Eneldo & 1 onça em 8 R.s & D001 \\
\hline Clavo (cravo pt.) [Syzygium aromaticum] & 1 onça em 2 P.s & D002 \\
\hline Ynojo (hinojo ga.) & $1 / 2$ onça em 4 R.s & D000.....4 \\
\hline Cidra (cidra pt.) & $1 / 2$ onça em 12 R.s & D001.....4 \\
\hline Corteza de Naranja (Casca de Laranja pt.) & em 8 R.s & D001 \\
\hline Lavendula & $1 / 2$ onça em 4 R.s & D000.....4 \\
\hline Hierva Buena & 1 onça em 1 peso & D001 \\
\hline Manzanillas & 1 onça em 1 peso & D001 \\
\hline Poleó (poejo pt.) [Mentha pulegium] & $1 / 2$ onça à 8 R.s & D001.....4 \\
\hline \multicolumn{3}{|l|}{ Ruda No sirve } \\
\hline Tomillo (Tomilho pt.) [Thymus vulgaris] & 1 onça em 1 peso. & D001 \\
\hline \multicolumn{3}{|l|}{ Savina No Sirve[Capsicum chinense] } \\
\hline Succino (âmbar pt.) ${ }^{42}$ & $1 / 2$ libra em 6 P.s & D006 \\
\hline Salvia (sálvia pt.) [gênero salvia] & $\begin{array}{llll}\begin{array}{l}\text { Uma } \\
\text { peso }\end{array} & \text { onça } & \text { em } & 1 \\
\end{array}$ & D001 \\
\hline \multicolumn{3}{|l|}{ Box No sirve } \\
\hline Palo Santo (Madeira Sagrada pt.) ${ }^{43}$ & Uma $\begin{array}{lll}\text { onça } & \text { em } 1\end{array}$ & D001 \\
\hline
\end{tabular}

\footnotetext{
${ }^{38}$ Conhecida também como mirto.

39 "Todo el mundo conoce y sabe lo que es este aceyte, por ser aun mas usual que el de almendras." (Gregorio, 1803: 11).

${ }^{40}$ Acreditamos que se refira ao famoso médico italiano Andrea Mattioli, que viveu entre 1501 e 1577, e se notabilizou como um dos mais famosos tradutores de Dioscórides.

41 Parece que usualmente são referidos como azeites destilados. Gregório, no entanto, refuta tal concepção. "Estos son los que se conocen en la Farmácia com el nombre impropio de aceytes asenciales, que hemos ya indicado com el verdadeiro nombre de aceytes voláteis ...” (Gregorio, 1803: 12).

42 Pedra preciosa, que provém de resina vegetal de coníferas fossilizadas.
} 


\begin{tabular}{|l|l|l|}
\hline & peso & \\
\hline Junipero (zimbro pt.) [família das Cupresaceas] & 1 libra em 6 pesos & D006 \\
\hline Agenjo (Ajenjos vg.) (Absinto pt.) & 1 /2 onça em 4 R.s & D000....4 \\
\hline Vitriolo $^{44}$ & 4 onças à 8 R.s & D004 \\
\hline Anis (erva- doce pt.) [Pimpinella anisum] & 1 libra em 12 pesos & D012 \\
\hline Philosophico & 1 l/2 libra em 3 P.s & D003 \\
\hline & & D336....7 \\
\hline
\end{tabular}

Suma anterior. D336...7

\begin{tabular}{|l|l|l|}
\hline Trementina (terebintina pt. ) & $1 / 2$ libra em 1 peso. & D001 \\
\hline Petroleo (Petróleo pt.) & $1 / 2$ libra em 3 P.s & D003 \\
\hline
\end{tabular}

Espiritus. $^{45}$

\begin{tabular}{|c|c|c|}
\hline De vino (vinho pt.) & 1 libra em 1 peso & D001 \\
\hline Romero (Alecrim pt.) [Rosmarinus officinalis] & 2 libras à 12 R.s & D003 \\
\hline Nitro Accido [ácido nítrico ou nitroso] ${ }^{46}$ & $1 / 2$ libra à 20 R.s & D003....6 \\
\hline Cuerno de Cierbo (chifre de cervo pt.) ${ }^{47}$ & 1/2 libra em 3 P.s & D003 \\
\hline Sal Ammoniaco [cloreto de amônia] & $1 / 2$ libra em 20 R.s & D002....4 \\
\hline Coclearea & 1/2 libra em 3 P.s & D003 \\
\hline Vitriolo & $1 / 2$ libra em 2 pesos & D002 \\
\hline Aguafuertes (água-forte) ${ }^{48}$ & 1 libra em 3 P.s & D003 \\
\hline Nitro dulze (nitro-doce pt.) & 1 libra em 3 P.s & D004 \\
\hline
\end{tabular}

Bálsamos $^{49}$

\begin{tabular}{|l|l|l|}
\hline $\begin{array}{l}\text { De copeube VG (copaíba pt.) [árvores do gênero } \\
\text { copaifera] }\end{array}$ & l/2 libra em 4P.s & D004 \\
\hline Peruviano (peruano pt.) & 1 libra em 5 pesos & D005 \\
\hline
\end{tabular}

43 Dentre as plantas referidas como palo santo estão: Bulnesia sarmientoi, Lignum vitae, Bursera graveolens.

${ }^{44}$ Pode se referir à diversos minerais; sulfatos com cristais parecidos com vidro.

${ }^{45}$ Espécie de essência retirada de vegetais e animais: “(Termo Chimico) Geralmente fallando, são a parte mais sutil, e mais pura, extrahida de substancia sólida, ou líquida, por destilação, ou por outro modo. (Bluteau, 1728: 282).

${ }^{46}$ Nítrico: "Este ácido se compone de azoe y oxigeno; y por esta razon las materias animales quando se pudren, Forman uma porcion de este líquido, que se desprende en forma de gas, y se cree de consiguiente que ellas son las que mas contribuyen á su formacion. [...] El ácido nítrico quando está muy puro, es susceptible de mantenerse en forma de vapores roxos; pero lo mas regular es el estar en forma de licor transparente, blanco, muy volátil, que despide humos encarnados de un olor nauseabundo, y cuyo peso específico es una tercera parte mas pesado que el agua destilada.” (Gregorio, 1803: 35-36) Nitroso: "Este ácido es lo mismo que el anterior, con la particularidad de estar menos saturado de oxigeno." (Gregorio, 1803: 37).

${ }^{47} \mathrm{Na}$ verdade, trata-se de uma planta: platycerium cifurcatum.

48 "Se há tenido hasta ahora el agua fuerte como un ácido compuesto del nitro y del vitriolo de marte, calcinado ad albedinem, que se emplean en su composicion [...] pero en rigor no es mas que el ácido nítrico puro, mas ó menos concentrado.” (Gregorio, 1803: 85).

49 Secreções vegetais, compostas de resinas aromáticas. 


\begin{tabular}{|c|c|c|}
\hline Azufre termentinado (Enxofre terebintinado pt.) ${ }^{50}$ & 1/2 libra em 3 P.s & D003 \\
\hline Anódino $^{51}$ & 4 onças à 2 R.s & D001 \\
\hline Cathólico (católico pt.) ${ }^{52}$ & 1 libra em 5 pesos & D005 \\
\hline
\end{tabular}

Tinturas, y elixer.s (Tinturas e elixires pt.)

\begin{tabular}{|l|l|l|}
\hline Elixer de Vitriolo (Elixir de Vitríolo pt.) & 1/2 libra em 12 R.s & D001....4 \\
\hline Propietatis & 1/2 libra em 12 R.s & D001....4 \\
\hline Azafran & 1 libra em 3 P.s & D003 \\
\hline Láudano líquido $^{53}$ & 1 libra à 6 P.s & D006 \\
\hline Mirrha (Mirra pt.) [Commiphora myrrha] & 1 libra à 6 P.s & D006 \\
\hline $\begin{array}{l}\text { Aloe (Babosas ou aloés pt.) [Aloe succotrina e Aloe } \\
\text { vera] }\end{array}$ & 1/2 libra à 6 P.s & D006 \\
\hline Agenjos (ajenjos ga.) (absinto pt.) No sirve & & \\
\hline Castoneo 54 & 4 onças em 2 P.s & D002 \\
\hline Cantaridas 55 & 2 onças em 1 peso & D001 \\
\hline De Jabon (sabão pt.) & 1 libra em 3 pesos & D003 \\
\hline & & D417...1 \\
\hline
\end{tabular}

Fólio 4536r.

Suma anterior.

D417...1

\begin{tabular}{|l|l|l|}
\hline Succino (âmbar pt.) & 4 onças em 2 pesos & D002 \\
\hline Piedra Ematistis & 4 onças em 2 p.s & D002 \\
\hline Ruibarbo (ruibarbo pt.) [Rheum rhabarbarum] & 1 onça em 2 R.s & D000.....2 \\
\hline
\end{tabular}

Sal Volátil

\begin{tabular}{|l|l|l|}
\hline De Cuerno de Siervo (chifre de cervo pt.) & 4 onças em 4 p.s & D016 \\
\hline Sacuno Volátil & 1/2 onça em 12 R.s & D001....4 \\
\hline Tantaro Soluble & 3 onças em 2 p.s & D002 \\
\hline Flor de Menfys & 1 onça em 1 peso. & D001 \\
\hline Agenjo (absinto pt.) & 4 onça em 2 R.s & D002....4 \\
\hline
\end{tabular}

Emplastos $^{57}$

\footnotetext{
Arpenico. 3 libras à 12 R.s D004.....4

50 Sobre o enxofre: é um elemento químico, símbolo S, número 16.

${ }^{51}$ Refere-se a capacidade de suavizar dores.

52 Produtos do oriente destilados em vinho. (Furtado, 2005: 103).

${ }^{53}$ Extrato de ópio com efeito sedativo também: remédio de eficácia comprovada.

54 “Ciertas bolsas que cria el castor em las igles y contienen uma sustância medicinal de olor fuerte.” (Picatoste, 1887: 223).

${ }^{55}$ Feito à base de um besouro com o mesmo nome.

${ }^{56} \mathrm{O}$ tântalo é um elemento químico, que. curiosamente, só foi descoberto em 1802. Símbolo Ta, com o número 73

57 Medicamento exterior de substancia solida, \& glutinosa, cõposto de vários simples, ou drogas, amassadas num corpo (Bluteau, 1728: 64).
} 


\begin{tabular}{|c|c|c|}
\hline Confortativo de Vigo & 1/2 libra em 6 R.s & D000.....6 \\
\hline Diaquilon menor $^{58}$ & 4 libras à 12 R.s & D006 \\
\hline Diaquilon mai. $^{\text {or }}$ & 1/2 libra 8 R.s & D001 \\
\hline Diaquilon Gomado & 1/2 libra à 16 R.s & D003 \\
\hline Diapalma ${ }^{59}$ & 4 libras à 12 R.s & D006 \\
\hline Minio (Tetróxido de chumbo) & 1/2 libra em 6 R.s & D000.....6 \\
\hline De Ranas simples (rãs simples pt.) ${ }^{60}$ & 4 libras à 3 p.s & D012 \\
\hline Podragico & 1 libras à 12 r.s & D001....4 \\
\hline (Ilegível) & 2 onças em 6 R.s & D000.....2 \\
\hline De Hernia $^{61}$ & 1 libras à 12 r.s & D001....4 \\
\hline Histerico $^{62}$ & 4 onças em 4 R.s & $\mathrm{D} 000 \ldots . . .4$ \\
\hline Manus Dey (mão de Deus pt.) & 3 onças em 3 R.s & $\mathrm{D} 000 \ldots . . .3$ \\
\hline Matrical & 2 onças em 2 R.s & $\mathrm{D} 000 \ldots . .2$ \\
\hline Meliloto [Melilotus officinalis] & 1/2 libra em 6 R.s & D000.....6 \\
\hline Begigatorio $^{63}$ & 1/2 libra em 3 R.s & D002....3 \\
\hline De Jabon (sabão pt.) & 1/2 libra em 12 R.s & $\mathrm{D} 011 \ldots .2$ \\
\hline & & D495....1 \\
\hline
\end{tabular}

Suma anterior D495....1

\begin{tabular}{|l|l|l|}
\hline Azafran & 4 libras à 2 p.s & D008 \\
\hline Estomaticon $^{64}$ & 3 onças em 6 R.s & D000...6 \\
\hline Musilago (mucílago ga.) $^{65}$ & 2 onças em 2 R.s & D000.... \\
\hline
\end{tabular}

Confeccíones:

\begin{tabular}{|c|c|c|}
\hline Triaca (triaga pt.) ${ }^{66}$ & $1 / 2$ libra em 10 R.s & D001....2 \\
\hline Diascordio fracastreo $^{67}$ & 4 onças em 2 p.s & $\mathrm{D} 002 \ldots$. \\
\hline Mirtridato $^{68}$ & 4 onças em 1 peso. & D001 \\
\hline Triaca de Venecia (triaga de Veneza pt.) & 4 onças em 1 peso. & D001 \\
\hline Alkerma $^{69}$ & 2 onças em 20 R.s & D002....4 \\
\hline De Jazintos (jacinto pt.) [Hyacinthus orientalis] & 1 libras à 10 pesos. & \\
\hline Gentil cordial & $1 / 2$ libra à 6 p.s & D009 \\
\hline
\end{tabular}

58 “Emplasto desecativo” (Picatoste, 1887: 112).

59 “Emplasto desecativo” (Ibíd).

60 “se usan desolladas y desentrañadas para caldos.” (Gregorio, 1803: 135).

${ }^{61}$ Acreditamos tratar-se de um emplasto utilizado especificamente contra hérnias.

${ }^{62}$ Aventa-se a possibilidade de que o emplasto histérico seja específico para o tratamento da histeria.

63 Acreditamos que se refira a um emplasto para tratamento de doenças da bexiga.

${ }^{64}$ Acreditamos que se refira a um emplasto para tratamento de doenças do estômago.

${ }^{65}$ Fibra vegetal solúvel proveniente das sementes de plantas como o linho, a verdolaga etc.

${ }^{66}$ São compostos feitos com várias plantas, raízes, ervas e frutos, entre outros.

${ }^{67}$ Espécie de Opiato ou Eleituario soporifero, 'q resiste ao veneno. (Bluteau, 1728: 213.

68 Antiveneno composto de mais de 80 ingredientes, cuja origem remete ao nome Rei Mithiridates. (Bluteau, 1728: 517).

69 Acreditamos que se refere ao Grana Kermes: los cocos enteros, secos y hechos polvos, y el zumo de ellos espesado." (Gregorio, 1803: 133). 


\begin{tabular}{|l|l|l|}
\hline Yedra Magna $^{70}$ & $1 / 2$ libra em 2 p.s & D002 \\
\hline
\end{tabular}

Preparaciones y Polvos

\begin{tabular}{|c|c|c|}
\hline Arcano duplicado $^{71}$ & 1 libras em 5 pesos & D005 \\
\hline Etíope Mineral $^{72}$ & 1 libras em 2 pesos & D002 \\
\hline Antimônio diaforético $^{73}$ & 4 onças en 4 p.s & D004 \\
\hline Piedra Vezar (Pedra Bezoar pt.) ${ }^{74}$ & 4 onças en 2 pesos & D002 \\
\hline Coral Blanco [corallium album] ${ }^{75}$ & 4 onças à 3 r.s & D001....4 \\
\hline $\begin{array}{l}\text { Cuerno de Cierbo quemado(chifre de cervo } \\
\text { queimado pt.) }\end{array}$ & 1 libra em 2 p.s & D002 \\
\hline Christal Montano & $1 / 2$ libra em 8 r.s & D001 \\
\hline Dientes de Jabali (Dentes de Javali) $^{76}$ & 2 onças em 6 r.s & D000...6 \\
\hline Bezoardico de Curvo $^{77}$ & 3 onças em 12 r.s & D001... 4 \\
\hline Ojos de Cangrejo $^{78}$ (olhos de carangueijo pt.) & 1 libra em 16 r.s & D002 \\
\hline Coral Ruvio & 1 libra em 16 r.s & D002 \\
\hline & & D556... 5 \\
\hline
\end{tabular}

Suma anterior.

Fólio 4537r.

\begin{tabular}{|l|l|l|}
\hline $\begin{array}{l}\text { Madre de Perla (madrepérola pt.) [mater perlarum] } \\
\text { Piedra de Granate }\end{array}$ & $1 / 2$ libra em 1 peso & D001 \\
\hline Jazintos $^{80}$ & 1 onça em 2 p.s & D002 \\
\hline Piedra Ematistis & 1 inça em 2 pesos & D002 \\
\hline Piedra Lazuli sim prep. $^{\text {r }}$ (preparo) $^{81}$ & 2 libras à 2 p.s & D004 \\
\hline Piedra Pomer $^{82}$ & 1 libra 30 p.s & D030 \\
\hline
\end{tabular}

${ }^{70}$ Acreditamos que se refira à planta hiedra terrestre (Glechoma hederacea).

${ }^{71}$ Extrato ou sal que se tira do salitre (Bluteau, 1728: 472).

${ }^{72}$ Plínio menciona uma erva sob a denominação de Etíope. (Ibid: 354).

73 “metal Blanco, brillante, inalterable al aire” (Picatoste, 1887: 87).

${ }^{74}$ A concreção mais conhecida e apreciada era a pedra bezoar oriental, encontrada no estômago de cabras da Pérsia. Sua cor variava, podendo ir do negro ao branco, passando pelas pardas e pelas mescladas. Formadas por camadas de lâminas calcáreas superpostas, creditava-se a elas o poder de opor-se aos envenenamentos, sendo apreciadas e utilizadas em várias partes do mundo pela virtude maravilhosa de atuar como contraveneno universal.” (Almeida, 2009: 112-113).

75 "Producción marina en forma de arbolito" (Picatoste, 1887: 292). Bluteau destaca que o branco é mais leve que os outros.

76 "los colmillos hechos polvos del." (Gregorio, 1803: 131).

${ }^{77}$ Preparado com pedra bezoar do Dr. Curvo Semmedo.

78 "Ciertas prezuelas calcáreas convexas por un lado y planas por otro que crían interiormente los cangrejos y que sólo se ven en ellos al tiempo de la muda.” (Gisbert, 1986: 377).

79 "conchas levigadas donde se encuentran las perlas que cria el.” (Gregorio, 1803: 133).

${ }^{80}$ Deriva do latim granatus: com grãos, tem um tom púrpura.

${ }^{81}$ É utilizado até a atualidade. Nesta definição do lápis lazuli feito à base da pedra, encontramos que: "Mejora la expresión, alivia el estrés, y disipa la depresión". In http://www.gemselect.com/spanish/geminfo/medicinal-gemstones.php Acesso em 11/04/13 


\begin{tabular}{|c|c|c|}
\hline Piedra medicamentora (medicamentosa vg.) & $1 / 2$ onça em 4 r.s & D000... 4 \\
\hline Zafiros (safira pt.) & 2 dragmas em 2 p.s & D002 \\
\hline Nitro de antimônio ${ }^{83}$ & 1 onça em 1 p.o & D001 \\
\hline Succino Blanco pp & $1 / 2$ libra em 12 r.s & D001... 4 \\
\hline Polvos de vivora (pós de víbora pt.) & 1 onças em 2 p.s & D002 \\
\hline Polvos de cascara de huebo (pós de casca de ovo pt.) & $1 / 2$ libra em 4 r.s & D000... 4 \\
\hline Polvos de sal amoniaco & $1 / 2$ libra em 8 r.s & D001 \\
\hline Sal de tartaro ${ }^{84}$ & 1/2 libra em 3 p.s & D003 \\
\hline Christal tartaro $^{85}$ & $1 / 2$ libra em 1 peso & D001 \\
\hline $\begin{array}{l}\text { Sal Catartica [uma referência indica como sulfato de } \\
\text { sódio, } \mathrm{Na}_{2} \mathrm{SO}_{4}{ }^{86} \text {. Porém outra indica como } \\
\text { (Epsomite) }\left[\mathrm{MgSO}_{4} 7 \mathrm{H}_{2} \mathrm{O}\right]\end{array}$ & $1 / 2$ libra à 6 r.s & D001... 1 \\
\hline Sal Prunela [a base de nitro fundido] & 4 onças em 4 r.s & D004... 4 \\
\hline Nitro & 1 libra à 8 r.s & D001 \\
\hline Sal tartaro vitriolado & 2 onças em 8 r.s & D001 \\
\hline Vitriolo de Martes [sulfato de ferro III, $\left.\mathrm{Fe}_{2}\left(\mathrm{SO}_{4}\right)_{3}\right]$ & 1 onça em 4 r.s & $\mathrm{D} 000 \ldots 4$ \\
\hline Azafran de Marte ${ }^{87}$ & $1 / 2$ libra em 8 r.s & D001 \\
\hline Azafran de Marte astring. ${ }^{\text {te }}$ (adstringente pt.) ${ }^{88}$ & 4 onças em 4 r.s & $\mathrm{D} 000 \ldots 4$ \\
\hline Azafran Id. aperitivo ${ }^{89}$ & 2 onças em 8 r.s & D001 \\
\hline $\begin{array}{l}\text { Mercurio dulze nov.n sublimado (mercurio doce } \\
\text { pt.) }\end{array}$ & 4 onças em 3 pesos & D003 \\
\hline & & D618... 6 \\
\hline
\end{tabular}

Suma anterior

Fólio 4537v.

\begin{tabular}{|c|c|c|}
\hline Suma anterior ........... & .. D618...6 & \\
\hline Mercurio crudo ${ }^{91}$ & 1 libra em 8 p.s & D008 \\
\hline Precipitado $^{92}$ ruvio & 1 libra em 6 p.s & D006 \\
\hline Precipitado blanco (precipitado branco pt.) ${ }^{93}$ & $1 / 2$ libra em 3 p.s & D003 \\
\hline
\end{tabular}

${ }^{82}$ Acreditamos que se refira à pedra pomez; ígnea de tipo vulcânico.

${ }^{83}$ Acreditamos que se referira ao nitrato de amônio, sal com a fórmula $\mathrm{NH}_{4} \mathrm{NO}_{3}$.

${ }^{84}$ Uma das denominações do carbonato de potássio, fórmula $\mathrm{K}_{2} \mathrm{CO}_{3}$.

85 “A borra, ou parte terrea do vinho que evaporada, e separada, se endurece, e chega a petrficarse pegada aos lados da vasilha. Do vinho branco se forma Tartaro branco, do vinho tinto, tartaro vermelho. Cristal de tartaro he tartaro branco purificado, fervido, evaporado e cristalizado.” (Bluteau, 1728: 56).

${ }^{86}$ Sobre as definições dos sais ver: http://www.infopedia.pt/termos-medicos/sal

87 “El término azafrán se aplica a los sólidos con color rojizo, como el azafrán. El óxido férrico que se empleó como pigmento colorante, aparece como sadanu en los escritos sumerios. Ver mais em: http://heurema.com/DFQ/DFQ13-SimbQ2/Simbolismo\%20Qu\%EDmico2.pdf

88 “Com a qualidade fria que tem aperta os poros.” (Bluteau, 1728: 136).

89 “Id: ver abreviatura; aperitivo: tem virtude para tirar as obstruções e opilações do corpo.” (Ibíd: 422).

90 “Aquele do qual se tira toda o sal e matéria corrosiva.” (Ibíd: 434).

91 “Ainda não está separado na matriz ou mina onde se gera.” (Ibíd: 434).

92 “[...] substância dissolvida em algum licor corrosivo e que apartada, e desunida do seu dissolvente por meyo de agua usual, que se lhe deytou em certo modo se precipitou, indo-se ao fundo do vaso. (Ibid: 682).

${ }^{93}$ Feito à base de mercúrio, se reduz a um pó branco. 


\begin{tabular}{|c|c|c|}
\hline $\begin{array}{l}\text { Azeite de Nuez Noscada (Noz Moscada) [Myristica } \\
\text { fragans] }^{94}\end{array}$ & 2 onças à 4 pesos & D008 \\
\hline Estoraque líquido $^{95}$ & 4 onças à 4 r.s & D002 \\
\hline Clavos de comer (cravos pt.) & $1 / 2$ libra em 4 p.s & D004 \\
\hline Esperma de Ballena (Esperma de baleia pt.) $^{96}$ & 2 libras a 2 p.s & D004 \\
\hline Azucar de Romo & $1 / 2$ libra em $4 \frac{1}{1} 2$ p.s & D004... 4 \\
\hline Azafran de Castilla $^{97}$ & 4 onças à 4 r.s & D002 \\
\hline Flor de Mafias & 3 onças à 4 r.s & $\mathrm{D} 001 \ldots 4$ \\
\hline Resina de Xalapa & 4 onças a 4 r.s & D002 \\
\hline Alcanfor $^{98}$ & $1 / 2$ onça à 4 r.s & D000... 6 \\
\hline Cochinilla fina $^{99}$ & 2 onças à 8 r.s & D002 \\
\hline gelierva de Rosas & 4 onças em 4 r.s & D000... 4 \\
\hline Borraja & $1 / 2$ libra em 6 r.s & $\mathrm{D} 000 \ldots 6$ \\
\hline De Naranja (Laranja pt.) & $1 / 2$ libra em 6 r.s & D000... 6 \\
\hline De Azedera & 4 onças em 4 r.s & $\mathrm{D} 000 \ldots 4$ \\
\hline
\end{tabular}

Pulpa (Polpa)

\begin{tabular}{|l|l|l|}
\hline Cañafistola (Canafístula pt.) & 6 libra à 12 P.s & D009 \\
\hline Electuario catholico $^{100}$ & 1 libra a 4 p.s & D004 \\
\hline $\begin{array}{l}\text { Extracto de Junipero (extrato de zimbro pt.) [família } \\
\text { das Cupresáceaes] }\end{array}$ & 1/2 libra em p.s & D002 \\
\hline Tamarindos [família fabaceae] & 2 libras à 8 r.s & D002 \\
\hline
\end{tabular}

Semillas (sementes)

\begin{tabular}{|c|c|c|}
\hline Ameos $^{101}$ & 2 onças à 2 r.s & D004... 4 \\
\hline Amomo $^{102}$ [família das Zingiberraceae] & 3 onças à 2 r.s & D0000...6 \\
\hline Eneldo & 3 onças em 1 r.s & D000...1 \\
\hline
\end{tabular}

\footnotetext{
94 "El modo de extraerle consiste em moler las nueces moscadas em mortero de piedra caliente, hasta reducirlas á una pasta fina, como el cação; despues se meten en un saco de lienzo fuerte, y se meten en la prensa tambien caliente." (Gregorio, 1803: 11).

95 Licor feito de planta do mesmo nome, parecida com marmeleiro. Gênero Styrax. Várias referências bíblicas.

96 "Es una materia oleosa, concreta, blanca y cristalina, que se halla en unas cavidades que tiene el cerebro del.” (Gregorio, 1803: 131).

${ }^{97}$ Acreditamos que se refira a uma variedade proveniente da região de Castela, Espanha.

98 "Es una substancia inflamable, solubre en el acohol, blanca, cristalina, ligera, desmonuzable entre los dedos, que en el comercio se vende en panes de á dos libras de una figura orbicular convexa, que nos viene de Holanda, y tiene un olor fragrantísimo y penetrante, y un sabor cáustico. [...] se debe mirar como un producto muy particular y único en su género, propio de ciertos y determinados vegetables, y que de consiguiente debe excluirse de todos aquellos órdenes y series de substancias, con quienes estaba confundido por autores respecto á haberse hallado en él caractéres propios y particulares, distintos de las resinas y gomo- resinas.” (Gregorio, 1803: 89).

99 “los insectos enteros y hechos polvos” (Ibíd: 131).

100 Tem virtudes purgativas.

101 “Planta com cheiro semelhante ao orégano.” (Picatoste, 1887: 74).

102. “Planta medicinal de la Índia, de fruto acre y estimulante”. (Ibíd: 75).
} 
Suma anterior

Fólio 4538r.

\begin{tabular}{|c|c|c|}
\hline Anis & 3 onças em 1r.s & D000... 1 \\
\hline Canavis (Cannabis) & 6 onças em 2 p.s & $\mathrm{D} 000 \ldots 2$ \\
\hline cidra & 1 onça em 1 r.s & $\mathrm{D} 000 \ldots 1$ \\
\hline Culantro apolillado (coentro envelhecido pt.) & 5 onças & $/ /$ \\
\hline Cardo Santo & 3 onças em 1 r.s & D000... 1 \\
\hline Dauco $^{103}$ Cretino ${ }^{104}$ & 1 libra em 8 r.s & D001 \\
\hline Membrillos (Marmelo pt.) & 2 onças em 1 r.s & $\mathrm{D} 000 \ldots 1$ \\
\hline Alolba [Trigonella foenum-graecum] & 1/2 libra em 8 r.s & D001 \\
\hline Linasca (linaza vg.) & $1 / 2$ libra em 8 r.s & D001 \\
\hline Melón (Melão pt.) & 4 onças em 1 r.s & $\mathrm{D} 000 \ldots 1$ \\
\hline Sandia (Melancia pt.) & 6 libras em 6 r.s & $\mathrm{D} 000 \ldots 6$ \\
\hline Almidon (amido pt.) & 2 libras em 8 r.s & D001 \\
\hline Mostaza (Mostarda pt.) & 5 libras em 5 r.s & $\mathrm{D} 000 \ldots 5$ \\
\hline
\end{tabular}

Arinas (farinhas)

\begin{tabular}{|c|c|c|}
\hline Habas (feijão pt.) & 4 onças em 2 r.s & $\mathrm{D} 000 \ldots 2$ \\
\hline Alolbas & 3 onças em 2 r.s & $\mathrm{D} 000 \ldots 2$ \\
\hline Arroz & 1 onça em 1 r.s & D000... 1 \\
\hline de Garbanzos (Arroz de grão- de- bico pt.) & $1 / 2$ libra em 2 r.s & $\mathrm{D} 000 \ldots 2$ \\
\hline de Lino (Arroz de linho pt.) & $1 / 2$ libra em 3 r.s & D000... 3 \\
\hline
\end{tabular}

Polvos (Pós)

\begin{tabular}{|c|c|c|}
\hline De Flor de Azufre (Flor de enxofre pt.) ${ }^{105}$ & 6 onças a 8 r.s & D006 \\
\hline Celestes & $1 / 2$ libra em 6 r.s & $\mathrm{D} 000 \ldots 6$ \\
\hline de Azufre (de enxofre pt.) & 4 onças em 2 r.s & $\mathrm{D} 000 \ldots 2$ \\
\hline $\begin{array}{l}\text { Cuerno de Cierbo quemado (chifre de cervo } \\
\text { queimado pt.) }\end{array}$ & $1 / 2$ libra 8 r.s & D0001 \\
\hline
\end{tabular}

Zenizas (cenizas ga.) (cinzas pt.)

\begin{tabular}{|l|l|l|}
\hline de vetama & 4 onças em 2 r.s & D000... 2 \\
\hline & & D703.. 1 \\
\hline
\end{tabular}

Suma anterior......

Fólio 4538v.

\begin{tabular}{|l|l|l|}
\hline de Sarmiento $^{106}$ & $1 / 2$ onça & D000... \\
\hline
\end{tabular}

\footnotetext{
103 “biznaga, yerba. De, prep. que denota posesión, o pertenencia, el modo de hacer algo, de dónde se sale, de lo que se trata, la materia de una cosa, lo que contiene una vasija, etc”. (Ibíd: 336).

${ }^{104}$ Cretino, neste caso, é sinônimo de vulgar, comum.

${ }^{105}$ Nome dado ao enxofre em pó: obtém-se por precipitação ou sublimação.
} 


\begin{tabular}{|c|c|c|}
\hline De Rayz de Angelica [Angelica archangelica] & 1 onça & D000... 1 \\
\hline Aristolaquia (aristolóquia ga.) [A. clematitis] & 2 dragmas em $1 / 2$ r.s & D000... 1/2 \\
\hline Aro [Familia de las Aráceas] & 1 onça em 1 r.s & D000... 1 \\
\hline Bistorta [Polygonum bistorta] & 1 onça em 1 r.s & $\mathrm{D} 000 \ldots 1$ \\
\hline Butia (butiá pt.) [ Família das Arecaceae] & $1 / 2$ onça em 1 r.s & D000... 1 \\
\hline $\begin{array}{l}\text { Contra hierva (contra erva pt.)[ Flaveria } \\
\text { contrayerba] }\end{array}$ & 2 onças em 4 r.s & $\mathrm{D} 000 \ldots 4$ \\
\hline Calamo Aromatico (Açoro pt.) [acorus calamus] & 1 onça em 1 r.s & D000... 1 \\
\hline $\begin{array}{l}\text { Elevoro blanco (eleboro ga.) (heléboro pt.) [gênero } \\
\text { Helleborus] }\end{array}$ & $1 / 2$ onça em 1 r.s & D000... 1 \\
\hline Enula [Inula helenium] & $1 / 2$ onça em 1 r.s & D000... 1 \\
\hline Elevoro negro (eleboro ga.) (heléboro pt.) & $1 / 2$ onça em 1 r.s & $\mathrm{D} 000 \ldots 1$ \\
\hline Genciana [Gentiana lutea] $]^{107}$ & 2 onças em 2 r.s & D000... 2 \\
\hline Galanja (galanga ga.) [Kaempferia galanga] & $1 / 2$ onça em 4 r.s & $\mathrm{D} 000 \ldots 4$ \\
\hline Hermodatiles (hermodáctilo ga.) & 1 onça em 1 r.s & D000... 1 \\
\hline Mei [Panicum miliaceum] & 1 onça em 1 r.s & D000... 1 \\
\hline Quina [Cinchona officinalis] ${ }^{108}$ & 2 onças em 8 r.s & D001 \\
\hline $\begin{array}{l}\text { Lirios florencia(Lírio de Florença pt.)[Família } \\
\text { Irideas] }\end{array}$ & 1 onça em 1 r.s & D000... 1 \\
\hline Orozus de Pays (alcaçuz pt.) & 1 onça em m. ${ }^{0}$ r.s & $\mathrm{D} 000 \ldots 01 / 2$ \\
\hline $\begin{array}{l}\text { Hipecaquana (Ipecacuanha) [Psychotria } \\
\text { ipecacuanha] }\end{array}$ & 1 onça em 4 r.s & D000... 4 \\
\hline Mechoachan ${ }^{109}$ & $1 / 2$ onça em 2 r.s & D000... 1 \\
\hline $\begin{array}{l}\text { Rapontico (reponchigo ga.) [Campanula } \\
\text { rapunculus] }\end{array}$ & 1 onça em 1 r.s & D000... 1 \\
\hline $\begin{array}{l}\text { Xalapa (jalapa ga.) (maravilha pt.) [Mirabilis } \\
\text { jalapa] }\end{array}$ & $1 / 2$ onça em 4 r.s & D000... 4 \\
\hline Ruibarbo & 1 onça em 4 r.s & D000... 4 \\
\hline Sen [Família Papilionáceas] & 1 onça em 2 r.s & D000... 2 \\
\hline $\begin{array}{l}\text { Zarza Parrilla (zarzaparilla ga.) (salsaparilla pt.) } \\
\text { [Smilax aspera] }\end{array}$ & $1 / 2$ onça em 2 r.s & D000... 2 \\
\hline \multirow[t]{2}{*}{ de China } & 1 onça em 2 r.s & D000... 2 \\
\hline & & D709... 4 \\
\hline
\end{tabular}

106 Acreditamos que se refira à carqueja. No ano de 1749 o “Padre Martín Sarmiento [...] escribe un opúsculo que titula: "Disertación sobre las virtudes maravillosas y uso de la planta llamada carqueixa” (Sendín, 2010, blog pessoal.) Ver mais em: http://fernandezsendin.blogspot.com.br/2010/10/la-carqueixaplanta-medicinal.html Acesso: 11/05/2013

${ }^{107}$ Parece ser originária das regiões montanhosas do centro-sul da Europa.

108 Usada, especialmente como anti- febril, a Quinaquina: "He a casca de húa arvore do Perù, que na Provincia de Quito, nasce em huns montes, perto da Cidade de Loxa. He quase do tamanho de húa cerejeyra, dà folhas redondas, \& adentadas; lança húa flor comprida, tirante a vermelho, ao pé da qual sahe húa bainha, em que està encerrada húa espécie de amêndoa, chata, branca \& envolta em húa delgada membrana. Há duas espécies de Quinaquina, húa mansa, \& otra brav, aquella he muito mais estimada que esta.” (Bluteau, 1728: 62).

${ }^{109}$ Mechoacán: “certa raíz medicinal que se trae de Nueva España.” (Picatoste, 1887: 702). 
Fólio 4539r.

Suma anterior.

D709...4

\begin{tabular}{|c|c|c|}
\hline Palo Santo (Madeira Sagrada) & 1 onça em 1 r.s & D000... 1 \\
\hline Baleriana (valeriana ga.) [Família Valerianaceae] & 2 onças em 2 r.s & $\mathrm{D} 000 \ldots 2$ \\
\hline Agenjible (jengibre ga.) (gengibre pt.) & 1 onça em 1 r.s & D000... 1 \\
\hline $\begin{array}{l}\text { Serpentaria virginal (Serpentária pt.) [Aristolochia } \\
\text { serpentaria] }\end{array}$ & 1 onça em 2 r.s & D000... 2 \\
\hline Zedoaria [Curcuma zedoaria] & 1 onça em 1 r.s & D000... 1 \\
\hline Cosaralina $^{110}$ & $1 / 2$ onça em 2 r.s & $\mathrm{D} 000 \ldots 2$ \\
\hline Peonia (peônia pt.) [Família peoniceae] & 1 onça em 2 r.s & $\mathrm{D} 000 \ldots 2$ \\
\hline Granada (romã pt.) [Punica granatum] & 1 onça em 1 r.s & D000... 1 \\
\hline Hierva Buena & $1 / 2$ onça $1 / 2$ r.s & $\mathrm{D} 000 \ldots 1 / 2$ \\
\hline Culantro (coentro pt.) & $1 / 2$ onça $1 / 2$ r.s & D000... 1/2 \\
\hline Cominos (cominho pt.) [Cuminum cyminum] & $1 / 2$ onça $1 / 2$ r.s & D000... 1/2 \\
\hline Z (T)urpeto & $1 / 2$ onça 2 r.s & D000... 2 \\
\hline Anis (anis pt.) & $1 / 2$ onça $1 / 2$ r.s & D000... 1/2 \\
\hline Ynojo (hinojo ga.) & $1 / 2$ onça $1 / 2$ r.s & D000... 1/2 \\
\hline
\end{tabular}

Polvos de Goma ${ }^{111}$

\begin{tabular}{|c|c|c|}
\hline Mirra (Mirra pt.) & 2 onças 2 r.s & D000... 2 \\
\hline Menfy & $21 / 2$ onça em 6 r.s & D000... 6 \\
\hline Ammoniaco (amoníaco pt.) & 3 onças em 3 r.s & D000...3 \\
\hline Arabiga (árabe pt.) ${ }^{112}$ & $2 \frac{1}{2}$ em um r.s & D000...1 \\
\hline Santonico (Santónico pt.) ${ }^{113}$ & 1 onça em 2 r.s & $\mathrm{D} 000 \ldots 2$ \\
\hline Sandalo ruvio (sândalo pt.) [Família Santalaceae] & 2 onças em 4 r.s & D000...4 \\
\hline Tormentila ( sete- em- rama pt.) [Ptentila Erecta] & $1 / 2$ onça em 3 r.s & $\mathrm{D} 000 \ldots 3$ \\
\hline Sangre de drago (sangue de dragão pt.). ${ }^{114}$ & 1 onça em 2 r.s & $\mathrm{D} 000 \ldots 2$ \\
\hline Gracilla 115 & 1 onça em 2 r.s & $\mathrm{D} 000 \ldots 2$ \\
\hline $\begin{array}{l}\text { Almasiga (almaciga ga.) (mástique pt.) [Pistacia } \\
\text { lentiscus] }\end{array}$ & $1 / 2$ onça em 1 r.s & $\mathrm{D} 000 \ldots 1$ \\
\hline Olivano & 1 onça em 2 r.s & $\mathrm{D} 000 \ldots 2$ \\
\hline Canela & $1 / 2$ onça em 6 r.s & D000...6 \\
\hline
\end{tabular}

${ }^{110}$ Acreditamos que se refira à coralina, cujo nome científico é [Corallina Linnaeus].

111 As gomas são, segundo Bluteau: "Humor viscoso que sahe de algumas arvores, \& se endurece. [...] Tem as Gommas differentes nomes, conforme as differéças das arvores donde sahem.” (Bluteau, 1728: 92-93).

112 "He hum licor, ou succo, que se espreme da semente, ou das folhas, \& dos frutos juntamente de hum arbusto espinhoso, chamado Acacia, que se dá no Egypto [...]” (Ibíd: 93).

${ }^{113}$ Mistura resultante de duas plantas marinhas: "En el siglo XVI se llamaba santónico o semilla contra las lombrices a la mezcla de las cabezuelas florales del ajenjo marino con las de otra especie similar, el santónico o tomillo blanco. El ajenjo marino se viene usando desde tiempos de Dioscórides como vermífugo infantil." Originária das regiões costeiras da Europa, exceto no mediterrâneo. Ver mais em: http://www.hipernatural.com/es/pltsantonico.html Acesso: 04/05/2013

${ }^{114}$ É uma resina vermelha que se pode obter através dos seguintes gêneros botânicos: Cróton, Dracaena, Daemonorops, Pterocarpus e Calamus rotang.

${ }^{115}$ Acreditamos tratar-se da graciela: “planta medicinal y amarga” (Picatoste, 1887: 549). 
Suma anterior.

Fólio 4539v.

\begin{tabular}{|c|c|c|}
\hline Palo Santo (Madeira Sagrada pt.) & 2 onças em 4 r.s & D000... 4 \\
\hline Guteta $^{116}$ & $1 / 2$ onça em 2 r.s & D000... 2 \\
\hline Tragacanto [goma base de Astragalus gummifer] ${ }^{117}$ & $1 / 2$ onça em 1 r.s & D000... 1 \\
\hline Aloes epatica (Babosas pt.) ${ }^{118}$ & 1 onça em 4 r.s & D000... 4 \\
\hline Aloes Succotrina $^{119}$ & 1 onça em 4 r.s & $\mathrm{D} 000 \ldots 4$ \\
\hline Alumbre quemado (alume queimado pt.) ${ }^{120}$ & $1 / 2$ onça em 2 r.s & $\mathrm{D} 000 \ldots 2$ \\
\hline Alumbre de roca (alume de rocha pt.) & $1 / 2$ onça em 2 r.s & D000... 2 \\
\hline Millepedes & $1 / 2$ onça em 4 r.s & D000... 4 \\
\hline Tutia $^{121}$ & 4 onças em 8 r.s & D001 \\
\hline
\end{tabular}

Pildoras (Pílulas pt.)

\begin{tabular}{|l|l|l|}
\hline Balsamicas & $1 / 2$ onça em 4 r.s & D000... 4 \\
\hline Catholicas (Católicas pt.) & 1 onça em 8 r.s & D0001 \\
\hline Gochias & 1 onça em 8 r.s & D0001 \\
\hline De tribus $^{122}$ & 1 onça em 4 r.s & D000... 4 \\
\hline Mercuriales (Mercuriais pt.) $^{1 / 2 \text { onça em } 8 \text { r.s }}$ & D0001 \\
\hline Antiamasticas (anti- asmáticas pt.) & 1/2 onça em 8 r.s & D0001 \\
\hline Trociscos de Raccis $^{123}$ & 1 onça em 8 r.s & D0001 \\
\hline De Agarico $^{124}$ & 1 onça em 2 p.s & D0002 \\
\hline
\end{tabular}

${ }^{116}$ Segundo Bluteau, "Os melhores se fazem com raiz de Peonia, ou Rosa albardeira, \& Visgo, feitos em pó cranio humano, \& unha de Gram Besta raspados, \& açúcar rsado tambem em pó, \& pós de Diambra sem Alimiscar;” (Bluteau, 1728: 162).

117 “La goma tragacanto es el exudado seco de la corteza del Astragalus gummifer, o de otras Astragalus gummifer especies asiáticas de Astragalus. Conocida desde la antigüedad y sus primeras referencias se deben a Theophrastus y es conocida como cuerno de cabra quizás por su apariencia a estos. Es un arbusto pequeño de tipo perenne dándose mas bien en lugares secos del Asia Menor y en regiones montañosas y áridas del medio este. La goma exuda espontáneamente de cortes hechos a los troncos. El exudado es en forma de tiras o hojuelas las cuales se hacen quebradizos al secarse. Las fechas de recolección se extienden desde Mayo hasta Septiembre para las tiras y desde Agosto hasta Noviembre para las hojuelas. Después de la recolección la goma es clasificada a mano en varios grados." Ver mais em: http://www.bristhar.com.ve/tragacanto.html Acesso: 01/06/2013

${ }^{118}$ Acreditamos que se refira a um preparado específico para doenças do pâncreas.

${ }^{119}$ Chamamos a atenção para o fato de que esta é a primeira vez que o inventariante relaciona um item composto à base de plantas, valendo-se do nome científico da mesma.

120 "En efecto, el alumbre puesto en una olla sin vidriar, gruesamente quebrantado, á un fuego fuerte, se liqua, levanta ampollas, hierve como azúcar en seco, y no pierde en este caso sino el agua de cristalizacion, lo qual se conoce quando ha cesado de echar vapor y de levantar ampollas, para lo qual debe menearse con una espátula de hierro; por esta razon es mas cáustico, sus virtudes se hallan mas reunidas que antes de calcinarse, y se puede sacar de él un espíritu mas fuerte y concentrado que antes de esta operación, el qual trae Lemerí en su Curso Chimico;” (Gregorio, 1803: 104).

${ }^{121}$ Acreditamos que se refira a tuia, planta pertencente ao gênero thuja.

${ }^{122}$ Há uma referência a elas em Silveira Pinto, 1846.

${ }^{123}$ Há uma referência a elas em Dávila, 2010.

${ }^{124}$ É uma “espécie de hongo.” (Picatoste, 1887: 41). 


\begin{tabular}{|l|l|l|}
\hline Mirrha (Mirra pt.) & 1 onça em 1 peso & D0001 \\
\hline Polvos Cordiales
\end{tabular}

\begin{tabular}{|l|l|l|}
\hline De la condesa (da condessa pt.) & $1 / 2$ onça em 8 r.s & D001 \\
\hline $\begin{array}{l}\text { De Margarita (Margarida pt.) [Chrysanthemun } \\
\text { leucanthemum] }\end{array}$ & 1 dragma em 8 r.s & D001 \\
\hline De Margariton [Chrysanthemum maximum] & 1 onça em 16 r.s & D002 \\
\hline Coral Blanco (Coral branco pt.) & 1 onça em 4 r.s & D000... 4 \\
\hline Piedra bezar pp (Pedra bezoar pt.) & 1 onça em 8 r.s & D001 \\
\hline Guteta & 1 onça em 16 r.s & D002 \\
\hline & & D736..1 1 1/2 \\
\hline
\end{tabular}

Suma anterior

\begin{tabular}{|c|c|c|}
\hline Restrictivos (restritivos pt.) ${ }^{125}$ & 1 onça em 4 r.s & D000... 4 \\
\hline De cuerno de ciervo (chifre de cervo pt.) ${ }^{126}$ & 2 onças em 8 r.s & D001 \\
\hline Higado de Antimonio (fígado de antimônio) & $1 / 2$ onça em 8 r.s & D001 \\
\hline Laudano opiado (láudano de ópio) ${ }^{127}$ & 1 onça em 16 r.s & D002 \\
\hline Antiectico de Poterio $^{128}$ & $1 / 2$ onça em 16 r.s & D002 \\
\hline Castoreo (castor pt.) ${ }^{129}$ & 1 dragma em 2 r.s & D0000... 2 \\
\hline Vidrio de Antimodrio (antimônio vg.) & $1 / 2$ onça em 2 p.s & D002 \\
\hline Tartaro emético (Tártaro Emético pt.) ${ }^{130}$ & $1 / 2$ onça em 4 r.s & D000... 4 \\
\hline Piedra calaminar (pedra calaminar pt.) [ calamina] & 2 onças em 12 r.s & D001... 4 \\
\hline Piedra bezar occidental ${ }^{131}$ & $\begin{array}{l}\text { 13/4 libras sinpp. } \\
\text { em } 10 \text { pesos. }\end{array}$ & D010 \\
\hline $\begin{array}{l}\text { Madre de Perla, sin moler (madrepérola sem moer } \\
\text { pt.) }\end{array}$ & 1 libra em 6 pesos & D006 \\
\hline Ojos de Cangrejo (olhos de carangueijo pt.) & 5 libras à 6 p.s & D030 \\
\hline Coral Ruvio & 6 libras à 6 p.s & D036 \\
\hline Coral Blanco (coral branco pt.) & $1 / 2$ libra em 2 pesos & D002 \\
\hline
\end{tabular}

\footnotetext{
${ }^{125}$ A Farmacopea Matritense traz a receita dos polvos restrictivos de Cipres: "De bol de Armenia, de piedra hematites, de raiz bistorta, de rosas encarnadas, de bayas de arrayan, de balaustrias, de nueces de cipres, de almácigo, de myrra, de incienso, de sangre de drago.” In: Farmacopea Matritense. Por Cosme Martinez, 1823.

${ }^{126}$ Gregorio relaciona além dos chifres, “las astas, el príapo y los huesos del corazon” (Gregorio, 1803: 130 ) , destacando seus fins medicinais.

127 "He hum extracto de ópio, mas preparado con varios ingredientes, \& correctivos, que o fazem tan salutifero,” (Bluteau, 1728: 53).

128 "Es uma mezcla íntima de cal de hierro, de antimonio y de estaño, ó unos óxidos de hierro, de antimonio y de estaño por el nitro, hechos por la via seca," (Gregorio, 1803: 136).

129 "Ciertas bolsas que cria el castor em las igles y contienen uma sustância medicinal de olor fuerte." (Picatoste, 1887: 223).

${ }^{130}$ Tártaro Emético ou tártaro duplo de antimônio e potássio - que vem em forma em forma de cristais hidrossolúveis." Ver mais em: http://super.abril.com.br/ciencia/elementos-morte-446035.shtml Acesso: 21/05/13

131 "Son unas concreciones lapídeas que se encuentran en el estõmago de la Capra Bezoartica." (Gregorio, 1803: 134).
} 
Raízes

\begin{tabular}{|l|l|l|}
\hline Althea & $\begin{array}{l}1 \text { libra del Paris em } \\
4 \text { r.s }\end{array}$ & D000... 4 \\
\hline Angelica & 1 libra em 8 r.s & D001 \\
\hline Aro & 4 libras em 6 r.s & D000.. 6 \\
\hline Aristholoquia [aristolaquia vg.] & 2 libras em 6 r.s & D000... 6 \\
\hline de Azaro (Ásaro pt.) [Asarum europaeum] & 2 libras em 8 r.s & D001 \\
\hline Bardana [Arctium lappa] & 1 onça em 1 r.s & D000... 1 \\
\hline Bistorta & 3 libras à 8 r.s & D003 \\
\hline Butua [Chondodendron platyphyllum] & 1 libra em 8 r.s & D001 \\
\hline Calamo aromatico (Açoro pt.) & 3 libras a 8 r.s & D003 \\
\hline raiz de China [smilax China] & 2 libras à 4 p.s & D008 \\
\hline & & D850... 1/2 \\
\hline
\end{tabular}

Suma anterior

Fólio 4540v.

\begin{tabular}{|c|c|c|}
\hline Consolida mai. $^{\text {or }}$ [Symphyíum officinale, L.] & 2 1/2 libra a 8 r.s & D002.... 4 \\
\hline Cohombro (Pepino do Mar pt.) & 2 libras à 8 r.s & D002 \\
\hline Digtamo blanco [Dictamnus albus] & $1 / 2$ libra em 6 r.s & D000.... 6 \\
\hline Elevoro blanco (eleboro ga.) (heléboro pt.) & 3 libras à 8 r.s & D003 \\
\hline Elevoro negro GA (eleboro ga.) (heléboro pt.) & $1 \frac{1}{1} 4$ libra à 8 r.s & $\mathrm{D} 001 \ldots 2$ \\
\hline Galanje (galanja vg.) & 4libras à 8 r.s & D004 \\
\hline Genuana (genciana vg.) & 3 libras à 8 r.s & D003 \\
\hline Hermodatiles & 1 libra à 8 r.s & D001 \\
\hline Xalapa (jalapa ga.) (maravilha pt.) & $3 / 4$ em $4 \frac{1}{1} 2$ pesos & $\mathrm{D} 004 \ldots 4$ \\
\hline $\begin{array}{l}\text { Imperatoria [Peucedanum ostruthium (L.) W. } \\
\text { Koch.] }\end{array}$ & 1 libra à 8 r.s & D001 \\
\hline Hipecaguana (Hipecaquana vg.) & $21 / 2$ libras a 4 p.s & D010 \\
\hline $\begin{array}{l}\text { Lirios florencia(Lírio de Florença pt.)[Família } \\
\text { Irideas] }\end{array}$ & 3 libras à 12 r.s & D004...4 \\
\hline Mei & 1 libra à 16 r.s & D002 \\
\hline $\begin{array}{l}\text { espica de Nardo (espiga de Nardo pt.) [Polianthes } \\
\text { tuberosa] }\end{array}$ & $1 / 2$ libra em 3 pesos & D003 \\
\hline Peonia (Peônia pt.) & 3 1/4 libras à 10 r.s & D004... 1/2 \\
\hline $\begin{array}{l}\text { Polipodio (feto doce pt.) [Poypódium vulgare } \\
(L)]\end{array}$ & 2 libras à 8 r.s & D002 \\
\hline $\begin{array}{l}\text { Pelitre (pelitre da Dalmácia pt.) [Tanacetum } \\
\text { cinerariifolium] }\end{array}$ & $21 / 2$ libras à 2 pesos & D005 \\
\hline Ruibarbo & 2 onças à 4 r.s & D001 \\
\hline $\begin{array}{l}\text { Cebolla alvarrana (cebolla albarrana ga.) (cebola } \\
\text { do mar pt.) [Urginea maritima] }\end{array}$ & 2 onças em 2 r.s & $\mathrm{D} 000 \ldots 2$ \\
\hline Serpentaria & 4 onças em 8 r.s & D001 \\
\hline Z (T)urpeto & $11 / 2$ libra em 2 pesos & D002 \\
\hline Tormentila (sete- em- rama pt.) & 3 1/4 libras à 8 r.s & D003... 2 \\
\hline Valeriana (baleriana vg.) & 2 libras à 8 r.s & D002 \\
\hline Bisentoico & 1 1/2 libras à 8 r.s & $\mathrm{D} 001 \ldots 4$ \\
\hline Cedoaria (zedoaria vg.) & 5 libras à 2 pesos & D010 \\
\hline
\end{tabular}




\begin{tabular}{|l|l|l|}
\hline Ajengible apolillado (gengibre antiquado pt.) $^{132}$ & 6 libra & ( \\
\hline Palo Santo (Madeira Sagrada pt.) & 2 libras à 4 r.s & D001 \\
\hline Lentisco (aroeira pt.) [Pistacia lentiscus] & 3 libras à 12 r.s & D004... 4 \\
\hline & & D930... 1 \\
\hline
\end{tabular}

Suma anterior

Fólio 4541r.

\begin{tabular}{|c|c|c|}
\hline Phodoneo & 1 libra à 12 r.s & D001... 4 \\
\hline Sandalo setrino (sândalo pt.) & 5 libras à 4 pesos & D020 \\
\hline Sândalo rubio (sândalo pt.) & 1 libra à 3 pesos & D003 \\
\hline Zasafras (sassafrás pt.) [Família Lauraceae] ${ }^{133}$ & 5 libras á 8 r.s & D005 \\
\hline Alcaparra & 1 libra à 8 r.s & D001 \\
\hline Cortezas de Costi (cascas de Costi) & 2 libras à 2 p.s & D004 \\
\hline cafee (café pt.) [Coffea arabica L.] & 3 libras à 10 r.s & D003... 6 \\
\hline Chinachina (quinaquina pt.) [gênero Myroxylin] $^{134}$ & $13 / 4$ libras à 3 pesos & D005... 2 \\
\hline agarico & $1 / 2$ libra em 6 P.s & D000... 6 \\
\hline
\end{tabular}

Gomas

\begin{tabular}{|l|l|l|}
\hline $\begin{array}{l}\text { Ammoniaco (amoníaco pt.) [extraída da Dorema } \\
\text { ammoniacum] }\end{array}$ & 4 libras à 2 pesos & D008 \\
\hline Arabiga (arábica pt.) & 8 libras à 8 r.s & D008 \\
\hline Asafetida (assa- fétida pt.) [gênero Ferula] & 3 libras à 10 r.s & D003...6 \\
\hline Bedelio [Commiphora africana] & $1 \frac{1}{4}$ libras à 8 r.s & D001...2 \\
\hline Menfy & 1 libra 3 pesos & D003 \\
\hline Copal ${ }^{135}$ & 3 libras à 4 pesos & D012 \\
\hline euoforvio (euforvio pt.) & 2 libras à 4 pesos & D008 \\
\hline Galvano ${ }^{136}$ & 2 libras a 4 pesos & D008 \\
\hline Guayaco (guayacán ga.) (guáiaco pt.) [Guaiacum & $4 \frac{1}{2}$ libras à 12 r.s & D006...6 \\
\hline
\end{tabular}

\footnotetext{
132 Apolillado refere-se a algo envelhecido ou a corrompido. Neste caso, parece tratar-se da segunda opção pela ausência de valor atribuído ao mesmo.

133 Duas espécies são originárias da Europa e uma da América do Norte.

134 Também conhecido como bálsamo americano, foi por muito tempo confundida com a quina. Considerando que a quina já foi referida anteriormente, acreditamos que o inventariante trate aqui do dito bálsamo. Sobre o tema ver mais em: Ortiz Crespo, 1994: 130-136.

${ }^{135}$ É uma resina extraída de várias plantas e que pode ser encontrada em diversas formas: "Duas espécies de Hymenaea: a Hymenaea maritima e a Hymenaea stigonocarpa, produzem a resina Copal do Brasil, que difere da Jetaicica de Marcgrave ou Goma jerahy ou Jatobá, que provém da Hymonea courbaril Linneo (ver Jetahy); difere também da última que tem a cor vermelha, por ser a sua amarela. O Copal do Brasil é mole, enquanto o Copal duro ou verdadeiro provém da Hymonea verrucosa de Lamarck, árvore de Madagascar, da Ilha Mourisca ou do Elocarpus copallifera das Índias Orientais. O Copal falso, que vem da América espanhola ou das Antilhas, tira-se do Rhuscopallinum. O Nome de Resina animé que os ingleses dão ao Copal brasileiro pertence à resina que provém da Hymonea courbaril Linneo. Cumpre designar claramente a árvore que fornece cada espécie de resina, bálsamo, ou goma para conseguir o exame e estudo de cada uma delas. Ver mais em: http://www.mast.br/multimidias/botanica/frontend_html/artigos/index-id=111.html Acesso: 26/06/13.

${ }^{136}$ Não localizamos informações sobre a composição do Galvano. Há uma referência sobre o uso de suas gomas em: Roma, 1753.
} 


\begin{tabular}{|c|c|c|}
\hline officinale] & & \\
\hline $\begin{array}{l}\text { Guta Gamba (gutagamba ga.) [família das } \\
\text { gutíferas] }\end{array}$ & 12 libras à 8 r.s & D012 \\
\hline Ysica & 8 libras à 4 r.s & D004 \\
\hline $\begin{array}{l}\text { Ladano (ládano) [resina da Cistus ladanifer ou } \\
\text { cistus cretinus] }^{137}\end{array}$ & $1 \frac{1}{2}$ libras à 6 pesos & D009 \\
\hline Almasiga & 4 libras à 8r.s & D004 \\
\hline Mirra & $61 / 2$ libras à 4 pesos & D026 \\
\hline Olivano & 8 libras à 8 r.s & D008 \\
\hline Opopanacco (Opopânace pt.) [gênero Opopanax] & $11 / 2$ libra à 2 p.s & D003 \\
\hline Sagapeno (sagapeno pt.) [gênero Ferula] & 2 libras à 2 pesos & D004 \\
\hline & & 1D103... 1 \\
\hline
\end{tabular}

Suma anterior

Fólio 4541v.

\begin{tabular}{|c|c|c|}
\hline Sangre de drago & 2 1/2 libras à 8 r.s & D002...4 \\
\hline Sarcacola (Sarcocola ga.) [Penaea sarcocolla] & 4 onças em 8 r.s & D001 \\
\hline $\begin{array}{l}\text { escamonea (escamônia pt.) [Família } \\
\text { Convolvulaceae] }\end{array}$ & $11 \frac{1}{2}$ libra à 6 pesos & D009 \\
\hline Estoraque & 4 libras à 20 r.s & D010 \\
\hline Junipero & $21 / 2$ libras à 2 pesos & D005 \\
\hline Tacamaca ${ }^{138}$ & 3 onças à 3 r.s & ............3 \\
\hline Alquitarra (alquitirra vg.) ${ }^{139}$ (alquitrã pt.) & 2 libras a 8 r.s & D002 \\
\hline Balsamo Toletano & 4 onças em 2 p.s & D002 \\
\hline
\end{tabular}

Succos (sucos pt.)

\begin{tabular}{|l|l|l|}
\hline Berebento de Chipre & $1 / 2$ libra em 8 r.s & D001 \\
\hline Aloes epatica (babosa pt.) & 3 libras à 3 pesos & D009 \\
\hline Aloes Suceotrino (babosa pt.) & 3 libras à 3 pesos & D009 \\
\hline Extracto de orozu (alcaçuz pt.) & $1 / 2$ libra em 2 p.s & D002 \\
\hline Hipoquitido & 1 libra a 10 r.s & D001... 2 \\
\hline Opio & 9 onças em 8 pesos & D008 \\
\hline
\end{tabular}

Flores

\begin{tabular}{|l|l|l|}
\hline Violeta & 4 libras a 3 p.s & D012 \\
\hline Baija de Laurel (baya vg.) (baga de loureiro pt.) & $1 / 2$ libra à 6 p.s & D001... 1 \\
\hline $\begin{array}{l}\text { Baya de enebro (baga de zimbro pt.) [família das } \\
\text { Cupresaceas] }\end{array}$ & $1 \frac{1 / 2 \text { libra à } 6 \text { r.s }}{}$ & D001... 1 \\
\hline Cañafistola (Canafístula pt.) & 2 libras à 8 r.s & D002 \\
\hline Extracto de coloquintida [Citrullus colocynthis] & 1 libra à 3 p.s & D003 \\
\hline Cubebas [Piper cubeba] & $\frac{1}{1 / 2}$ libra em 2 pesos & D002 \\
\hline Marabolano Berlerico ${ }^{140}$ & $\frac{1}{1 / 2}$ libra em 2 p.s & D002 \\
\hline
\end{tabular}

\footnotetext{
${ }^{137}$ Originária das regiões mediterrânicas.

138 Acreditamos que se refira à resina do Calophyllum tacamahaca.

139 “Planta leguminosa/ goma que fluye de esta planta” (Picatoste, 1887: 68).
} 


\begin{tabular}{|l|l|l|}
\hline Yndico & 1 libra à 2 pesos & D002 \\
\hline $\begin{array}{l}\text { Miravolano ceverico (mirabolano ga.) [Família } \\
\text { Rosaceae }\end{array}$ & $1 / 2$ libra 2 pesos & D002 \\
\hline Agallas $^{141}$ & 8 libras à 8 r.s & D008 \\
\hline $\begin{array}{l}\text { Pimienta larga (pimenta longa pt.) [Piper } \\
\text { longum] }\end{array}$ & 3 onças em 3 r.s & D000... 3 \\
\hline & & $1 \mathrm{D} 200 \ldots 7$ \\
\hline
\end{tabular}

Suma anterior 1D200...7

\begin{tabular}{|c|c|c|}
\hline Dictamo negro[ gênero Dictamnus] & 4 onças em 4 r.s & D000... 4 \\
\hline Cardomomo [Família Zingiberaceae] & 1/2 libra em 12 r.s & D001... 4 \\
\hline Alolvas (alolba vg.) & 5 libras a 8 r.s & D005 \\
\hline Linaza & 2 libras à 8 r.s & D002 \\
\hline Alumbre de Castilla (alume de Castela) & 2 libras à 6 r.s & D001... 4 \\
\hline Arcenico blanco [trióxido de arsênio $\mathrm{As}_{2} \mathrm{O}_{3}$ ] & $1 / 2$ libra em 4 r.s & $\mathrm{D} 000 \ldots 4$ \\
\hline Borax [borato de Sódio $\mathrm{Na}_{2} \mathrm{~B}_{4} \mathrm{O}_{7} \cdot 10 \mathrm{H}_{2} \mathrm{O}$ ] & $1 / 2$ libra em 3 p.s & D003 \\
\hline Zera amarilla (cera amarela pt.) & 4 libras à 6 r.s & D003 \\
\hline Cera negra (cera negra pt.) & 2 libras à 4 r.s & D001 \\
\hline Cera blanca (cera branca pt.) & $1 / 2$ libra em 5 r.s & D000... 5 \\
\hline Christal mineral & 1 libra em 8 r.s & D001 \\
\hline Sal Gemma (sal- gema pt.) ${ }^{142}$ & 3 libras à 4 r.s & D001...4 \\
\hline Azufre (enxofre pt.) & 3 libras à 4 r.s & $\mathrm{D} 001 \ldots 4$ \\
\hline Tartaro crudo (tártaro cru pt.) & 3 libras à 12 r.s & D004...4 \\
\hline Pez negro (peixe negro pt.) ${ }^{143}$ & 5 libras à 6 r.s & D003...6 \\
\hline Resina de Pino $^{144}$ & 2 libras à 4 r.s & D001 \\
\hline Piedra Lipis & 7 libras à 8 r.s & D007 \\
\hline $\begin{array}{l}\text { Vitrido blanco (Vitríolo Blanco vg.) (vítriolo } \\
\text { branco pt.) }\left[\mathrm{ZnSO}_{4}\right]\end{array}$ & 5 libras à 8 r.s & D005 \\
\hline $\begin{array}{l}\text { Uña de la gran bestia (unha da grande besta } \\
\text { pt.) }\end{array}$ & 2 onças em 2 r.s & $\mathrm{D} 000 \ldots 2$ \\
\hline Bolo armenico ${ }^{146}$ & 4 onças em 4 r.s & D000...4 \\
\hline
\end{tabular}

140 “fruto ovalado, carnoso y con hueso.” (Ibíd: 718).

141 “escrecencia redonda que se forma en ciertos árboles/ órgano de la respiración de los peces.” (Ibíd: 41).

142 Sal-gema é o nome que se dá ao cloreto de sódio $(\mathrm{NaCl})$.

${ }^{143}$ Há uma referência em: Pinto, 1852.

144 É retirada especialmente das coníferas.

145 Apesar do nome sugerir alguma ligação com o demoníaco, as uñas seriam as patas dos alces. Sobre o tema, ver mais em: http://www.cronicadelasmerindades.com/investiga/investigacion181.pdf Acesso: 13/05/2013.

146 “El bol tiene por base principal uma de estas tierras, que es la alúmina, y segun otros, tambien la magnesia, y despues otras tierras que tambien suele tener mezcladas, aunque en mas corta porcion. El color que esta substancia tiene mas ó menos encarnado, le proviene de una porcion de óxido de hierro que entra como principio componente del bol, llamado vulgarmente ocre. Su orígen proviene de la descomposicion de los shistos, los quales siendo formados de tierras y pyritas de hierro, suministran el bol arménico por una parte, y el sulfate de hierro por otra, á costa de oxigeno que el azufre y el hierro reciben del agua.” (Gregorio, 1803: 173). 


\begin{tabular}{|c|c|c|}
\hline Creta blanca & 2 libras à 8 r.s & D002 \\
\hline Tierra Japonica (terra japonesa pt.) & $1 / 2$ libra em 6 r.s & D000...6 \\
\hline Tierra Leninia & $1 / 2$ libra em 4 r.s & $\mathrm{D} 000 \ldots 4$ \\
\hline Ocre $^{147}$ & 2 onças em 1 r.s & $\mathrm{D} 000 \ldots 1$ \\
\hline Tierra de S. Pablo (terra de São Paulo pt.) & 4 onças em 2 r.s & $\mathrm{D} 000 \ldots 2$ \\
\hline Tierra sigillada blanca & $1 / 2$ libra em6 r.s & D000... 6 \\
\hline Tierra sigillada rubia $^{148}$ & 3 libras à 6 r.s & D002... 2 \\
\hline & & 1D252... 1 \\
\hline
\end{tabular}

Suma anterior.

Fólio 4542v.

\begin{tabular}{|c|c|c|}
\hline Cardenillo [acetato de cobre (II) $\mathrm{Cu}\left(\mathrm{CH}_{3} \mathrm{COO}_{2}\right.$ ] & $1 / 2$ libra em 2 p.s & D002 \\
\hline antimonio crudo (antimônio cru) ${ }^{149}$ & 3 libras à 8 r.s & D003 \\
\hline Oropimentes $^{150}$ & 1 onça em 1 r.s & D000... 1 \\
\hline $\begin{array}{l}\text { Alvaialde (albayalde ga.) [carbonato básico de } \\
\text { plomo (II) }\end{array}$ & 4 libras à 8 r.s & D004 \\
\hline $\begin{array}{l}\text { Mermellon [cinábrio; sulfeto de mercúrio II, } \\
\text { HgS] }\end{array}$ & 3 libras à 4 p.s & D012 \\
\hline Cinabrio natibo [sulfeto de mercúrio II, HgS] ${ }^{152}$ & 2 libras à 2 p.s & D004 \\
\hline Limadura de hierro (limalhas de ferro pt.) & 2 lib.s em 4 r.s & $\mathrm{D} 000 \ldots 4$ \\
\hline Litargiro (litargírio) (óxido de chumbo pt.) & 6 libras à 8 r.s & D006 \\
\hline Minio (tetróxido de chumbo pt.) & 2 libras à 8 r.s & D002 \\
\hline Plomo quemado (chumbo queimado pt.) & $1 / 2$ libra em 8 r.s & D001 \\
\hline Sucuno Rubio & 2 libras à 2 p.s & D004 \\
\hline Castoreo de Ruv. $^{\text {a }}$ & 3 onças em 3 p.s & D003 \\
\hline
\end{tabular}

Águas

\begin{tabular}{|c|c|c|}
\hline De Geciana comp. ${ }^{\text {ta }}$ (genciana composta vg.) & 5 libras à 8 r.s & D005 \\
\hline Escorzonera (Escorcionera vg.) & 4 libras à 4 r.s & D002 \\
\hline Chicoria & 4 libras à 4 r.s & D002 \\
\hline Cardo Santo & 4 libras à 4 r.s & D002 \\
\hline Verdolaga yd. en todo & yd. en todo & D002 \\
\hline Borraja & Yd. lo mismo & D002 \\
\hline
\end{tabular}

\footnotetext{
${ }^{147}$ Refere-se a um mineral terroso, composto com óxido de ferro e hidratado e argila.

148 “Tierra sigilada, que llaman tambien rubrica Lemnia, del nombre de la islã de Lemnos, de donde la estreian los antiguos. Es una espécie de tierra ó lapiz de diferentes colores, á la que se dá el nombre de sigilada por la impresion de los sellos, que comunmente lleva. Esta tierra es pesada, blanda y friable, comunmente roja, pero mas á menudo blanca, y de color de limon: es muy adstringente, por lo que se suele usar contra las hemorrágias y otras enfermidades; entra tambien em la composicion de la triaca." (Boy, 1840. T. IV: 747).

${ }^{149}$ São os metais que contêm mais de $90 \%$ de antimônio.

150 “Mineral amarillo venenoso compuesto de arsénico y azufre.” (Picatoste, 1887: 772).

151 “sustancia que se saca del plomo tratado por el vinagre; es parecida al yeso mate y venenosa.” (Ibíd: 53).

152 "Es el azogue combinado con el azufre, y sublimado por los calores subterráneos en masas de color encarnado, algunas veces cristalizado con estrias brillantes.” (Gregorio, 1803: 293).
} 


\begin{tabular}{|c|c|c|}
\hline Ynojo (hinojo ga.) & 2 libras à 6 r.s & D001... 4 \\
\hline Yerba buena (Hierva Buena ga.) & 6 libras à 6 r.s & D004... 4 \\
\hline Agenjo (Ajenjos vg.) & 3 libras à 6 r.s & D002... 2 \\
\hline Peonia comp. ${ }^{\text {ta }}$ (peônia pt.) & 4 libr. ${ }^{\text {a }}$ a 8 r.s & D004 \\
\hline Aguafuertes (água-forte pt.) & 4 1/2 lib. ${ }^{a}$ a 2 p.s & D009 \\
\hline
\end{tabular}

Azeites

\begin{tabular}{|l|l|l|}
\hline Petroleo (Petróleo pt.) & $2 \frac{1}{2}$ lib.a a 4 p.s & D010 \\
\hline & & $1 \mathrm{D} 340 \ldots 0$ \\
\hline
\end{tabular}

Fólio 4543r.

Suma anterior

1D340...0

\begin{tabular}{|l|l|l|}
\hline Sugsino & $1 \frac{1}{2}$ libras à 6 p.s & D009 \\
\hline Vitriolo & 1 libra à 3 p.s & D003 \\
\hline Piedra rubia & 1 libra à 2 p.s & D002 \\
\hline Piedra blanca & 1 libra à 2 p.s & D002 \\
\hline Azeyte Blanco (azeite branco pt.) ${ }^{153}$ & 6 libras à 2 p.s & D012 \\
\hline Arraigan (arrayan vg.) & 6 libras à 1 p.s & D006 \\
\hline Nuez moscada (noz moscada pt.) & 1 libra em 6 p.s & D006 \\
\hline
\end{tabular}

Espirítus (Espíritos)

\begin{tabular}{|l|l|l|}
\hline Cuerno de cierbo (corno ce cervo pt.) & $1 / 2$ libra a 3 p.s & D003 \\
\hline Coclearia & $1 / 2$ libra a 6 p.s & D009 \\
\hline Azufre (Enxofre pt.) & $1 / 2$ libra em 6 r.s & D000...6 \\
\hline
\end{tabular}

Sales (Sais pt.) ${ }^{154}$

\begin{tabular}{|l|l|l|}
\hline Marte & 4 onças à 8 r.s & D004 \\
\hline Agenjo (Ajenjo ga.) (Absinto pt.) & $1 \frac{1}{4}$ à 8 p.s & D010 \\
\hline salcatartica (sal catartica vg.) & 8 libras à 8 r.s & D008 \\
\hline Nitro blanco (nitro branco pt.) $^{155}$ & $1 \frac{1 / 2}{2}$ libras à 8 r.s & D002... 4 \\
\hline Soliman Crudo $^{156}$ & 1 libra à 6 p.s & D006 \\
\hline Azucar blanca (açúcar branco pt.) $^{1 / 1 / 4 ~ @ ~ a ̀ ~} 5$ p.s & D006... 2 \\
\hline Polbos azules $^{157}$ & $1 \frac{1}{2}$ libra em 1 peso & D0001 \\
\hline Marfil (marfim pt.) $^{158}$ & $1 / 2$ libra em 6 r.s & D000... 6 \\
\hline
\end{tabular}

\footnotetext{
${ }^{153}$ Há uma referência sobre um azeite branco chamado: “azeyte virgen de Provenza” (Núñez, 1780: 163).

${ }^{154}$ Existem os sais naturais e também os “feitos por arte”: O sal, que se faz por arte, se divide em tres classes, a saber, Sal animal, vegetal, \& mineral, para cuja preparação se reduzem os animaes, \& vegetaes em cinza, que se põem a ferver muyto tempo com água usual, \& se filtra para que fique o sal no fundo.” (Bluteau, 1728: 438).

155 Acreditamos que a referência como nitro branco se deva ao seu estado natural, já que sua cor é branca.

156 “Azogue sublimado” (Picatoste, 1887: 961).

${ }^{157}$ Acreditamos que sejam pós extraídos das pedras lazuli.
} 


\begin{tabular}{|c|c|c|}
\hline Magna & 4 libras à 3 p.s & D012 \\
\hline Antimonio hordinario (antimônio comum pt.) & 10 lib.s à 4 r.s & D005 \\
\hline Emplasto de aquilon mai. ${ }^{\text {or }} 159$ & 4 lib.s a 12 r.s & D006 \\
\hline Flor de estenfui & 4 onças à 8 r.s & D0004 \\
\hline & & $1 \mathrm{D} 458 \ldots 2$ \\
\hline
\end{tabular}

Suma anterior.

Fólio 4543v.

\begin{tabular}{|c|c|c|}
\hline Azafran (açafrão pt.) & 1 libra à 6 p.s & D006 \\
\hline Gomma ammoniaco (goma amoníaca pt.) ${ }^{160}$ & 3 lib.s a 2 p.s & D006 \\
\hline Ynguento de Altea (althea vg.) & 2 libras à 12 r.s & D003 \\
\hline Grasa de chancho (banha de porco pt.) & 2 lib.s à 4 r.s & D001 \\
\hline Extracto de Junipero (extrato de zimbro pt.) & 3 lib.s à 8 r.s & D003 \\
\hline Precipitado blanco (precipitado branco pt.) ${ }^{161}$ & $1 / 2$ libra em 3 p.s & D003 \\
\hline Tamarindos una Petaca $^{162}$ & $\begin{array}{l}118 \text { lib.s neto- à } \\
\text { 8r.s }\end{array}$ & D118 \\
\hline $\begin{array}{l}\text { Espiritu de vino (espírito de vinho pt.) [Alcohol } \\
\text { Etílico [C2H5OH] }]^{163}\end{array}$ & 14 libras a 8 r.s & D014 \\
\hline Aguard.te simple (aguardente simples pt.) & 14 libras à 4r.s & D007 \\
\hline Vinagre rosado (vinagre rosado pt.) & 2 libras à 6 r.s & $\mathrm{D} 001 \ldots 4$ \\
\hline Azeyte de Linaza (azeite de linhaça pt.) & 3 libr.s à 8 r.s & D003 \\
\hline Ysica pa(u)sada & $\begin{array}{l}4 \text { lib.s mui viexa } \\
\text { sin valor ninguno }\end{array}$ & $Z$ \\
\hline
\end{tabular}

Almacen (Armazém)

\begin{tabular}{|l|l|l|}
\hline Sen & 1 @ à 8 p.s libra & D075 \\
\hline Azogue (mercúrio pt.) & 18 libras à 2 p.s & D036 \\
\hline Canchalagua [Schkuhria pinnata] & 6 libras à 8 r.s & D006 \\
\hline Pimenta negra [Piper nigrum] & 26 lib.s à 8 r.s & D026 \\
\hline Tamandarindos & 24 lib.s à 8 r.s & D024 \\
\hline Tutia & 4 3/4 libras à 2 p.s & D009... 4 \\
\hline Dauco cretido (dauco vulgar pt.) & $13 / 4$ libra à 8 r.s & D001... 6 \\
\hline Cardamomo (cardomomo vg.) & $13 / 4$ libras à 8 r.s & D001... 6 \\
\hline Sandalo rubio & $13 / 4$ libras à 3 p.s & D005... 2 \\
\hline
\end{tabular}

158 "La sustância de que están formados los colmilhos del elefante; es dura, compacta y blanca." (Picatoste, 1887: 692).

159 "Viento cierzo ó del Norte" (Ibíd: 99) Acreditamos que se refira a um emplasto usado contra os assim chamados ventos do norte.

160 “La gomma ammoniaco è il succo che scola dal Dorema ammoniacum e da varie specie di ferule. Dorema - forse dal greco $\delta \omega ́ p \eta \mu \alpha=$ dono - è un genere di piante della famiglia Ombrellifere, con 4 specie: sono grandi erbe perenni simili alle ferule, che vivono nelle regioni subdesertiche della Persia. Esse forniscono - soprattutto il Dorema ammoniacum - la gommoresina detta appunto gomma ammoniaco. In: http://www.summagallicana.it/lessico/g/gomma\%20ammoniaco.htm

${ }^{161}$ As precipitações são a formação de sólidos durante reações químicas.

162 A petaca pode ser: "espécie de arca hecha de cueros ó de madera cubierta de ellos/ cajá pequeno para guardar el tabaco.” (Picatoste, 1887: 817).

163 http://al-quimicos.blogspot.com.br/2007/05/sabes-lo-que-es-el-espritu-de-vino.html Acesso 15/06/13. 


\begin{tabular}{|l|l|l|}
\hline Galanga & 2 3/4 libras à 8 r.s & D002... 6 \\
\hline Oropimiente & $10 \frac{1}{2}$ libras à 12 r.s & D015.. 6 \\
\hline Triaca embotecitos & $61 / 2$ lib.s a 3 p.s & D019... 4 \\
\hline & & 1 D847...0 \\
\hline
\end{tabular}

Suma anterior

$1 \mathrm{D} 847 \ldots 0$

Fólio 4544r.

\begin{tabular}{|c|c|c|}
\hline Flor de Masias (Macis ga.) ${ }^{164}$ & 12 1/2 onças à 8 r.s & D012... 4 \\
\hline Antimonio crudo & 24 libras à 4 r.s & D012 \\
\hline Imperatoria & 1 libra à 12 r.s & $\mathrm{D} 001 \ldots 4$ \\
\hline Vistorta (Bistorta vg.) & 12 onças à 10 r.s & D001... 2 \\
\hline Dientes de Jabali (Dentes de Javali pt.) & $21 / 2$ lib.s a 3 p.s & D007 \\
\hline Cardenillo & $22 \frac{1}{1 / 2}$ a 4 pesos & D090 \\
\hline Enula & 3 libras a 8 r.s & D003 \\
\hline Raiz de China & $31 / 2$ libras à 4 p.s & D014 \\
\hline Minio & $241 / 2$ libras a 8 r.s & D024.... 4 \\
\hline Vitriolo blanco & 4 1/2 libras à 8 r.s & D004... 4 \\
\hline Goma Araviga (arábica vg.) & 23 libras à 8 r.s & D023 \\
\hline Copal & 1 1/2 libras à 4 p.s & D006 \\
\hline Mandibulas & 2 1/2 libras à 4 p.s & D010 \\
\hline Esponjas $^{165}$ & 4 onças a r. ${ }^{\mathrm{t}} \mathrm{y} \mathrm{m}^{\mathrm{o}}$ & D000... \\
\hline Consuelda (confrei pt.) [Symphytum officinale] & $13 / 4$ libras à 8 r.s & D001... 6 \\
\hline Raiz de Angelica & $13 / 4$ libr.s a 8 r.s & D001... 6 \\
\hline Almaziga (almaciga ga.) & $23 / 4$ libras à 8 r.s & $\mathrm{D} 002 \ldots 6$ \\
\hline Bolo almenico (armênico vg.) & 5 1/2 libras à 8 r.s & D005... 4 \\
\hline Escamonea & $13 / 4$ à 6 p.s & D010... 4 \\
\hline Sinabrio artificial (cinabrio vg.) & 4 lib.s à 4 p.s & D016 \\
\hline Siperos largos & $13 / 4$ libras à 8 r.s & D001... 6 \\
\hline Scilla ceoa & $11 / 2$ libra a 2 p.s & D003 \\
\hline Alcanfor & 5 libras à 5 p.s & D025 \\
\hline Calamo aromatico & $1 / 2$ libra em 4 r.s & D000... 4 \\
\hline Uña de la gran vestia & 1 libra 2 p.s & $\mathrm{D} 002$ \\
\hline enula campana ${ }^{166}$ & 1 libra à 8 r.s & D001 \\
\hline madre de Perla & 4 3/4 libr.s a 2 p.s & D009...4 \\
\hline \multirow[t]{2}{*}{$\begin{array}{l}\text { Tarage (taraje ga.) (tamargueira pt.) [Tamarix } \\
\text { africana] }\end{array}$} & $1 / 2$ libra em 4 r.s & D000... 4 \\
\hline & & $2 \mathrm{D} 138 \ldots 4$ \\
\hline
\end{tabular}

Sello quarto, um quartillo, años de mil setecientos y sesenta y seis, y setenta y siete. ${ }^{167}$ Para los años de 1771/ $1772^{168}$

\footnotetext{
${ }^{164}$ Se refere à casca da semente da noz moscada.

165 Acreditamos que possa se tratar da "flor, alias cachía, amarela, odoritera” ou ainda aquela que "cria-se nas rochas do mar, e é planta marinha” (Bluteau, 1728: 763).

${ }^{166}$ Acreditamos que se refira a mesma espécie localizada anteriormente apenas como ênula.

${ }^{167}$ Informação que se encontra carimbada na parte central da página.
} 
Fólio 4544v.

Suma anterior

2D138... 4

\begin{tabular}{|c|c|c|}
\hline Sal Almoniaco & 25 lib.s a 2 p.s & D050 \\
\hline Castoreos & 2 libras à 12 p.s & D024 \\
\hline Goma de Vedelio $^{169}$ & 1 3/4 libras à 2 p.s & D003... 4 \\
\hline Opopanaco & $13 / 4$ libras à 14 pesos & D024... 4 \\
\hline Goma amoniaco (goma de amoníaco pt.) ${ }^{170}$ & 5 1/2 libras à 2 pesos & D011 \\
\hline Galvano & $51 / 2$ libras à 4 pesos & D022 \\
\hline Goma de enebro (goma de zimbro pt.) & 2 3/4 libras à 12 r.s & D004... 1 \\
\hline Mirra & 2 3/4 libras à 4 pesos & D011 \\
\hline Aluzema (alhucema ga.) [lavandula latifolia] & $1 / 2 @$ em 3 pesos & D003 \\
\hline Christal Tartaro & $161 / 2$ libras à 2 p.s & D033 \\
\hline Simienta de Alejandria ${ }^{171}$ & $1 / 2$ libra & D000... 6 \\
\hline Bórax & 8 libras à 6 pesos & D048 \\
\hline $\begin{array}{l}\text { Bitriolo de Ungria ( vitríolo da Hungria vg.) } \\
\text { [sulfato duplo de cobre e ferro] }\end{array}$ & $91 / 2$ lib.s No sirve & B \\
\hline Raiz de Galanga & 3 lib.s à 8 r.s & D003 \\
\hline Coralina & 1 libra à 8 r.s & D001 \\
\hline Piedra lipis & 12 libras à 8 r.s & D012 \\
\hline Goma olivano & 3 1/2 lib.s à 8 r.s & D003... 4 \\
\hline Goma de Limon (Goma de limão pt.) & 6 libras à 8 r.s & D006 \\
\hline Litargirio & 18 lib.s à 4 r.s & D009 \\
\hline Coral rubio [Corallim rebrum] & 8 lib.s à 4 r.s & D004 \\
\hline Goma olivano & 10 lib.s à 8 r.s & D010 \\
\hline escamonea & 3 lib.s a 6 p.s & D018 \\
\hline \multirow[t]{2}{*}{ Ambar Blanco (âmbar branco pt.) ${ }^{172}$} & $1 / 2$ libra à 4 r.s & D000... 4 \\
\hline & & $2 \mathrm{D} 440 \ldots 7$ \\
\hline
\end{tabular}

Suma anterior

Fólio 4545r.

\begin{tabular}{|l|l|l|}
\hline Eleboro negro & 3 1/2 lib.s a 8 r.s & D003... 4 \\
\hline Almaciga & 2 libras à 8 r.s & D002 \\
\hline Linaza & 2 libras à 4 r.s & D001 \\
\hline Ruibarbo apolillado & 3 tt.s & \\
\hline
\end{tabular}

\footnotetext{
${ }^{168}$ Informação que se encontra carimbada na parte superior esquerda da folha.

169 Sua denominação pode estar relacionada com um médico chamado Vedélio, provavelmente italiano, sobre o qual não temos maiores informações, porém, localizamos também uma planta chamada vedélia. (sphagneticola trilobata).

170 “Amoníaco ou goma de amoníaco, osso colorido substância com assinatura revoltante, gosto amargo, obtido a partir da leitoso exsudato da vítima caules de uma planta (dorema ammoniacum); In: http://portuguese.alibaba.com/product-free/gum-ammoniac-104359202.html Acesso: 31/03/13.

${ }^{171}$ Acreditamos que seja o mesmo que o santónico: “En el siglo XVI se llamaba santónico o semilla contra las lombrices a la mezcla de las cabezuelas florales del ajenjo marino con las de otra especie similar, el santónico o tomillo blanco. El ajenjo marino se viene usando desde tiempos de Dioscórides como vermifugo infantil” In: http://www.hipernatural.com/es/pltsantonico.html

172 Sobre o âmbar: "betún fósil amarillo, ligero y eléctrico, que se emplea para adornos/ sustancia aromática que se encuentra sobre las aguas del mar.” (Picatoste, 1887: 73).
} 


\begin{tabular}{|c|c|c|}
\hline Piedra Ematistis & 6 lib.s à 2 p.s & D012 \\
\hline Tartaro crudo & 16 lib.s à 4 p.s & D064 \\
\hline Alcanfor & 8 libras à 6 p.s & D048 \\
\hline Castoreo & 4 libras à 12 p.s & D048 \\
\hline Coralina & 3 libras à 8 r.s & D003 \\
\hline Goma azafetida (asafetida vg.) $^{173}$ & 2 l.a a 10 r.s & D002... 4 \\
\hline Flor de azufre (flor de enxofre pt.) & 13 lib.s a 3 p.s & D039 \\
\hline estoraque & $31 / 2$ à 20 n.s & D008... 6 \\
\hline Coloquintida & 2 lib.s à 8 r.s & D002 \\
\hline Resina de Jalapa & 12 onças em 6 p.s & D006 \\
\hline Ojos de cangrejo & 8 lib.s à 2 p.s & D016 \\
\hline Mirra & 1 libra à 4 p.s & D004 \\
\hline subsino & 3 lib.s à 2 p.s & D006 \\
\hline Volo armenico( bolo armenico vg.) & 18 lib.s à 8 r.s & D018 \\
\hline Flor de violeta & 6 l.s à 3 p.s & D018 \\
\hline Cominos & 2 lib.s à 4 r.s & D001 \\
\hline Cascara de Gibia & 2 l.s a 4 r.s & D001 \\
\hline $\begin{array}{l}\text { sal de Inglaterra (sal da Inglaterra) [Sulfato } \\
\text { de Magnesio; } \mathrm{MgSO}_{4} \cdot 7 \mathrm{H}_{2} \mathrm{O} \text {.] }\end{array}$ & 2@ Pausada & \\
\hline $\begin{array}{l}\text { Nitro no mui blanco (nitro não muito branco } \\
\text { pt.) }\end{array}$ & $11 / 2 @$ à 4 r.s & D018... 4 \\
\hline Caña fistula & 3 lib.s à 8 r.s & D003 \\
\hline Cardenillo & $13 \frac{1}{1} 2$ lib.s à 4 pesos & D054 \\
\hline Mecoacan (mechoachan vg.) & 4 l.s à 4 r.s & D002 \\
\hline \multirow[t]{2}{*}{ Zarza Parrilla } & 3/4 de@à 14 r.s libra & D031...4 \\
\hline & & 1 \\
\hline
\end{tabular}

Fólio 4545v.

Suma anterior

\begin{tabular}{|c|c|c|}
\hline Manteca de Puerco (manteiga de porco pt.) & 1 @ à 4 r.s & D012... 4 \\
\hline Ruibarbo & 1@ à 4 pesos & D100 \\
\hline de azafran & $31 / 4$ libra à 6 pesos & D019...4 \\
\hline esperma & 5 1/2 libras à 3 p.s & D016... 4 \\
\hline Balsamo copahive (copaíba vg.) & 4 li.s a 14 r.s & D007 \\
\hline Ungüento antonita & $61 / 2$ l.s a 10 r.s & D008... 1 \\
\hline Triaca & 9 l.s à 20 r.s & $\mathrm{D} 022 \ldots 4$ \\
\hline Balsamo copahive & 7 l.s a 14 r.s & D012...2 \\
\hline fermentina $^{174}$ & 30 l.s à 8 r.s & D030 \\
\hline sarsa Parrilla & 25 l.s à 14 r.s & D041... 2 \\
\hline Azufre & 9 @ 4 l.s neto à 4 r.s & D114... 4 \\
\hline Alumbre $^{175}$ & 181 l.s à 4 r.s & D090... 4 \\
\hline
\end{tabular}

173 É um composto: “Ferula assafoetida, estiércol del diablo. La asafétida es el jugo de las Ferulas estiércol del diablo que crecen en Iraq (Persia) y al noreste de la India. In: http://www.kremerpigmente.com/es/medios--aglutinantes-und-colas/aglutinantes-solubles-en-disolvente/balsamos-undceras/goma-asafetida-500-g-62070.html Acesso: 21/05/13

${ }^{174}$ Acreditamos que se refira a algum preparo à base de fermento.

175 Falando especificamente sobre o alumbre: "Sal compuesta de ácido sulfúrico y alúmina” (Picatoste, 1887: 70). 


\begin{tabular}{|l|l|l|}
\hline Pez rubia ${ }^{176}$ & 88 l.s a 4 r.s & D044 \\
\hline Palo santo & 1@ 1 l.a à 4 r.s & D013 \\
\hline Ysica & $\begin{array}{l}\text { 2@ } 2 \text { l.s neto à 4 r.s } \\
\text { lib.a }\end{array}$ & D026 \\
\hline & Suma & 3D410...6 \\
\hline
\end{tabular}

Ignacío Tolosa $=$ Lorenzo Infante

Razon de los efectos, y Medicamentos añadidos al prãl de esta oficina que ha mi pedimento me ha entregado el señor d. ${ }^{\mathrm{n}}$ Fernando Fabro en el Mes de Mayo de 1768....

\begin{tabular}{|l|l|l|}
\hline Mana $^{177}$ & 4 lib.s à 3 p.s & D012 \\
\hline Jalapa & 2 libras à 3 p.s & D006 \\
\hline $\begin{array}{l}\text { Piedra infernal (pedra infernal pt.) [nitrato de } \\
\text { prata } \mathrm{AgNO}_{3} \text { ] }\end{array}$ & 2 onças a 2 1/2 p.s & D005 \\
\hline Confeccion de krmes & 1 l.a em 12 p.s & D012 \\
\hline Cantaridas & 4 onças a 5 r.s & D002... 4 \\
\hline Azucar & 2@ à 5 p.s & D010 \\
\hline & & $3 \mathrm{D} 458 \ldots 2$ \\
\hline
\end{tabular}

Lorenzo Ynfante ${ }^{178}$

Fólio 4546r.

Carta $\%$ En conformidad del Papel contha de ayer que recivi de um le incluio el oxig. ${ }^{t}$ Ymbentario que hicieron de esta Botica el Boticario, y Medico d. ${ }^{\mathrm{n}}$ Lorenzo Ynfante, y d. ${ }^{\mathrm{n}}$ Ygnacio Tolosa; para que en su vista determine esa Ytl. ${ }^{\mathrm{e}}$ junta lo que halle por conven. ${ }^{\text {te }}$ Nrõ señor guarde a c m m. ${ }^{\mathrm{s}} \mathrm{a}^{\mathrm{s}}$. Colegio 24 de oct. $^{\mathrm{e}}$ de $1771=\mathrm{Blm}^{\circ}$. De o m su seg. ${ }^{\text {ro }}$ servidor. Fernando Fabro $=$ señor d. ${ }^{\mathrm{n}}$ Cayethano Teran, y Quebedo _ _ _ _ en la ciudad de cordoba en veinte, y cinco de oct. ${ }^{\mathrm{e}}$ de mill setecientos setenta y un años, estando en junta los señores de esta muy Ytt. ${ }^{\text {e }}$ Municipal de Temporalidades. Se hizo presente por el s. ${ }^{r}$ Presidente esta carta con los Ymbentarios que en ella se relacionan en doces foxas de papel blanco: Que tratado y conferido theniendose presenta la Carta de

\footnotetext{
176 "Por el nombre de Rubio se conoce a especies como el Bejel, Rubio, Lucerna, Alfondega, Chirriola, Escacho o Garneo. Es un pescado semigraso y de agua salada. Pertenece a la familia de los Tríglidos.” In: http://www.pescaderiascorunesas.es/productos/ficha/?id=87 Acesso: 03/06/13

177 Se refere ao Maná dos Boticários, definida como "Droga medicinal. Contra a antiga, \& commua opinião dos que imaginarão que o manà dos Boticarios he hum vapor levantado de dia com a força do Sol, \& coalhado de noite, o qual cahindo a modo de orvalho se assenta nas hervas, folhas, \& ramos das arvores, \& também em pedras, \& rochedos, \& que nas terras quentes se colhe congelado como goma antes do nascer do Sol. Altomaro Medico Napolitano, \& Joseph Donzello escrevem, que este manà he hum licor branco e suave que ou naturalmente por si mesmo, ou por incisão mana dos ramos, \& folhas dos freixos, assim bravos, como mansos, no tempo, ou pouco antes da Canícula, \& particularmente dos freixos da Calábria, \& acresentão estes dous Authores, que a opinião contraria he tão falsa, a saber, que o maná se desfaça, \& evapore com o calor do Sol, que antes o Sol o seca, \& o consdensa." (Bluteau, 1728: 278).

${ }^{178}$ Aqui encerra-se o primeiro inventário, feito no ano de 1768, logo após a expulsão dos Jesuítas da América espanhola, que se deu no ano anterior. Os dados a seguir referem- se ao inventário realizado no ano de 1771 que, lém dos dados arrolados no inventário anterior, adicionam o que não havia sido levantado em 1768. No texto que antecede o inventário propriamente dito, não encontramos qualquer explicação sobre as razões para a não conclusão do mesmo em 1768.
} 
diez y seis de septiembre del señor Governador de B. ${ }^{\mathrm{s}}$ Ayr. ${ }^{\mathrm{s}}$ y el capitulo, por el que se le ordena a d. ${ }^{\mathrm{n}}$ Fernando Fabro, dexe livre el colegio. y lo acordado en este particular en veinte y siete de dho; Por todo se re

Fólio 4546v.

solvio nombrar por à hora a d. ${ }^{\mathrm{n}}$ Lorenzo de Orduña por adm. ${ }^{\text {an }}$ de la dha causa, para que se reciva este de la Botica, Libreria, cosas de Yg. ${ }^{a}$ y de mas que hacia de vienes muebles, y todo lo que perteneze à oficinas y edificios inclusive Huertas, y lac. palntas de ellas, y fuera de ellas, interin que verificada la entrega por d. ${ }^{\mathrm{n}}$ Fernan. ${ }^{\text {do }}$ Fabro, determina las Personas que an de avitar los claustros, y Piezas interiores, y se huviesen de hazer cargo de los vienes espirituales. Yp ${ }^{\mathrm{a}}$ que se verifique la remocion de Botica, con el mas puntual arreglo se nombro a d. ${ }^{\mathrm{n}}$ Juan herrero, para que con d. ${ }^{\mathrm{n}}$ Yg. ${ }^{\mathrm{o}}$ Tholosa, como Botanista uno, y otro asistan à la entrega, y remorz. ${ }^{\mathrm{n}}$ para que al tiempo de ella reconozcan las piezas, y Botes, con lo que cada uno tuviese de sus simples, y de ellos hagan la t asacion conforme se fuere removiendo sin reservar cosa alg. ${ }^{\mathrm{a}}$ que pertenezca à la Botica, y uso de ella, haciendo para ello en esta sala

Fólio 4547r. por ante el señor Presidente el Juramento de fidelidad, pasandosele por aho señor oficio a d. ${ }^{\mathrm{n}}$ Fern. ${ }^{\text {do }}$ Fabro, para que este adbertido de esta resolucion, y que determine sré su entrega, y remorcion a el arbitrio de d.n Fernando de Arze Disputado de esta Junta; Y lo firmaron dhos señores por ante mi el presente escrivano de que doy fee Theran $=$ D. ${ }^{\mathrm{r}}$ sarmiento $=$ Gilledo $=$ Montenegro $=$ Ante mi Clem. ${ }^{\text {te }}$ Guerrero; escriv.${ }^{\circ}$ pp ${ }^{\text {co }}$ y del num. ${ }^{\circ}-$

Luego en el dho dia, Mes, y año.

Comparecieron en esta sala donde reside la Real Junta Municip. ${ }^{1}$ de Temporalidades, d. ${ }^{\text {n}}$ Juan herrero y d. ${ }^{\mathrm{n}}$ Ygnacio Tholosa, Peritos nombrados para el efecto que seprev. ${ }^{\mathrm{e}}$ en el decreto antezedente, de quiene el señor Presidente, por ante mi el presente escrivano les recivio juramento, el que hicieron, Y celebraron, por Dios nrõ Señor

Fólio 4547v. y una señal de Cruz según drõ var(x)o del qual prometieron de usar Fiel y legalmente el encargo que se les haze à todos sus leales saber, y entender. Y los firmaron con dho señor por ante mi de que doy fee $=$

Cayethano Theran quêbedo $=$ Juan Joseph herrero $=$ Ygnacio Tolosa $=$ Ante mi;

Celemente Guerrero, escrivano pp. ${ }^{\text {co }}$ y del Numero _ _ en dho dia hice saver el auto de la buelta à d. ${ }^{\mathrm{n}}$ Lorenzo de Orduña, quien quedo enterado de su conthenido, Y lo firmè= Guerrero, ess. ${ }^{\text {no }}$ publico

en la ciudad de Cordoba en nueve de Noviembre de mill Setezientos setenta y un años. el señor Diputado d. ${ }^{\mathrm{n}}$ Fernando de Arze cond. ${ }^{\mathrm{n}}$ Lorerenzo de Orduña, Adm. ${ }^{\text {on }}$ nombrado para el efecto conthen. ${ }^{\text {do }}$ en dho auto de la buelta, se trasladaron al Colegio de los Regulares espatriados, en donde mora el Sarg. ${ }^{\text {to }}$ ma. ${ }^{\mathrm{r}} \mathrm{d} .{ }^{\mathrm{n}}$ Fernando Fabro, à quien

Fólio 4548r.

haviendo sele Comnicado por dho señor Diputado el efecto a que se dirigia suyda (su vida), respondio hallarse enfermo en cama, y que para el Lunes ò Martes proximo, que se podria pasar à practicar la entrega de la Botica, y demas que se manda. Y para que conste lo mandò poner por diligencia, Y lo firmò con el dho Administrador de que doy 
fee $=$ Fernando de Arze, y Bustillo= Lorenzo de Orduña= Ante mi Clemente Guerrero Escrivano publico, y del Numero

en la ciudad de Cordoba, en doze dias del mes de Noviembre de mill setecientos setenta y un años el señor Diputado d. ${ }^{\mathrm{n}}$ Fernando de Arze con los Peritos, y Administrado Nombrados para la entrega, remocion de lo que se contiene en el Decreto de veinte y cinco de octubre, se trasladaron los noinados a el Colegio de los Regulares espatriados, en don de mora el

Fólio 4548v.

sargento ma. ${ }^{\mathrm{r}}$, d. ${ }^{\mathrm{n}}$ Fernando Fabro a quièn se le hizo presente el dho Decreto, que enterado dho señor de su conthenido, pasó inmediatam.te à la Botica, à efectuar en consorcio de d. ${ }^{\mathrm{n}}$ Lorenzo Ynfante, a cuio cargo à corrido la entrega que se previène, $\mathrm{y}$ en su virtud sediò principio en la forma seguiente.

Botica

\begin{tabular}{|l|l|l|}
\hline Águas $^{179}$ & Botica & Pesos ...... $^{\mathrm{S}}$ \\
\hline Primeiram. $^{\text {te }}$ Escorcíonera & 2 Libra à 4 R.s & D001 \\
\hline Yt. Chicoria & 4 Libra à 4 R.s & D002 \\
\hline Cardo Santo & 2 Libra à 2 R.s & D000.....4 \\
\hline Yt. Berdolaga & 3 Libra à 2 R.s & D000.....6 \\
\hline Yt. Borraja & 3 Libras à 2 R.s & D000.....6 \\
\hline Yt. Tumaria & 2 Libra à 4 R.s & D000...... \\
\hline Yt. Labendula & 2 Libra à 4 R.s & D001 \\
\hline Yt. Ynojo & 2 Libra à dos R.s & D000.....4 \\
\hline Yt. Azahar (flores de laranjeira, limoeiro e cidra) & 3 libras à 4 r.s & D001... 1 \\
\hline
\end{tabular}

$\operatorname{Vinos}^{180}$

\begin{tabular}{|l|l|l|}
\hline Emetico & 6 onças em 2 r.s & D000...2 \\
\hline Vinagre destilado & $1 / 2$ libras a 6 r.s & D001... 1 \\
\hline Vinagre esilitico & 2 lib.s à 4 r.s & D001 \\
\hline
\end{tabular}

Unguentos $^{181}$

\begin{tabular}{|l|l|l|}
\hline Blanco & $1 \frac{1}{1} / 2$ libras à 10 r.s & D001.. 7 \\
\hline Blanco Alcanforado & 3 libras à 12 r.s & D004...4 \\
\hline & & D017...6 \\
\hline
\end{tabular}

\footnotetext{
${ }^{179}$ Esta tabela contém praticamente os mesmos itens constantes no inventário de 1768, com exceção do torongil, que foi substituído pelo Azahar. A tabela do inventário de 1768 apresenta 21 itens, enquanto que a de 1771-1772, apenas 9. Os valores relacionados, no entanto, são diversos, se comparados entre si.

${ }^{180}$ Na tabela do primeiro inventário constam 5 itens, no de 1771-1772 encontramos 3, sendo que não há informações sobre as quantidades do Mellepedes e do Caliviado. Os valores também são diversos dos apontados no primeiro inventário.

${ }^{181}$ todo lo que sirve para ungir ó untar” (Picatoste, 1887: 1022) No inventário de 1768 eram 26 itens, no de 1771-1772 foram relacionados apenas 17.
} 
Fólio 4549r.

Suma anterior.

D017... 6

\begin{tabular}{|c|c|c|}
\hline Minio (Tetróxido de chumbo) & $1 / 2$ libra por m. ${ }^{0}$ R.s & D000... 1/2 \\
\hline Aragon & 1 libra à 12 R.s & D001....4 \\
\hline Sarna & $1 / 2$ libra à 8 R.s & D001....4 \\
\hline Altea (althea vg.) & 1 libra à 8 R.s & D001 \\
\hline Zacarias & $1 / 2$ libra à 8 R.s & $0001 \ldots . .4$ \\
\hline Amarillo & $21 / 2$ libras à 4 R.s & $0001 \ldots 2$ \\
\hline Calabaza & $11 / 2$ à 2 r.s & D000.....3 \\
\hline Mercurio comp. $^{0}$ & 12 onças em 3 p.s & D003 \\
\hline De la condessa & 12 onças a R.s & D000.....4 \\
\hline Basalicon & 1 libra à 4 R.s & D000.....4 \\
\hline Plomo & 1 libra 8 R.s & D001 \\
\hline Rosado sandalino & 12 onças em. & D001.....1 \\
\hline Balsamo alzedo $^{182}$ & 1 1/2 libra a 10 r.s & D001... 7 \\
\hline Nervino $^{183}$ & 1 libra em 3 r.s & D000... 3 \\
\hline Laurel & 2 onças à $\mathrm{r}^{\mathrm{t}}$ & D000... 2 \\
\hline
\end{tabular}

Lamedores $^{184}$

\begin{tabular}{|c|c|c|}
\hline Azederas & $1 / 2$ libra à 3 R.s & D000.....3 \\
\hline Borraxas (borraja vg.) & $1 / 2$ libra à 3 R.s & D000.....3 \\
\hline Emetico & 2 libras a 8 r.s & D002 \\
\hline Corteza de cidra & 1 libra à 8 r.s & D001 \\
\hline Chicoria & 1/2 libra em 8 R.s & D001 \\
\hline Apio (aipo) [Apium graveolens] & 1 libra 6 r.s & D000... 6 \\
\hline Quelmes & 4 onças R.t & $\mathrm{D} 000 \ldots 4$ \\
\hline Culantrillo & $1 / 2$ libra em 6 r.s & D000... 6 \\
\hline Orosur (Orozuz vg.) & 1/2 libra em 6 R.s & D000... 6 \\
\hline Violeta & $1 / 2$ libra quatro r.s & D000... 4 \\
\hline Mora (Moras vg.) & 2 libras à 6 r.s & $\mathrm{D} 001 \ldots 4$ \\
\hline \multirow[t]{2}{*}{ Magistral } & 3 libras à 12 r.s & D004... 4 \\
\hline & & D048... $4 \frac{1}{2}$ \\
\hline
\end{tabular}

Suma anterior

Fólio 4549v.

\begin{tabular}{|c|c|c|}
\hline Adormederas & 1/2 libra 4 r.s & D000... 4 \\
\hline Persico & $\begin{array}{l}21 / 2 \text { libras em } 2 \\
\text { frascos a } 2 \text { p.s }\end{array}$ & D005 \\
\hline Escordio & $11 / 2$ em 12 r.s & D001... 4 \\
\hline Coclearia coclearea vg.) & 1 libra em 12 r.s & D001... 4 \\
\hline Ojimiel silitico (oximiel) & 2 lib.s a 8 r.s & D002 \\
\hline
\end{tabular}

\section{Azeites $^{185}$}

\footnotetext{
${ }^{182}$ Acreditamos que se trate do bálsamo Alceo, referido no inventário de 1768.

${ }^{183}$ No inventário de 1768 foi feita a observação de que o nervino "no sirve”, neste, ele foi taxado.

${ }^{184}$ No primeiro inventário, esta categoria é composta por 33 itens, no de 1771-1772, há somente 17.
} 


\begin{tabular}{|c|c|c|}
\hline Almendras dulces sin fuego & $\begin{array}{l}2 \text { lib.s y } 4 \text { onças, a } \\
12 \text { r.s libra }\end{array}$ & D003... 3 \\
\hline Eneldo & $1 / 2$ libra em 2 r.s & D000... 2 \\
\hline Aparicio & 1 1/2 libra à 12 r.s & $\mathrm{D} 002 \ldots 2$ \\
\hline Acaparras (alcaparra vg.) & $1 / 2$ libra em 6 r.s & D000...6 \\
\hline Manzanilla & $1 / 2$ libra em 6 r.s & D000...6 \\
\hline Ruda & 1 libra em 6 r.s & D000... 6 \\
\hline Eufordio Euforbio vg.) & 3 onça a $\mathrm{R}^{\mathrm{t}}$ & D000... 3 \\
\hline Laurel & Libra y m. ${ }^{\mathrm{a}}$ a 4 r.s & $\mathrm{D} 000 \ldots 6$ \\
\hline Lombrizes & $1 / 2$ libra em 3 r.s & D000... 3 \\
\hline Hipericon (erva de são João pt.) & 1 libra em 8 r.s & D001 \\
\hline Linaza & 4 onças 1r.t & D000... 1 \\
\hline Azuzena (Azucena ga.) & $1 / 2$ libra em 8 r.s & D001 \\
\hline Patas $^{186}$ & $\begin{array}{l}3 \text { libras em dos } \\
\text { frascos à } 10 \text { r.s }\end{array}$ & D003... 6 \\
\hline Rosado & $1 / 2$ libra em 7 r.s & D000...7 \\
\hline escorpion & $1 / 2$ libra 6 r.s & D000...6 \\
\hline Zorro & 4 onças em 4 r.s & D000...4 \\
\hline Matheolo ${ }^{187}$ & 2 1/2 onças à 4 r.s & D001... 2 \\
\hline Piedra blanca & 4 onças a 4 r.s & D002 \\
\hline Pretolio (Petroleo vg.) & 3 onças à 6 p.s & $\mathrm{D} 002 \ldots 2$ \\
\hline \multirow[t]{2}{*}{ Agenjos } & $\begin{array}{l}1 \text { l. }{ }^{\mathrm{a}} \text { y } 4 \text { onças à } 12 \\
\text { r.s libra }\end{array}$ & D001... 7 \\
\hline & & D084... 1/2 \\
\hline
\end{tabular}

Fólio 4550r.

Azeytes ${ }^{188}$

Suma anterior.

$\mathrm{D} 084 \ldots 1 / 2$

\begin{tabular}{|c|c|c|}
\hline Eneldo & 1 onça 6 R.s & D000... 6 \\
\hline Clabo (clavo vg.) & $1 / 2$ onça em 4 r.s & D000... 4 \\
\hline Ynojo & 1 dragma em 1 r.t & D000.....1 \\
\hline Cidra & 1 onça em 6 r.s & D000....6 \\
\hline Narana & 1 onça em 6 R.s & D000... 6 \\
\hline Hierva Buena & 1 onça em 6 r.s & D000... 6 \\
\hline Manzanillas & 1 onça 4 r.s & D000... 4 \\
\hline Poleó & 1 onça em 6 r.s & D000....6 \\
\hline Ruda $^{189}$ & 1 onça em 6 R.s & D000.... 6 \\
\hline Savina $^{190}$ & $1 / 2$ onça 3 r.s & D000... 3 \\
\hline
\end{tabular}

${ }^{185}$ No primeiro inventário, esta categoria é composta por 25 itens, no de 1771-1772, são 20 itens.

${ }^{186}$ Existem várias plantas chamadas "Patas”, como pata de canguru e pata de elefante. Também pode estar se referindo às patas de algum animal.

${ }^{187}$ Acreditamos que refira-se a um azeite composto por Mathiolo.

188 Tanto no primeiro invetário, quanto no de 1771-1772, esta categoria tem relacionados 23 itens.

${ }^{189}$ No primeiro inventário, encontramos a observação de que a ruda “no sirve”, no de 1771-1772 ela foi taxada. 


\begin{tabular}{|c|c|c|}
\hline Tomillo & 1/2 onça 3 r.s & D000... 3 \\
\hline Succino & 1/2 libra em 4 P.s & D004 \\
\hline Salvia & $1 / 2$ onça 3 r.s & D000... 3 \\
\hline Nuez Noscada & 1 dragma 4 r.s & D000... 4 \\
\hline Palo Santo & 1 onça em 4 r.s & D000... 4 \\
\hline enebro & 12 onças à 4 p.s libra & D0003 \\
\hline Agenjo & 1/2 onça em 9 R.s & D001.....1 \\
\hline $\begin{array}{l}\text { Mejorana (manjerona) [Origanum majorana] } \\
\text { Origanum majorana }\end{array}$ & 1 dragma em 2 r.s & D000... 2 \\
\hline enebro & 2 onças à 2 r.s & D000... 4 \\
\hline Filosophico, ò Ladrillo (Philosofico vg.) & 6 onças a 2 r.s & $\mathrm{D} 001 \ldots 4$ \\
\hline Ynojo & 1 libra em 9 pesos & D009 \\
\hline Azeyte Vitriolo & 4 onças em 2 p.s & D002 \\
\hline Trementina & 2 onças em 2 r.s & $\mathrm{D} 000 \ldots 2$ \\
\hline
\end{tabular}

Espiritus $^{191}$

\begin{tabular}{|l|l|l|}
\hline Vitriolo & $1 \frac{1}{1 / 2}$ à 12 r.s & D002... 2 \\
\hline & & D $115 \ldots 51 / 2$ \\
\hline
\end{tabular}

Suma anterior

Fólio 4550v.

\begin{tabular}{|c|c|c|}
\hline Cuerno de ciervo & $\begin{array}{l}10 \mathrm{x} \text { onças em } 2 \\
\text { frasquitos à } 2 \mathrm{r} . \mathrm{s}\end{array}$ & D002... 4 \\
\hline Sar moniaco (Sal Ammoniaco vg.) & 5 onças a 2 r.s & D001... 2 \\
\hline Coclearia & Onza i m. ${ }^{\text {a }}$ a 3 r.s & $\mathrm{D} 000 \ldots 4^{1 / 2}$ \\
\hline Aguafuerte & 6 onças em 3 r.s & D000... 2 \\
\hline Nitro dulce & 1 libra em 3 p.s & D003 \\
\hline
\end{tabular}

Bálsamos $^{192}$

\begin{tabular}{|l|l|l|}
\hline De copayba & 1 libra em 2 p.s & 0002 \\
\hline Peruviano & 4 onças em 4 r.s & D000... 4 \\
\hline Azufre trementinado (Enxofre terebintinado pt.) & 6 onças em 8 r.s & D001 \\
\hline Anódino & $1 / 2$ libra em 10 r.s & $0001 \ldots 2$ \\
\hline Cathólico & 12 onças à 5 pesos & D004... 3 \\
\hline
\end{tabular}

Tinturas y eliser. ${ }^{\text {s }} 193$

\begin{tabular}{|l|l|l|}
\hline Elise vitriolo Elixer de Vitríolo vg.) & $1 / 2$ libra em 12 R.s & D001....4 \\
\hline
\end{tabular}

\footnotetext{
190 No inventário de 1768, encontramos a observação de que a savina “no sirve”, neste ela foi taxada.

191 No inventário de 1769, esta categoria é composta por 9 itens, no de 1771-1772, são relacionados apenas 6.

192 Tanto no primeiro, quanto no segundo inventário, a categoria apresenta o mesmo número de itens (5)., apresentados na mesma ordem, mas com valores diferentes.

193 No primeiro inventário, foram relacionados 13 itens, no segundo, há um aumento significativo para 21 itens.
} 


\begin{tabular}{|c|c|c|}
\hline Propietatis & 1/2 libra em 12 R.s & D001....4 \\
\hline Azafran & 1 libra em 20 r.s & D002... 4 \\
\hline Láudano líquido & 7 onças em 20 r.s & D002... 4 \\
\hline Mirrha & 7 onças à 5 p.s libra & D002... 11/2 \\
\hline Aloes & 9 onças à 5 p.s libra & 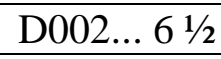 \\
\hline Castoneo (castoreo vg.) & 4 onças em 2 pesos & D002 \\
\hline Cuerno de cierbo & 5 onças à 2 r.s & D001... 2 \\
\hline Piedra de matitis (Piedra Ematistis vg.) & 4 onças em 2 p.s & D002 \\
\hline Cochinila & $1 / 2$ libra em 3 pesos & D003 \\
\hline Azufre & 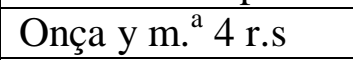 & D000... 4 \\
\hline Agenjos $^{194}$ & Onça y m. ${ }^{\mathrm{a}} 4 \mathrm{r.s}$ & D000...4 \\
\hline \multirow[t]{2}{*}{ Subsino } & $21 / 2$ onças em 15 r.s & D001... 7 \\
\hline & & $\mathrm{D} 159 \ldots 0$ \\
\hline
\end{tabular}

Fólio 4551r.

Suma anterior................. D159... 0

\begin{tabular}{|l|l|l|}
\hline $\begin{array}{l}\text { Espiritu de lavendula comp.to (espírito de } \\
\text { lavendula composto) }\end{array}$ & $\begin{array}{l}12 \text { onças à } 7 \text { pesos } \\
\text { libra }\end{array}$ & D004... 2 \\
\hline Agua del carmen (água de melissa pt.) & 1 l.a & D004 \\
\hline Espiritu de canela (espírito de canela pt.) & 1 libra em 8 p.s & D008 \\
\hline Salamoniaco & 2 1/1 onças em 2 p.s & D002 \\
\hline azufre & 1 onça e, 8 r.s & D001 \\
\hline vitriolo & 3 onças 6 r.s & D000... 6 \\
\hline Nuez noscada & 2 onças em 7 pesos & D007 \\
\hline & & D186 \\
\hline
\end{tabular}

Y en este estado por ser tarde se mandó suspender por el señor Diputado estas entrega para proseguirla otro Dia, y todos los simples, y compuestos htã (hasta) aqui tomados razon hizo Lu mñd deposito de ellos en el Conthenir Adm. ${ }^{n}$ d. . Lorenzo de Orduña, quien se dio por recivido de todos ellos à su enteras satisfaccion, y se obligò a tenerlos de manifiesto y prontos à la disposicion de los señores de la Yt.e Junta Municip.l entendiendose no harvese tomado raz. (razão) de los Botes, y frascos, en que se hallan, y dexarlo para su final; y en este estado dixo el señor d.n Fernando Fabro, por si, y en nré de d. ${ }^{\mathrm{n}}$ Lorenzo Ynfante

Fólio 4551v.

que protextaria, y protexta no les pare perruicio (por juízo) la nueva Tasacion de los medicamentos antezedentemente referidos, y los que en adelante se tasaren de esta Botica que fue de los Regulares espulsos, por la diferencia de precios aq. ${ }^{\mathrm{e}}$ se tasan dhas medicinas conforme à la tasacion primera que se hizo el año de sesenta y ocho por d.n Yg.o Thorosa (Tholosa vg.) y d.n Lorenzo Ynfante, reservando hazer sus recursos donde les convengas con la misma protexta de que no les pare perruicio, sin que por este se entienda que por esta protexta pretenden demorar, ni detener dha entrega de la Botica, por que solo se dirige a la utilidad de los vienes de S. M. (Su Magestad) y para

\footnotetext{
${ }^{194}$ No primeiro inventário, encontramos a menção de que o “ajenjo” "no sirve”, no de 1771-1772, ele foi taxado.

195 Os ingredientes, assim como a preparação do composto, podem ser encontrados em: http://www.botanical-online.com/medicinalsaguadelcarmen.htm Acesso: 13/05/13
} 
que no les qude responsavilidad por la diferencia de precio en que oy se tasan dhas medicinas por menores cantidades: Ylo firmaron todos los dhos señores Nominados en el referido Decreto de veinte y cinco de octubre proximo pausado, por ante mi

Fólio 4552r.

el presente esrivano de que doy fee $=$ Fernando de Arze, y Bustillos $=$ Fernando Fabro $=$ Lorenzo Ynfante $=$ Lorenzo de Orduña $=$ Juan Joseph herrero $=$ Ygnacio Tolosa $=$ Ante mi Clemente Guerrero, ss. ${ }^{\text {no }}$ publico, y del Numero

En quinze de dho Mes, y año se prosiguio esta entrega por los señores referidos, siendo presentes los demas nombrados en la forma esig.Tes_

Primeram. $\mathrm{t}^{\mathrm{e}}$ una onza de tartaro solable que tasaron en seis R. ${ }^{\mathrm{s}}$....D000... 6 \} Suma anter. ${ }^{\mathrm{r}} \mathrm{D} 186$

Yt. Onza y 10 adarm.s ${ }^{196}$ de sal subsino volatil que tasaron en 8 r.s........ D001 Yt. Doze adarmes de sal volat.s de cuerno de cierbo en dos pesos..... D002 Yt. una onza de Piedra Infern.l que tasaron en veinte r.s.............D002...4 Yt. 2 lib.s 12 1/2 onz.s de Agua de Rais que tasaron a doce R.s libra... D005... 2 3/4 Yt. 6 libras de Agua de Agenjos que tasaron à 6 r.s libra...D004...... 4 Yt. otro dho frasco, con $3 \frac{1}{2} 2$ libras q.e $\mathrm{D} 202 \ldots 3 / 4$

Suma anterior Fólio 4552v.

tasaron à 6 r.s libra. $\mathrm{D} 202 \ldots 3 / 4$

Yt. dos libras de Agua de eneldo, q.e tasaron a 4 r.s libra..........D001

Yt. 4 libras de Agua de Ruda, a 3 r.s libra....................D001... 4

Yt. $3 \frac{1}{2}$ libras de Agua de salvia a 3 r.s.......................D001... $21 \frac{1}{2}$

Yt. 3 libras 4 onzas de Agua de Poleo, q. ${ }^{e}$ tasaron à 3 r. ${ }^{\mathrm{s}}$ libra...D001..1 3/4

Emplastos $^{197}$

De Arsenico 3 1 $1 / 2$ libras q.e tasaron à 12 r.s libra.................D005... 2 de aquilon men.or 2 lib.s y 14 onz.s que tasaron a 8 r.s l.a.........D002... 7 de aquilon ma.or 13 onzas que tasar.n a 8 r.s libra...............D000... $61 / 2$ De Aquilon Gomado 3 lib.s y 11 onz.s ym.a à 12 r.s libra.............D005... 4 5/8 Yt. 5 onza de emplasto de Diapalma que tasaron en 3 r.s todo.....D000... 3 Yt. 4 onzas de emplasto de Miño q.e tasaron en un peso.........D001 (Minio vg) Yt. 2 lib.s y 4 onz.s de emplasto de rana simple q.e tasaron a 2 p.s l.s....D004...4 $\mathrm{D} 230 \ldots 1 \ldots 1 / 8$

Suma anterior Fólio 4553r. Yt. Emplasto de Ranas Quadruplic.do 2, 4 libr.s 2 onz.s que lo tasaron à 3 p.s l.a ....

\footnotetext{
196 “decimasexta parte de uma onza de peso.” (Picatoste, 1887: 35).

197 No primeiro invenário, esta categoria era composta por 17 itens, no segundo - de 1771-1772 - são relacionados 21 itens.
} 
D012...3

Yt. Emplasto de Galbano 3 onz.s que tasaron en un peso.....D001 (galvano vg.)

Yt. Antipodragico 11 onz.s que tasaron en 6 r.s.............D000...6

Yt. emplasto de ernia 5 onz.s q.e tasaron en 8 r.s.............D001 (hernia vg.)

Yt. emplasto Ysterico 30 onzas q.e tasaron en dos pesos todo....D002 (histérico vg.)

Yt. Manus dey 9 onzas, que tasaron en 3 pesos...............D003

Yt. emplasto de Promatisis $61 / 2$ onzas q.e tasaron en 4 p.s......D004

Yt. emplasto Begigatorio $41 \frac{1}{2}$ onz.s en um peso...............D001

Yt. Emplasto de Melilolo 7 1/2 onz.s que tasaron en un peso...D001 (meliloto vg.)

Yt. 4 libras 12 onz.s de emplasto negro de vidoz, que tasaron à 2 p.s l.a... D009... 4

Yt. Emplasto de Azafran 3 libras y 3 onzas q.e tasaron à 2 p.s libra...D006...3

Yt. Emplasto de Jabon 3 libras, y 3 onz.s q.e tasaron à 12 r.s libra...D004...6 1/4

D276...7 .. 3/8

Suma anterior

D276...7... 3/8

Fólio 4553v.

Yt. Emplasto de tomaticon ${ }^{198} 11$ onz.s q.e tasaron en 2 p.s $1 / 2$ r.l todo...D002... 1/2

Yt. 3 1 1/2 onzas de emplasto de muiselago, que tasaron à 2 r.s onza.....D000... 7 (musilago vg.)

Confeccíones $^{199}$

Triaca Magna $^{200} 11$ onzas que tasaron à razón de 4 pesos libra...D002... 6 (triaga magna pt.)

Yt. Mitridato 12 onzas que tasaron à 4 p.s libra...... D003

Yt. alquesmes 1 l.a y 12 onz.s que tasar.n à razón de 4 pesos onza...D112(alkerma vg.)

Yt. confecciones de jacintos 1 libra, y nueve onzas, à razón de 4 p.s libra... D006...2 (jazinto vg.)

Yt. yedra magna 5 1/2 onzas, que tasar.n à razón de 4 pesos libra... D001... 3

Yt. confeccion de Gentil cordial 1 lib.a 7 onzas y 1⁄2 à razón de 4 pesos libra... D005.. 7

Diferentes Preparaz. ${ }^{\mathrm{s}}$ y Polvos ${ }^{201}$

Alcano duplicado 14 onz.s que tasar.n en 3 pesos todo.... D003 (arcano vg.)

Estiope mineral $^{202} 1$ libra, y 3 onzas q.e tasaron en 20 r.s todo....... D002... 4

198 No primeiro inventário, este produto aparece registrado como estomaticon. No de 1771-1772, encontramos registro de tomaticon, que acreditamos tratar-se do mesmo que consta no inventário de 1768.

${ }^{199}$ No inventário de 1768, esta categoria é composta de 8 itens, no de 1771-1772, são somente 6.

200 Acreditamos tratar-se da triaca de Andrómaco, médico romano que teria incluído na composição a carne de víbora. Acreditamos que esta triaca magna é a mesma que consta simplesmente como triaca no inventário de 1768.

${ }^{201}$ No primeiro inventário, foram levantados 52 itens, no de 1771-1772, foram relacionados 55.

202 No primeiro inventário, encontramos registrado como etíope. Sobre ele, encontramos uma única referência:http://books.google.com.br/books?id=MegBiGZMaYC\&pg=PA154\&lpg=PA154\&dq=est\%C3 \%ADope+mineral\&source=bl\&ots=rxv0VsjVvK\&sig=pzVlBd16PreysCwAJ_I8ZqKVDFE\&hl=pt\&sa= X\&ei=4I92UZubDKvL0gHzr4DYBw\&redir_esc=y\#v=onepage\&q=est\%C3\%ADope\%20mineral\&f=fals e Acesso: 24/03/13 
Suma anterior

D415...5 .. 7/8

Fólio 4554r.

Antimonio diaforetico $^{204}, 9$ 1/2 onzas, q.e tasaron en 2 pesos todo.... D002

Cuerno de ciervo preparado y quem.do $71 \frac{1}{2}$ à 2 r.s onza... D001... 7

Christal Montano 13 onzas que tasaron en 1 peso...........D001

Dientes de Jabali preparados 5 onz.s a 2 r.s... ..........D001...2

Visuadico de curbo 1 onza, y 12 adarm.s que tasaron à razón de 3 p.s onza... D005...2

(Bezoardico de Curvo vg.)

Ojos de cangrejos preparados 12 adarm.s que tasaron à razón de 4 p.s onza...D003

Cuatro onzas de coral rubio que tasaron à 2 pesos onza......D008

Yt. Madre de Perla preparada onza y m.a que tasaron à 2 pesos onza...D003

Yt. Jacintos preparados 2 onz.s a 2 p.s onza D004 (Jacinto vg.)

Yt. Piedra de matitis preparada 1 lib.a y 5 onzas à 2 pesos libra.... D002... 5 (ematistis vg.)

Yt. Granates preparados $21 \frac{1}{2}$ que tasaron à 3 p.s onza.... D007...4

Yt piedra lapis la firis 1 l.a onza $1 / 2$ à ocho r.s onza que tasaron.... D017...4

Yt. Piedra pomez 14 onz.s en 8 r.s..... D001 (poner vg.)

Yt. saphiros 10 onza, y 1 adarme à 3 p.s onza.............D003...1 11/2 (zafiros vg.)

D466...6... 3/8

Suma anterior

Fólio 4554v.

Yt. Nitro antimonio 4 onz.s que tasaron à peso onza......D004

Yt. subsino blanco preparado 10 Xonz.s q.e tasaron à peso onza.... D010

Yt. Cascaras de huevos 13 onz.s en Polvo, à 4 r.s...........D006...4

Yt. Alterio de Azufre 5 onz.s a 2 r.s.......D001...2

Yt. sal de Agenjos 2 libras, y 14xonz.s que tasaron à razón de 12 p.s libra... D034...4

Yt. sal cartartica onze onzas à 3 r.s... D004...1 (catartica vg.)

Yt. sal moniaco 1 libra y 5 onzas à tres reales onza...D007...7(sal ammoniaco vg.)

Yt. sal de tártaro 3 onz.s que tasar.n en um peso todo......D001

Yt. sal carthatica 1 libra, y 10xonz.s à 3 r.s onza.........D009...6 (catartica vg.)

Yt. sal de cuerno de ciervo volatil dos onzas à 3 pesos onza.... D006

Yt. sal Brunela 7 onz.s que tasaron en 4 r.s...... D000...4 [Brunella vulgaris]

Yt. 13 onz.s de Nitro, que tasaron à razón de 4r.s l.a.... D000... 3 11/4

Yt. sal de tártaro vitriolado 1 onza y 12 adarmes, que tasaron en 1 p.o... D001

D565...7 ...5/8

Suma ant ${ }^{\mathrm{r}}$

Fólio 4555r.

Yt. sal de Agenjos 7 onz.s a raz.n de doze pesos libra..... D005...2

\footnotetext{
203 Quase todos os valores que aparecem ao final da página estão rasurados. Pode-se aventar que tenham sido corrigidos após a escrita do inventário por alguém responsável pela conferência do mesmo.

204 “Es un óxido de hierro y de antimonio mezclados íntimamente, pulverulento, suave al tacto, pesado, insípido, y de color fusco; ó sea el antimonio y el hierro oxidados por el nitro, y mezclados. (Gregorio, 1803: 140).
} 
Yt. vitriolo de esmarte ${ }^{205} 2$ onzas, y 2 adarmes, que tasaron a peso la onza...D002...2

Yt. Azafran de marte adtrigente 8 onzas, y 4 darmes, à 6 r.s onza... D006...1 11/2

Yt. soliman crudo, 3 lib.s y 10 onz.s que tasaron, à 5 pesos libra... D018...1

Yt. Mercurio dulce 13 onz.s y 4 adarmes, à 3 pesos onza.... D009...8 $\quad$ y 12

Yt. precipitado Blanco 6 onz.s Darmes, que tasaron,, à 8 r.s onza... D006...6

Yt. Azeyte de nuez Noscada 5 onz.s à 2 pesos onza.... D010

Yt. estoraque liquido 15 onzas que tasaron a razón de 4 p.s libra... D003...6

Yt. sal de Saturno 1 libra y 7 onz.s que tasaron à 6 r.s onza.... D017... 2 [(acetato de chumbo (II) ) $\mathrm{Pb}\left(\mathrm{C}_{2} \mathrm{H}_{3} \mathrm{O}_{2}\right)_{2 .]}$

Yt. Flor de Masias, quatro onzas, que tasaron à dos pesos onza... D008

Yt. flor de Menfy medias

$1 / 8$

Fólio 4555v.

Suma ant ${ }^{\mathrm{r}}$

onza que tasaron en 6 r.s................ D000...6

D0052... $61 / 8$

En este Estado por ser tarde se suspendio esta entrega, para proseguirla otro dia, cuia tasación dixeron los Peritos haverla hecho según su leal saber, y entender y todos los dos frascos, y Botes htã (hasta) aquí tomado razón, se hizo cargo de ella el Administrador nombrado d. ${ }^{\mathrm{n}}$ Lorenzo Orduña, à su entera satisfacción excepto no haverse tomado razón de los dhos frascos y votes, por dexarlo para la final de esta entrega. Y en este estado dixo el señor d. ${ }^{n}$ Fernando Fabro, por si, y en nré (nombre) de d.n Lorenzo Ynfante, que reproducia la protexta que tiene hecha en la primera diligencia de esta entrega. Y lo firmaron todos los dos señores por ante mi el presente escribano de que doy fee $=$ Fernando de

Fólio 4556r.

Arze y Bustillos $=$ Fernando Fabro $=$ Lorenzo Ynfante $=$ Juan Joseph Herrero $=$ Lorenzo Orduña $=$ Ygnacio Tolosa $=$ Ante mi Clem. ${ }^{\text {te }}$ Guerrero, escribano pp $^{\text {co }}$ y del $\mathrm{Num}^{\circ}$ en diez y seis días de dho mes, y año se prosiguio esta entrega, y remoción en la smã (semana) siguiente. _ -

Primeram.te media libra de vinagre rosado, que tasaron en 4 r.s

Suma Ant. ${ }^{\mathrm{r}}$ D652... 6 1/8

Yt. Apostolorun Ynguento ${ }^{206}, 1$ l.a que tasaron en 2 pesos.... D002 [ pomada apostólica pt.]

Yt. media libra de Grasa de Anates que tasaron en 4 r.s... D000...4

Yt. 1 libra de conserva de Rosas, q.e tasaron en dos pesos... D002 (conserva de rosas pt.)

Yt. 7 onzas y $1 \frac{1}{2}$ de Resina de Jalapa que tasaron à peso la onza... D007...4

Yt. 2 onzas de Alcanfor que tasaron à 12 r.s... D001...4

\footnotetext{
${ }^{205}$ Acreditamos que se trate de vitríolo de esmalte. Localizamos informações sobre o vitríolo verde, que é o sulfato de ferro (II).

206 “Apostolórum, Unguento- alias de Venus, detersivo das chagas.” (Morales Silva, 1789: 159).
} 
Yt. una onza de Grana cochinila que tasaron en 2 pesos... D002

Yt. Ar(z)quegenjos 7 1/2 onz.s que tasaron à 4 r.s onza... D003...6

Suma ant ${ }^{\mathrm{r}}$

Fólio 4556v.

Yt. Netuario denitivo 1 l.a y 11 onzas, que tasaron, a 4 r.s l.a... D006...6

Yt. conserva de Asedera 14 onzas, que tasaron à razón de 2 pesos libra...D001...6 (azedera vg.)

Yt. 1 libra, y 15 onz.s de conserva de Naranjas, que tasaron à dos pesos libra... D003...7

Yt. conserva de Persico 13 onz. ${ }^{\mathrm{s}}$ y m. ${ }^{\mathrm{a}}$ que tasaron à raz. ${ }^{\mathrm{n}}$ de $2 \mathrm{p.}^{\mathrm{s}} \mathrm{l}^{\mathrm{a}} . . \mathrm{D} 001 \ldots 5$ 1/2

Yt. conserva de Borraxa 1 l.a 7 1/2 onz.s que tasaron à 2 p.s l.a... D002... 7 1/2

Yt. extracto de Gesiana 1 l.a que tasaron en 2 pesos 4 r.s...D002...4 (genciana vg.)

Semillas $^{207}$

Ameos 7 onzas, q.e trasaron en 6 r.s... D000...6

Yt. Amomo $71 \frac{1}{2}$ onz.s que tasaron à 3 r.s onza...............D002... 6 1/2

Yt. eneldos 6 onz.s que tasaron à real onza..................D006...6

Yt. 3 adarmes de Apio, que tasar.n en un r.s................D000...1

Yt. de Anis dos onzas de semilla que tasaron en m.o r.s......D000... 1/2 208

Fólio 4557r.

Suma anterior.

Yt. de canabis 1 l.a y 5 onzas à 2p.s libra....................D004...5

Yt. de cidra 4 onz.s y m.a que tasaron en 1 r.s...............D000...1

Yt.. 6 onzas de culantro, que tasaron en 1 r.s................D000...1

Yt. de cardo santo 5 onzas, que tasaron en 2 r.s..............D000...2

Yt. Nauco cretino 1 l.a y 6 onz.s y m.a que tasaron en un peso...D001 (dauco vg.)

Yt. Delantexa tres onzas y m.a que tasaron en m.o r.s.....D000... 1/2 (lantexa vg.) ${ }^{209}$

Yt. Alorbas 12 onz.s y m.a q.e tasaron en un peso.............D001 VG (alolba)

Yt. libra y siente onzas de Linaza que tasaron en 6 R.s.........D000...6

Yt. de melon catorze onzas en un R.s.....................D000...1

Una libra, y una onza de cardamomo, que tasaron à 2 p.s l.a...D002...1

Yd. De Ynojo 2 lib.s 4 onzas que tasar.n en ocho R.s...........D001

Yt. Zebadas libra y m.a que tasar.n en m.o R.s..............D000... 1/2 (cebada ga.)

Yt. 4 libras y 13 onz.s linaza a 4 r.s l.a..................D002...3 1/4

Fólio 4557v.

Suma ant ${ }^{\mathrm{r}}$

\footnotetext{
207 No primeiro inventário, foram relacionados 16 itens, neste, 26. No primeiro, as arinas foram inventariadas separadamente, no de 1771-1772, algumas delas foram incluídas na categoria das semillas.

${ }^{208}$ Cabe ressaltar que esta é primeira página do inventário que não informa o total ao seu final.

209 Há uma cidade na Espanha com esse nome, mas acreditamos que refira-se a alguma planta que, infelizmente, não pudemos identificar. Há, contudo, uma referência a esta planta em obra que trata da vida de Francisco de Borja. Nela, encontramos a informação de que Borja passou muito tempo alimentando-se das ditas lantexas. In: Nieremberg, 1644: 38.
} 
Yt. siete onzas de Adormideras a dos r.s onza................D001...6

Yt. libra y m.a de Mostaza, que tasaron a 2 p.s libra...........D003

Yt. 6 libras, y 4 onzas de Alobras que tasaron à 6 r.s libra......D004... 5 11/2

Yt. Arina de Abas, tres onz.s que tasaron en m.o R.s...D000..... 1/2 (habas vg.)

Yt. Arina de Alorbas 10 1/2 onzas que tasaron a razón de seis r.s libra...D000...1

Yt. Arina de Arroz, quatro onzas, que tasaron en 12 r.s....D000...1

Yt. arina de Garvanzo 12 1/2 onz.s que tasaron en 1 r.s......D001...1 (garbanzo vg.)

Yt. arina de Linaza, nueve onzas, que tasaron à razón de quatro reales libra...D000...3 $1 / 4$

Polvos $^{210}$

Flor de Azufre 13 onzas, que tasar.n a dos reales onza..........D003...2

Azules una libra, y nueve onzas q.e tasaron à 2 p.s la libra......D003...1

Fólio 4558r.

Suma ant ${ }^{\mathrm{r}}$

Yt. Polvos de Azufre 1 l.a y 2 onz.s que tasaron à 2 r.s libra.....D000.

Yt. 6 onzas de Gaycho, que tasar.n en 3 r.s................ D000...3

Yt. Polvos de raiz de Angelica $1 \frac{112}{2}$ onza, que tasaron à 3 r.s onza.....D000... 4 1 1/2

Yt. De Aro, 5 onzas y m.a que tasaron a 2 r.s onza....... D001... $2 \frac{11}{2}$

Yt. Vistocta 3 onzas y $1 / 2$ que tasar.n em 6 r.s todo.......D000...6 (bistorta vg.)

Yt. Butua, onza y m.a que tasaron em 6 r.s todo...........D000...6

Yt. 2 onzas de siliptico, que tasar.n em dos R.s............D000...2

Yt. Contrayerva, 3 onzas, y 4 adarmes, que tasaron à 3 r.s onza... D001... 1 3/4

Yt. Calamo Aromatico $2 \frac{1}{2} 2$ onzas, à quatro R.s onza y seis adarmes, que la tasaron em 2r.s... D000...2

Yt. Eleboro blanco uma onza, y seis adarmes, que la tasaron em 2 r.s...D000...2

Yt. Quatro onzas de Polvos de Jenciana, que tasaron à 2 r.s onza...D001 (genciana vg.)

Yt. Dos onzas de ameos que tasaron à 2 r.s onza.... D000...4

Fólio 4558v.

Suma antezed. ${ }^{\text {te }}$

Yt. Angelica una onza en 3 r.s... D000...3

Yt. Cinco onzas de emodatiles que tasaron a dos R.s onza....D001...2 (hermodatile vg.)

Yt. Enula campana, $1 / 2$ onza que tasaron em 1 r.s......D000...1

Yd. quina $2 \frac{1}{2}$ onzas, que tasaron a razon de 2 r.s onza..... D000...5

Yd. Lirio de Florenz.a dos onzas que tasaron a 4 r.s onza.... D001

Yt. De Orozur 3 onzas que tasaron en 1 r.s...... D000...1 (orozus vg.)

Yd. 1 onza y 10 Adarmes de Ipescasquana, que tasaron a seis reales onza... D001... 13/4 (Ipecacuana vg.)

Yd. 1 onza de Capontico, que tasaron em 1 r.s...... D000...1 1 (rapontico vg.)

Yt. Jalapa 1 1 1/2 onza, que tasaron em 4 r.s............. D000...4

Yt. Mechoacan 3 onzas que tasaron a r.s onza........D000...3 (mechoachán vg.)

Yd Ruibarbo 10 adarmes, à razon de 5 pesos libra...D000...2 1/2

${ }^{210}$ No inventário de 1768, havia somente 4 itens relacionados, no de 1771-1772, encontramos um número muito superior, já que foram levantados 38 itens. 
Yt. Raiz de China 2 1/2 onzas, que tasaron em dos R.s todo....D000...2

Suma ant ${ }^{\mathrm{r}}$

Fólio 4559r.

Yd. de Palo santo 3 11/2 onzas, que tasaron à 3 R.s onza....D001... 2 1/2

Yd. de Baleriana 2 onzas y $1 / 2$ que tasaron em dos R.s.....D000...2

Yt. Agenjible $2 \frac{1}{1} 2$ onzas, que tasaron à 3 r.s onza..........D000... 7 1 1/2

Yt. Sepentaria virginiana 3 onz.s que tasaron a 2 r.s onza....D000...6 VG (serpentaria virginal pt.)

Yt. Serbaria 2 onzas que tasaron a dos R.s onza.... D000...4 $4^{211}$

Yt. Coralina 1 onza que tasaron en 2 r.s.....D000...2

Yt. 3 onz.s y 4 adarmes de Peonia que tasaron à 2 r.s onza... D000...6 1/2

Yt. cascara de Granada 2 onzas que tasaron en m.o R.t... D000... 1/2

Yd. Yerba buena $1 / 2$ onza, que tasaron en m.o R.t... D000... 1 1/2

Yd. De culantro media onza, que tasaron en m.o R.t.... D000... 1/2

Yd. Cominos, $1 \frac{1}{2} 2$ onza que tasaron en dos R.s... D000...2

Yt. 2 onzas de tripeto, que tasaron à 2 r.s onza.... D000...4

Fólio 4559v.

Suma ant $\mathrm{r}^{\mathrm{r}}$

Yt. media onza de Anis, que tasaron en m.o r.t.....D000... 1/2

Yt. de Ynojo 1 1/2 onza, que tasaron en m.o r.t.......D000... 1/2

Polvos de Goma ${ }^{212}$.

Yt. Menfy 4 onzas que tasaron à dos R.s onza.... D001

Yt. 3 1/2 onza de Goma Amoniaca à 3 r.s onza....D001... 2 1/2

Yt. goma arabiga $81 / 2$ onzas que tasaron a 2 r.s onza.... D002... 1

Yt. Santonicos 2 onzas que tasar.n à 2 r.s onza.... D000...4

Yt. sandalo rubio 4 onzas a 3 r.s onza.... D001... 4

Yt. Raizes de termentina $21 / 2$ onzas, que tasaron á 2r.s onza...D000...5 (tormentila vg.)

Yt. Incienso 2 onzas, que tasaron a 2 r.s onza... D000...4 (incenso pt.)

Yt. de Amaciga $1 \frac{1 / 2}{2}$ onza, que tasaron en un R.t.... D000...1 (almaciga vg.)

Yd. De Goma de Palo santo 3 1/2 onz.s que tasaron à 3 r.s onza... D001... 2 1/2

Fólio 4560r.

Suma anterior

Yt. Butagamba 1 onza, que tasaron en 2 r.s... D000...2

Yt. tragacanto $1 / 2$ onza, que tasaron en $1 \mathrm{r.t}$

Yt. Asibar epatica $1 \frac{1 / 2}{2}$ onza que tasaron à 3 r.s onza... D000... 4 1/2 213

Yt. Aloes de sucotrino ${ }^{214} 1$ onza y 4 adarmes, que tasaron à 3 r.s onza... D000... 3 3/4

${ }^{211}$ Parece referir-se ao “Sorbus aucuparia”, planta da família das rosáceas. O ácido sórbido é retirado da vagens não maduras dessa planta.In: http://milksci.unizar.es/bioquimica/temas/aditivos/conservantes.html Acesso: 18/04/13

${ }^{212}$ No inventário de 1768, encontramos 21 itens nesta categoria, no de 1771-1772, aparecem 27 itens.

213 Outra nomenclatura para aloe.

${ }^{214}$ Especificamente sobre o sucotrino, sabe-se que é um "acibar que viene de la islã de Socotora." (Picatoste, 1887: 968). 
Yt. Alumbre quemado 2 1⁄2 onz.s que tasaron à razon de 8 R..s l.a... D000... 1 1/4

Yt. Piedra Calamina que tasaron en 1 r.t... D000...1

Yt. milepedes, 4 onzas, que tasaron à 3 r.s onza... D001... 4 (millepedes vg.)

Yt. Tucia $31 \frac{1}{2}$ onzas, que tasaron à 3 r.s onza... D001... $21 \frac{1}{2}$

Yt. 5 onzas de Pildora Catholica, que tasaron à 6 r.s onza... D003...6

Yt. Pildoras coquias $1 / 2$ onza, que tasaron en 2 R.s... D000...2

Yt. Pildoras de tribubu; onza y m.a, q.e tasaron à 3 r.s onza... D000... 4 11/2

Yt. 2 1/2 onzas de Pildoras Mercuriales, que tasaron a 3 r.s... D000... 7 11/2

Fólio 4560v.

Suma anterior.

Yt. Antiasmaticas 1 onza, que tasaron en 4 r.s... D000... $4 \quad$ (anti- asmáticas pt.)

Yt. Pildoras marciales 2 onzas q.e tasaron à 3r.s onza... D000...6 $6^{215}$

Yt. Pildoras de mirra 1 onza que tasaron en 1 peso.... D001

Yt. Agarico $1 \frac{1 / 2}{2}$ onza, que tasaron en 9 r.s... D001... 1

Yt. Polvos de coloquintida 2 onzas que tasaron en 3 R.s... D000...3

Yt. tosico de Rasis conopio 3 onz.s que tasaron en 4 r.s cada una...D001...4

D771... $75 / 8$

En este Estado por ser tarde se suspendio esta enrega, y Remosion, para porserguirla otro dia, cuia Tasacion, dixeron los Peritos nombrados haverla hecho, assi leal saber, y entender, y todolo htã aquí tomado Razon hizo elis. ${ }^{\mathrm{e}}$ Diputado entrega al Administrad. ${ }^{\mathrm{r}}$ nombrado d. ${ }^{\mathrm{n}}$ Lorenzo de Orduña, q. ${ }^{\mathrm{n}}$ sedio por recivido de todo ello, varonlas obrigaciones de tal: y en este

Fólio 4561r

estado dixo el señor D. ${ }^{\mathrm{n}}$ Fernn ${ }^{\mathrm{do}}$ Frabro que reproducia la protexta que tiene hecha en la primera diligenz. ${ }^{a}$ de esta entrega. Y lo firmaron todos los dhos señores Por ante mi de que doy fee $=$ Fernando de Arze y Bustillos $=$ Fernando Fabro $=$ Lorenzo Ynfante $=$ Lorenzo orduña $=$ Juan Jp'h herrero $=$ Ygnacio Tolosa $=$ Antemi Clem. ${ }^{\text {te }}$ Guerrero.

Escrivano pp.co y del numero

En dho dia, mes y año, em prosecur.n de la entrega, y Remosion preven.da por todos los Señores conthenidos en a antezedente seprocedio en la forma, y manera Sig.te (seguinte)

Polvos Cordíales ${ }^{216}$

Suma anterior.....

\footnotetext{
${ }^{215}$ As pildoras marciais seguiam a seguinte receita: Limaduras de hierro porfirizadas (60g); Extracto blando de ajenjos.. c.s; H.S.A píldoras de gvj (3 dec.), Son las pildoras marciales de Sydenhan de la F. M. Nota: Algunas veces se añade 3j (4gr.) de canela en polvo ó 3B (2gr.) de acíbar. 1: Clorosis, histérico, hipocondría, dispepsia y leucorrea. D. Tres ó cuatro píldoras, mañana y noche. In: Álvarez Alcalá, 1850.

${ }^{216}$ No inventário de 1768, foram relacionados 20 itens, e, surpreendentemente, no de 1771-1772, foram listados 79 itens, número quase 4 vezes maior.
} 
De la condesa 1 onza, que tasaron en 6 r.s...D000...6

Yt. 3 onzas, y 14 adarmes de diamargariton frigido que tasaron en doze R.s onza... D005... $61 / 4$ ( margariton vg.)

Fólio 4561v

Suma ant $\mathrm{r}^{\mathrm{T}}$

Yt. de Nuez Noscada 5 1/2 onzas, que tasaron à 8 r.s onza..D005...4

Yt. coral blanco preparado $2 \frac{1}{2}$ onzas que tasaron à razon de 2 r.s onza...D000...5

Yt. 1 onza, y 14 adarmes de Yedra vesar, que tasaron à 2 r.s onza... D000...4 (piedra bezar vg.)

Yd. De ojos de cangrejos preparados 15 adarmes, que tasaron a razon de 2 R.s onza... D000...2

Yt. $1 \frac{1 / 2}{2}$ onza de Polvos de Madreperlas (madre de perlas vg.)

Yt. coral rubio preparado 1 onza en dos reales... D000...2

Yt. de cuerno de sierbo rasinado preparado que tasaron à raiz de cinco pesos libra, $\mathrm{y}$ son 3 onz.s ...D000... $71 \frac{1}{2}$

Yt. Polvos de restrictivos, 3 onz.s que tasaron à 3 r.s onza... D001...1

Yt. Polvos de Guteta $1 \frac{112}{2}$ onza, q.e tasaron, à 6 r.s onza... D001...1

Yt. onza, y catorze adarmes de higado de antimonio, que tasaron á razon de 8 r.s

libra...D000...1

Fólio 4562r

Suma anterior

Yt. Higado antimonio dos onzas q.e tasaron à razon de 8 r.s la libra... D000...1

Yt. 4 adarmes de Laudano peado que tasaron en dos R.s...D000...2 (laudano opiado vg.)

Yt. antietico de Poterio 1 onza, y 4 adarmes en 6 R.s....D000...6

Yt. Polvos de Juanes (RG) 6 onzas y m.a que tasaron à 4 r.s onza...D003...2

Yt. Polvos de Castorio 4 adarmes que tasaron en 3 R.s... D000...3 $\quad$ (castoreo vg.)

Yt. Pildoras de estoraque 3 onzas que tasaron à 4r.s onza... D001...4

Yt. ambar un adarme, que tasaron en 6 R.s... D000... 6

Yt. azafran de castilla en polvos $1 \frac{1 / 2}{2}$ onza que tasaron en 9 r.s...D001...1

Yt. Libo de Antimonio 7 onz.s y m.a que tasaron à 3 r.s onza... D002... 6 1/2

Yt. Tartaro Emetico 1 onza que tasaron en um peso... D001

Yt. armiscle 3 onzas a razon de ocho pesos onza... D024 (almízcle ga.) (almíscar) ${ }^{217}$

Yt. 4 adarmes de Coraz. ${ }^{\mathrm{n}}$ de cierbo, q. ${ }^{\mathrm{e}}$ tasaron en $4 \mathrm{r}^{\mathrm{s}} . . . \mathrm{D} 000 \ldots 4$ (coração de cervo pt.)

Suma ant ${ }^{\mathrm{r}}$

Fólio 4562v

Uma libra, y dos onzas de coral Blanco, que tasaron à dos pesos la l.a... D002...2

Yt. coral ruvio quatro libras y tres onzas, que tasaron à dos pesos libra...D008...3

Yt. 1 libra de ojos de cangrejos, q.e tasaron en quatro pesos... D004

Yt. 15 onzas de Madre de Perla que tasaron en 6 R.s... D000...6

Yt. Piedra vezar 1 l.a y 12 onz.s q.e tasaron à 4 pesos libra... D007

Yt. Piedra Calamina 5 onzas, q.e tasaron, a Rt onza... D000...5

217 “sustância animal muy olorosa, que se saca del desmán” (Picatoste, 1887: 66) Também pode ser retirado de algumas plantas como a "Mimulus inoschalus “. 
Yt. Piedra de matitis $71 / 2$ libras que tasaron a 3 p.s... D022...4

Yt. Piedra Judaica 9 onzas, q.e tasaron a razon de 4 p.s l.a... D002...2

Yt. 1 l.a y 4 onzas de diferentes piedras preciosas, que tasaron en doce pesos todo...D012 (diferentes pedras preciosas pt.)

Yt. Piedra y man muerta 12 onzas, que tasaron à razon de quatro pesos libra... D003

Yt. raiz de Altea 2 libras

Fólio 4563r

Suma ant ${ }^{\mathrm{r}}$

... y 6 onzas que tasaron em 4r.s todo... D000...4 (althea vg.)

Yt. 12 onzas de Raiz de Angelica, que tasaron en 1 peso... D001

Yt. Apio 1 libra que tasar.n en 6 R.s..... D000...6

Y. quatro l.s y 12 onzas de Raiz de Aro, que tasaron à 2 p.s l.a... D013...4

Yt. 1 l.a y 6 onzas de Aristolaquia que tasaron à 2 pesos la l.a...D002...6

Yt. 1 l.a y 15 onzas de raiz de Aro que tasaron, à 12 R.s libra... D003

Yt. 1 l.a, de raiz de esparragos, que tasaron en 12 r.s... D001...4 (aspargos pt.)

[Aspargus officinalis]

Yt. vistorta 3 lib.s y 12 onzas, q.e tasaron à 12 R.s libra... D005...5

(bistorta vg.)

Yt. Butua 1 l.a que tasaron en doze R.s Cdigo a 3p.s l.a... D003

Yt. libra, y siete onza de Calagua la, que tasaron à 6 R.s libra... D001...1 (galanga vg.)

Yt. Calamo Aromatico $21 / 2$ l.a à 6 p.s libra... D015

Yt. una libra, y 6 onzas de raiz de China, que tasaron a 3 p.s l.a... D004...1

Fólio 4563v

Suma ant ${ }^{\mathrm{r}}$

Yt. raiz de consolida ma. ${ }^{\mathrm{r}}$ dos libras, que tasaron à dos pesos libra... D004

Yt. tres libras, y 5 onz.s de Coombro que tasaron à quatro pesos libra... D013...2

(Pepino do Mar vg.)

Yt. 1/2 libra de Ditamo Blanco en dos pesos todo...D002 [gênero Dictamnus]

Yt. 2 libras y 12 onzas de elevoro vlanco, que tasaron à 3 p.s libra...D008...2

Yt. elevoro Negro, 13 onzas, que tasaron à razon de 3 p.s libra...D002... $31 \frac{1}{2}$

Yt. enula campana $2 \frac{1}{2} 2$ libras q.e tasaron à 8 pesos libra... D007...4

Yt. de Ynojo $1 \frac{112}{2}$ libra, que tasar.n à 4r.s libra... D000....6

Yt. 5 libras y 12 onz.s de Galanja que tasaron à 3 p.s libra..D017...2 (galanga ga.)

Yt. Gensiana 3 libras 2 1⁄2 onzas q.e tasaron à 3 p.s libra... D009... 3 3/4 (genciana vg.)

Yt. 4 r.s de orozu de la tierra en libra y. m.a... D000...4

Yt. raiz de emperatoria 1 libra q.e tasaron en dos pesos.... D002 (imperatoria vg.)

Fólio 4564r

Suma anterior.

Yt. Ypecaquana 1 libra y 2 onz. ${ }^{\mathrm{s}}$ que tasaron a 8 p. ${ }^{\mathrm{s}}$ libra..D009 (Hipecaquana vg.)

De Lirios de Florencia 1 libra, y 5 onzas, que tasaron a 4 p.s libra...D005...2

Yt. 2 libras y m.a de Mechoacan que tasaron à 12 R.s libra...D003...6

Yt.1 l.a y $1 / 2$ de raiz de mey, que tasaron a 12 r.s libra... D002...2

(mei vg.)

Yt. Raiz de Nardos 7 onzas que tasaron em um pesos... D001

Yt. Peonia 4 libras y 2 onzas, que tasaron à 2 pesos livra... D008...2

Yt. 2 libras, y 3 onzaas de Pelitre que tasaron à 12 R.s libra... D003... 2 1/21

Yt. 10 onzas de Rapontico, que tasaron em 4 R.s... D000...4 
Yt. Serpentaria 6 onzas,, q.e tasaron en $4 \mathrm{r}^{\mathrm{os}} \ldots$ D000....4

Yt. 1l.a y 4 onzas de turpeto, q.e tasaron em 4 R.s... D000...4

Yt. Tormentila 1 libra y 14 onz.s que tasaron à 12 r.s libra.... D002... 6 11/2

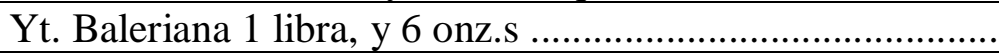

Fólio 4564v

Suma anterior

que tasaron à 12 r.s libra... D002...2 $1 / 2$

Yt. vicentogico 1 libra, y 5 onzas que tasaron à 12 R.s libra... D001... 7 3/4 (bisentoico vg.)

Yt. sedoaria 5 libras, y 13 onzas, q.e tasaron à 12 R.s libra... D008...5 3/4 (zedoaria vg.)

Yt. Agenjible 3 libras, que tasaron en 4 pesos todo... D004

Yt. 12 onzas de Linalo es, que tasaron em 3 pesos... D003 ${ }^{218}$

Yt. 4 libr.s y 12 onzas de Palo de Guayacan, que tasaron à 12 r.s l.a...D007...1(Guayaco vg.)

Yt. Palo de Lantisco 2 libras y 10 onzas a 12 r. onza..D063 [Pistacia lentiscus]

Yt. Palo rodonico 1 l.a q.e tasaron en 12 r.s... D001...4r

Yt. sandalo zetrino, 4 libras, u dos onzas, que tasaron à 2 p.s L.a.... D008... 2 (setrino

vg.)

Yt. sândalo Ruvio, 2 libras, y dos onzas que tasaron à 2 p.s l.a... D004...2

D148... $37 / 8$

En este estado por ser tarde se suspendio esta entrega, y remosion y los Peritos nombrados Dixeron

Fólio 4565r.

haver hecho su tasacíon segun sus leal saber, y entender, y todo lo htã (hasta) aqui tomado razón hizo entrega de ello el Señor Diputado nombrado à d. ${ }^{\mathrm{n}}$ Lorenzo de Orduña Administrador nombrado quien se recivio de ello à toda su entera satisfacion, y se obligo como tal a tener de manifiesto todo lo recibido htã (hasta) el presente, a la disposición de los Señores de la (Y)Jt. ${ }^{\mathrm{e}}$ Junta, y en este estado dijo el señor d. ${ }^{\mathrm{n}}$ Fernando Fabro, q. ${ }^{\mathrm{e}}$ por si, y d. ${ }^{\mathrm{n}}$ Lorenzo Ynfante reproducia la protexta que tenia hecha en la primer dilig.a de esta entrega, y demás que lleva expuesto. Y lo firmaron todos dos señores por ante mi de que doy fee $=$ Fernando de Arze y Bustillos= Fernando Fabro= Lorenzo Ynfante= Lorenzo de Orduña= Juan Joseph herrero=

Fólio 4565v.

Ig. ${ }^{0}$ Tolosa $=$ Ante mi Clemente Guerrero, escribano publico, y del Numero _en la

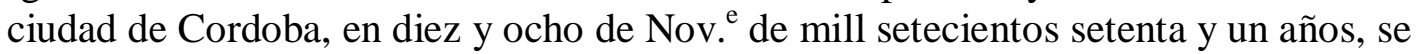
prosiguió esta entrega, Remosion, y tasación por todos los Conthenid. ${ }^{\mathrm{s}}$ señores, en la fmã (forma) sig. ${ }^{\text {te }}----$

Suma anterior

218 "árbol de las Indias, de mandera pesada y amarga." (Ibíd: 660) Também pode estar se referindo ao Linalol: "O Linalol é usado em larga escala por indústrias de cosméticos e aromáticas. Aproximadamente $70 \%$ dos compostos produzidos por essas indústrias contém linalol em sua fórmula. Enquanto produtos populares utilizam o linalol sintético, os produtos mais finos e perfumes utilizam somente o linalol natural, extraído do Pau-rosa. O Pau-rosa é uma árvore que provém de florestas tropicais brasileiras e demora cerca de 30 anos para crescer. Hoje em dia, é a principal fonte de linalol natural.” In: http://www.linax.com.br/oleos.html Acesso: 02/06/13 
Primeram.te 1 libra, y 3 1/2 onzas de flor de violeta en dos frascos, q.e tasaron à dos pesos la libra... D002... $3 \frac{11}{2}$

Yt. tres libras, y tres onzas de sasafras, que tasaron, a doze Reales libra... D004...6 1/4 (zasafras vg.)

Yt. libra y media de corteza de Naranja China, que tasaron à peso libra... D001...4 ${ }^{219}$

Yt. treze onzas de Corteza de Alcaparras que tasaron a 12 R.s libra...D001...1 3/4

Fólio 4566r.

Suma ant $\mathrm{r}^{\mathrm{r}}$

Yt. corteza de cidra 3 1/2 libras que tasaron en 8 r.s libra...D003...4

Yt. 2 libras de corteza de costi; q.e tasaron à 4 R.s... D001

Yd. De Cascara de Granada un A.l D000...1

Yt. 4 onzas de cafe, que tasaron en 3 R.s... D000...3

Yt. 2 libras, y 1 onza de Quina que tasaron à 4 pesos libra... D008...2

Yt. 1 libra y 1 onza de Argarico que tasaron à 4 R. ${ }^{\mathrm{s}}$ onza...D008...4 (agarico vg.)

Gomas

Admoniaco 2 libras, y 12 onzas que tasaron à 6 pesos libra... D016...4 (amoniaco vg.) Yt. Arabiga 7 libras, y 12 onzas que tasaron à 6 pesos libra... D046...4

Yt. Asafeclida, 2 libras, y 3 onz.s à 6 pesos libra... D013...1 (asafétida vg.)

Vt. Bedelio 15 onzas, q.e tasaron à razón de 6 pesos libra... D005...5

Yt. Menfy 2 onzas, que tasar.n à 3 R.s onza... D000...6

Suma ant ${ }^{\mathrm{r}}$

Fólio 4566v.

Yt. Goma copal 2 1/2 libras, que tasar.n à 6 pesos libra... D015

Yt. Goma de Limon 2 lib.s y 4 onz.s á 6 pesos libra... D013...1

Yt. euforvio 2 l.s que tasaron à 6 pesos libra... D012

Yt. Galbano 1 libra, y 4 onzas, à seis pesos libra... D007...4 (galvano vg.)

Yt. Goma de Palo santo 4 libras, que tasaraon à 6 p.s libra... D024

Yt. Gutagamba 14 libras, que tasaron à 6 p.s libra... D084 (guta gamba vg.)

Yt. Hisica, 12 libras, que tasaron à 6 pesos libra... D072 (Ysica vg.)

Yt. de Limon13 onzas à raz.n de 6 pesos libra.... D0047

Yt. Polvos de Yedra una onza que tasaron en un peso... D001

Yt. 15 onzas y m.a de Ladano q.e tasaron à 6 pesos libra... D005... 6 1/2 (láudano vg.)

Yt. Laca 5 onzas y m.a que tasaron à 6 pesos libra... D002... 1/2 220

Yt. Mirra 6 libras que tasaron

Fólio 4567r.

Suma anterior......................

à 6 pesos libra... D036 (mirrha vg.)

Yt. opoponaco 1 libra, y 2 1/2 onzas que tasaron à 6 pesos libra... D006... 7 1⁄2

Yt. saga peno 1 libra, y 6 onzas que tasaron a 6 pesos libra... D008...2 (sagapeno vg.)

${ }^{219}$ É a primeira menção feita à laranja china, que não foi relacionada no inventário de 1768.

220 "especie de goma resinosa encarnada/ color rojo que se extrae de la cochinilla, de la rubia y del palo del Brasil.” (Picatoste, 1887: 638). 
Yt. Sangre de Drago 2 1/2 libras, q.e tasaron à 6 pesos libra... D015

Yt. sal cocoli 15 onzas, q.e tasar.n à 6 pesos libra...D005...5 (Sarcacola vg.)

Yt. estoraque 3 libras, y 4 onzas que tasaron à 6 pesos libra... D019...4

Yt. 1 libra, y 12 onzas de Grasilla, que tasaron à 6 pesos libra... D010...4 (gracilla vg.)

Yt. de Tacamaca $1 / 2$ libra a 6 p.s l.a...D003

Yt. traga canto 2 libras, y 7 onzas que tasaron à 6 pesos libra... D014...5 (tragacanto vg.)

Yt. Balsamo Toletano m.a libra que tasaron à 6 pesos libra... D003

Yt. de Tirivito Goma 1 libra tres y m.a onzas, que tasaron à 6 pesos libra...D007...2

Suecos VG (Succos) $)^{221}$

De Acasia $61 \frac{1}{2}$ onzas, q.e tasaron ............

Suma ant ${ }^{\mathrm{r}}$

Fólio 4567v.

a razon de 6 p.s libra... D002... 3 1 1/2 [várias espécies do gênero acacia]

Yt. asibar 5 libras y 2 onzas, q.e tasaron à 6 p.s libra... D030...6

Yt. Asivar sucotrina 6 libras que tasaron à 6 pesos libra.... D036 (asibar vg.)

Yt. extracto de oro sur, que tasaron, a razón de 6 pesos libra... D (orozuz vg.)

Yt. Hispotiquido 15 onzas que tasaron à 6 pesos libra... D005...5

Yerbas. (Ervas) $)^{222}$.

Manzanilla 1 libra, y 14 onzas que tasaron à 2 r.s libra... D000... 3 1 1/2

Yt. flor de Azar 1 libra que tasar.n en quatro R.s... D000...4 (azahar vg.)

Yd. Flor de violetas 2 onzas, que tasaron a R.s onza... D000...2

Yt. Ballas de Laurel 1 l. $^{\mathrm{a}}$ y 10 onz..$^{\mathrm{s}}$ que tasaron à 2 pesos libra...D003..2

Yt. Ballas de enebro 1 libra, y cinco onzas q.e tasaron a 2 p.s libra...D002...5

Suma ant ${ }^{\mathrm{r}}$

Fólio 4568r.

Yt. cavezas de adormideras 10 onzas, que tasaron a razon de 2 pesos libra... D001...2 (cabeça de papoula pt.)

Yt. Aluzema 9 onzas que tasaron en 1 P.t... D000...1

Yt. coloquintida extracto 2 libras y 7 onzas, que tasaron à 8 p.s libra...D019...4

Yt. ubebas 1 libra y 3 onzas, q.e tasaron, à 4 pesos libra... D004...6 (cubeba vg.)

Yt. miravolanos, 4 libras de los cinco miravolanos, que tasaron à 3 pesos libra... D012 (marabolano vg.)

Yt. agallas de Asipres, 1 lib.a y 4 onzas, que tasaron à 2 r.s l.a... D000... 2 1/8 (cipres

ga.) (cipreste pt.) [várias espécies da família das Cupressaceae]

Yt. 9 libras, y 13 onzas de agallas finas, que tasaron à 2 p.s l.a.... D019...5

Yt. tamarindos $2 \frac{1}{2} 2$ libras, que tasaron à 2 pesos libra... D005

Yt. flor de Ditamo cretino 15 onzas, que tasaron en 2 p.s... D002 (digtamo vg.)

Yt. escordio 1 libra, y 11 onzas q.e tasaron à 4 pesos libra... D006...6

\footnotetext{
221 Tanto no primeiro, quanto no segundo inventário foram relacionados 6 itens nesta categoria.

${ }^{222}$ Cabe ressaltar que no inventário de 1768, não havia uma categoria específica para Yerbas.
} 
Fólio 4568v.

Suma anterior......

Yt. sen m.a libra, que tasaron en 9 r.s... D001...1

Yt. culantro 3 libras, que tasaron à dos R.s libra... D000...6

Yt. alumbre molido 1 libra, y 3 onz.s crudo de castilla, que tasaron á 12 r.s libra...

D001... 6 $1 \frac{1}{4}$

(alume cru e moído de Castela pt.)

Yt. Arsenico vlanco 2 lib.s y 1 onza, que tasaron à 4 p.s libra....D008...2 (arcenico blanco vg.)

Yt. Borax uma libra y dos onz.s que tasaron à 2 pesos libra... D002...2

Yt. zera amarilla 2 libras, y 9 onz.s que tasaron à 4 r.s libra... D001...2

Yt. Christal mineral 1 libra, y 15 onzas , que tasaron á dos p.s l.a D003...7

Yt. sal amoniaco 1 libra,, y 1 onza que tasaron à 6 pesos libra... D006...3

Yt. sal Gemas, cinco libras y m. ${ }^{\text {a }}$ que tasaron à 2 pesos libras...D011 (gemma vg.)

Yt. azufre 9 libras, y 15 onzas, q.e tasaron 4 r.s libra... D004... 7 3/4

Yt. tartaro crudo 5 libras, y 4 onz.s q.e tasaron à 2 p.s libra... D010...4

Fólio 4569r.

Suma ant ${ }^{\mathrm{r}}$

Yt. Pez griega 1 libra, y 1 onza, q.e tasaron em um peso todo... D001 223

Yt. pez negra 4 libras y $1 \frac{1}{2}$ que tasaron à 4 R.s libra... D002...2

Yt. Piedra lipe $31 \frac{1}{2}$ libras, a 12 r.s l.a... D005... 2 [sulfato de cobre (II) $\left(\mathrm{CuSO}_{4}\right)$ ]

Yt. Vitriolo Blanco 5 libras y media, que tasaron à 12 r.s l.a... D008...2

Yt. Polvo de Uña de la gran vestia, onza y m.a que tasaron à peso onza...D001...4

Yt. Unicornio $2 \frac{1}{2} 2$ onzas, que tasaron à peso onza...D002...4

Yt. Bolo armetico $1 \frac{1 / 2}{2}$ onza que tasaron à 8 R.s libra... D000... 3/4

$1 \mathrm{D} 863 \ldots 41 / 4$.

En este estado por ser tarde se suspendio esta entrega, y remoz. ${ }^{n}$ para proserguirla òtro dia, cuia tasacion dixeron los Peritos haver hecho asu leal saver, y entender, y todos los dho ungredientes y demas que se hallan tomado razon se hizo entrega por el señor Diputado en d. ${ }^{\mathrm{n}}$ Lorenzo _

Fólio 4569v.

Suma ant ${ }^{\mathrm{r}}$

de Orduña, Administrador ombrado, quien sedio por recivido de ellos à su entera satisfaccion y se òbligo ai tenerlos de manifiesto à la disposicion de los señores de la Yt. $^{\text {e }}$ Junta Municipal, ò de otro Juez competente, y en este estado Dixo el señor d. ${ }^{\mathrm{n}}$ Fernando Fabro, que por si, y en nré de d. ${ }^{\mathrm{n}}$ Lorenzo Ynfante reproducia la protexta que tenia hecha en la primer diligencia de esta entrega, y demas que lleva expuesto, y lo firmaron todos los dhos señores por ante mi de que doy fee $=$ Fernando de Arze y Bustillo $=$ Fernando Fabro $=$ Lorenzo Ynfante $=$ Lorenzo de Orduña $=$ Juan Joseph herrero $=$ Yg. ${ }^{\circ}$ Tolosa $=$ Ante mi Clemente Guerrero. ess. ${ }^{\text {no }}$ (escrivano) publico, y del numero _ _ _ _ en la ciudad de Cordoba, en diez

\footnotetext{
${ }^{223}$ Acreditamos referir-se ao “aguarrás”, a essência da terebintina.

${ }^{224} \mathrm{O}$ chifre de unicórnio referido aqui trata-se, na verdade, do chifre de rinoceronte, que foi por muito tempo utilizado como medicamento.
} 
Fólio 4570r.

y nueve dias del mes de Nov.e de mill setecientos setenta, y un años en prosecucion de la entrega, y remision prevenidas, los dha señores de tranladar. ${ }^{\mathrm{n}}$ a la Botica referida, $\mathrm{y}$ en ellas se precedio en la fmã sig. ${ }^{\text {te }}+--$

\section{Suma de la $\mathrm{B}^{\text {ta }}$}

Primeram.te Pimienta larga, y redonda blanca 1 libra, y 5 onzas que tasaron à peso libra... D001... 2 1/2

Yt. Decreta Blanca 2 libras, y 9 onzas, que tasaron à 3p.s l.a... D007... 5 11/2 VG

Yt. 6 onzas de tierra Jiponica, que tasaron à razon de tres pesos libra... D001...1 (japonica vg.)

Yt. tierra Lemnia libra que tasaron en 3 pesos... D003 (tierra Leninia vg.)

Yt. Tierra de ocrea med.a libra que tasaron em doze R.s... D001...4

Yt. tierra de S.n Pablo, 13 onz.s que tasaron à razon de 3 p.s libra... D002... 31/2

Yt. tierra sigilada blanca, 1 l.a que tasaron en 3 p.s libra... D003

Suma ant ${ }^{\mathrm{r}}$

Fólio 4570v.

Yt. tierra sigilada ruvia, 3 libras, q.e tasaron a 3 pesos libra... D009

Yt. antidemonio 6 libras, t 4 onz.s que tasaron a 4 pesos libra... D025

Yt. sinagrio Nativo, 3 libras qe tasaron à 3 pesos libra... D009 (cinabrio vg.)

Yt. Limadura de hierro 4 libras y 4 onzas, que tasaron en 1p.so todo...D001

Yt. Litagirio de oro $71 / 2$ libras, que tasaron a 2 pesos libra...D015

Yt. Plomo quemado 1 libra, y dos onzas, que tasaron en un peso...D001

Subsino $3 \frac{1}{2} 2$ libras que tasaron à dos pesos libra... D007

Yt. Cantaridas 4 r.s... D000..4

Yt. Castoreo de Rusia 5 onzas, que tasaron en 4 pesos todo... D004

Yt. cuerno de cierbo resinado, 2 lib.s y doze onzas, que tasaron a 2 p.s libra...D005...4

Yt. marfil, 15 onzas, que tasaron en 3 pesos... D003

Yt. craneo Humano m.a onza, que tasaron en un peso... D001 (crânio humano pt.) ${ }^{225}$

Suma ant ${ }^{\mathrm{r}}$

Fólio 4571r.

\begin{tabular}{|l|}
\hline Yt. Colapicio 12 onzas, que tasar.n en un peso... D001 \\
\hline Yt. milepedes 2 onzas, que tasar.n en un peso... D001 \\
\hline Polvos de Pliuia 9 onzas, que tasaron en 2 pesos... D002 \\
\hline Sangre de macho 6 onzas, que tasaron en doze R.s... D001...4 (sangue de macho pt.) \\
\hline Espelma de Ballena 13 onz.s que tasaron en doze R.s...D001...4 (esperma vg.) \\
\hline Yt. flor de sauco 4 onzas, que tasaron en 4 r.s... D000...4 [família das Adoxáceas] \\
\hline Yt. Romero m.a libra, que tasaron en dos R.s... D000...2 \\
\hline Yt. Rosas dos r.s... D000...2 \\
\hline Yt. doradilla 3 libras à 2 r.s libra... D000...6 \\
\hline Yt. cardo santo, 2 libras, que tasaron a 4 r.s... D001 \\
\hline Yt. salvia 3 libras a 2 r.s... D000...6 \\
\hline
\end{tabular}

225 “es la parte osea de la cabeza que cubre el cerebro del hombre; se usa del que no ha sido enterrado hecho polvo." (Gregorio, 1803: 131). 
Yt. 3 libras de escordio, que tasaron en un peso... D001

Yt. Bervena 4 r.s... D000...4 GA (verbena) [gênero da família das Verbenaceae]

Yt. 8 libras de varios Jarabes avinagrados, que se mandar.n derramar... D (xaropes avinagrados pt.)

Fólio 4571v.

Suma ant ${ }^{\mathrm{r}}$

Yt. 56 frascos grandes de christal em que se hallan dha Bevidas y otros Bacios, que tasaron cada uno en 18 r.s... D126

Yt. 82 de dhos de segunda clave mas medianos, que tasaron à doze R.s... D123

Yt. 102 de dhos mas medianos y mucho mas pequeños de var. ${ }^{\text {s }}$ (várias) calidades, que tasaron unos, con otros à ocho R.s... D102

Yt. 142 Botes de varias clases de Losa de Sevilla, que tasaron unos con otros à 6 r.s cada uno... D106...4

Yt. 66 Botes de madera pintad. ${ }^{\mathrm{s}}$ a el olio grande, que tasaron à ocho r. ${ }^{\mathrm{s}}$ cada uno...D066

Yt. 81 dhos medianos pintados à el oleo, que tasaron à 4 r.s cada uno... D045...4

Yt. 25 Botes grandes de estaño que tasaron à peso... D025

Yt. la Pieza de dha Botica se compone de ocho varas de largo de naciente, à pomente, $\mathrm{y}$ de

Fólio 4572r.

Norte a sur seis varas y alrededor de ella se halla un estante que su primer Cuerpo alto es Pintado de azul, encarnado, y dorado y en sus extremos, una cenepha ${ }^{226}$ en la misma Conformidad pintada, y dorada, y en los quatro rincones de el Quatro laminas redondas hasi mismo Pintadas, y doradas con sus Lienzos con las adbocacion de s. ${ }^{\mathrm{n}}$ Ygnacio, s. ${ }^{\mathrm{n}}$ Fran. ${ }^{\mathrm{co}}$ Xavier, s. ${ }^{\mathrm{n}}$ Luis Gonzaga, y s. ${ }^{\mathrm{n}}$ estanislado. y el segundo no se halla como el primer. Pintado ni dorado, si no de el color de la propia Madera, con cinco orden. ${ }^{\mathrm{e}}$ de cajones maiores, y menores que se componen de doscientos setenta y dos Cajones $\underline{227}$ con sus letreros de lo que enzerravan en si, los quales sirven de vasa a dho estante, $\mathrm{y}$ este se compone inclusive la cenepha referidas de tres varas, y dos Tercia y de

Fólio 4572v.

alto advirtien doze que en los quatro Rincones dhos se hallan los tres dhos sin Puertas, ni vidrieras, y el otro con Puerta, y vidrieras, y el otro con Puerta, y vidrieras, que no lo tasaron los Peritos por no ser de su facultad

\section{Suma antezed.te}

Yt. a la parte del naciente de dha pieza de Botica se halla una ventana de Cuerpo entero con su rexa (reja ga.) de hierro a la calle con su sñe recilla de Alambre de lo mismo con sus vidrieras con nueve vidrio quebrados y sus Puertas de tableros pintadas de Berde, $\mathrm{y}$ sré dhas Ventana una Phenepha ochabada de madera pintada a el oleo, y dorada con su

\footnotetext{
226 “lista sobrepuesta, bordada ó tejida en las extreminades de las cortinas doseles, camas, colagaduras, etc./ la lista del médio em las casulas que suele ser de diferente color. " (Picatoste, 1887: 231).

227 A informação relativa ao número de cajones - 272 - está sublinhada no documento original. Acreditamos que tenha sido a forma encontrada pelo inventariante para registrar o surpreendente volume dos “bens” que os jesuítas possuíam armazenados na botica do Colégio de Córdoba.
} 
Cortinal de estapadillo, ò Saras a azul riveteada con cinta carmesi, y en su frente, se halla la Puerta entrada a dhas Botica de tablero con cerra

Fólio 4573r.

dura y llave de metal amarrillo con dos tiradores de lo mismo, todo ello vien (bien) tratado, y corrientes y sobre dha Puerta otra cenefa mas mediana lo mismo que la anterior con su cortina.

Yt. una /ra/ pieza sobre la Puerta del obrador pintada y dorada

Yt. un mostrador de dos varas de largo, que sirve para el despacho de dha Botica, y una vara de alto, y otra de ancho ochavado con siete cajones al frente, y otro de su respaldo, y este con llave, y cerradura corriente

Yt. otro dho pequeño que se halla al pie de la ventana referida para el despacho de las medicinas a la calle

Yt. ocho onzas de plata Labrada que se compone de unas Baclancitas en un Budo, y dos em cadidas de servicio de dha Boticas que tasaron en siete pesos marco... D007

Suma ant ${ }^{\mathrm{r}}$

Fólio 4573v.

Yt. dos Alimirezes de Piedra negra pequeños con sus manos de Palo, que tasaron en dos pesos... D0002

Yt. un Alimirez de plomo con su mano de lo mismo con peso de cinco libras, que tasaron en seis reales... D000...6

Yt. tres dos medianos con una mano de Bronze com peso de 4 libras, y 4 onzas, que tasaron à 4 reales libra... D002...1

Yt. un Almirez mediano de Bronze con su mano con peso de cinco libras, quatro onzas q.e tasaron à quatro libra... D002...5

Yt. otro dho mas grande con su mano, con peso de onze libras que tasaron à quatro R.s libra... D005...4

Yt. unas Balancitas mui pequeñas con diez pezas de granos su cajita de madera, y su pescante de hierro en que se mantiene dhas Balancitas

Fólio 4574r.

Suma anterior

que tasaron en ocho pesos... D008

Yt. un esplaclulero de madera de una tercia de largo, y lo mismo de Alto con su cajoncito con seis espátulas de Yerro, una de hueso, y una de metal amarillo, q.e tasaron todo ello en tres pesos... D003

Yt. un cajoncito con su Pescante de Madera, con tres gabelillas y de dho Pescante penden unas valancitas pequeñas amarillas sin marco, que tasaron en quatro pesos...

D004

Yt. una casita pequeña de dorar Pildoras, con medio libro de oro y de Plata, que tasaron en cinco r.s ... D000...5

Yt. un tintero, y salvadera de estaño en una pieza que tasaron en dos R.s... D000.... 2

Yt. quatro espátulas grandes, y quatro pequeñas de hierro, con peso de tres Libras que tasaron à tres reales libra... D001...1 
Suma ant ${ }^{\mathrm{r}}$

Fólio 4574v.

Yt. una Jeringa de estaño mediana, que tasaron en quatro p.s... D004.0

Yt. un formon, y clabo grande, de hierro, que tasaron en dos R.s...D000...2

Yt. un Martillo, y un Punzon de hierro que tasaron en 4 r.s...D000...4

Yt. una Sierra de hierro, que tasaron en dos pesos... D002

2D614...2 3/4

En este estado por ser tarde se suspendio esta entrega y remoción para proseguirla quando convenga y los dos Peritos tasadores, dixeron haver hecho esta tasación asu s leal saber, y entender, y todo lo hasta aqui tomado razón, hizo el señor Diputado entrega a d.n Lorenzo de Orduña, Adm. ${ }^{\text {or }}$ Nombrado, para ello, quien se dio por servido à su entera satisfacion vaxo (baxo) las obligaciones que antecedentemente van explicadas. Y en este estado dixo el señor d. ${ }^{\mathrm{n}}$ Fernando Fabro

Fólio 4575r.

Suma anterior

que reproducia la protexta q. ${ }^{\mathrm{e}}$ anteriormente tiene hechas, y demás que constan en estas dilig. ${ }^{\mathrm{s}}$ y lo firmaron dos señores de que doi fee $=$ Fernando de Arze, y Bustillos $=$ Fernando Fabro $=$ Lorenzo Ynfante $=$ Juan Joseph herrero $=$ Lorenzo de Orduña $=$ Ygnacio Tolosa $=$ Ante mi Clemente Guerrero escribano, publico, y del Num. ${ }^{\circ}$ en dho dia, Mes, y año.

Se procedio la entrega, y Remocion de los trastes de cocina de dha Botica en la forma y manera siguiente

Primeramente dos pilares de Nogal torneados, de una vara de alto enterrados en el suelo, arrimados al Mostrador del despacho de dha Botica, que servían para poner los

Almirezes

Suma ant ${ }^{\mathrm{r}}$

Fólio 4575v.

que no tasaron por no ser de su facultad.

Yt. un Banquito de Madera de Pino viexo que servia de asiento en dha Botica, que no tasaron por dha Razon

Yt. un Pescante de Hierro que se halla clavado en el Mostrador de dha Botica, de una bara de alto que servia de cargador de Balanzas con pesas de tres libras, que tasaron à tres reales libra... D001...1

Yt. un cortador de Raizes à hechura de un Machete con su tablas, que tasaron en dos pesos... D002

Yt. una sierra de dos Tercias de largo cortante por ambas partes, que tasaron en dos pesos... D002

Yt. una caxa de Madera de Pino de vara y medio de largo dos Tercias de Alto, y lo mismo

Suma ant ${ }^{\mathrm{r}}$

Fólio 4576r. 
de ancho con su eslabon (corrente) para poner candado: doze abrazaderas de herro en las esquin. ${ }^{\mathrm{s}} \mathrm{y}$ dos Aldabones, que sirven de agarradera, que no tasaron por no ser de su facultad

Yt. tres Tamizes mediano el uno servible, y los demás inservibles, que tasaron en un peso todos.... D001

Yt. dos espumaderas de Azofar con los clavos de hierro que tasaron en doze R.s ambas... D001...4

Yt. dos Cazerolas de Azafran con sus cabos de hierro, que tasaron en tres pesos ambas... D003

Yt. cacitos de hierro Chiquito que tasaron à seis R.s cada uno... D002...2

Fólio 4576v.

Suma anterior

Yt. una regadera de oja de lata pequeña usada en tres R..s... D000...3

Yt. dos Peroles de Azofar para Baños remendados, que tasaron siete pesos ambas... D007 (caldeirões de bronze pt.)

Yt. otro mas mediano mui abollado que tasaron en doze R.s... D001...4

Yt. un Alambique mediano, que tasaron en veinte pesos... D020

Yt. otro dho mas mediano, que tasaron en quinze pesos... D015.

Yt. otro dho pequeñito, que tasaron en cinco pesos... D005

Yt. una sarten de cobre viejo, q.e tasaron en quatro R.s... D000...4

Yt. un Plato ondo de estaño viejo especie de fuente que tasaron en tres R.s... D000...3

Yt. dos Piedras mármol de preparar, que tasaron en doze p.s... D012

Yt. una Banquilla de dos pies en donde se halla sentada una-

Suma ant ${ }^{\mathrm{r}}$

Fólio 4577r.

de dhas Piedras, que no tasaron por no ser de su facultad.......

Yt. una prensa que se halla enbutida en la Pared del uso de dha Botica, para sacar Azeytes con sus Aperos correspondientes que no tasaron por no ser de su facultad.... Yt. dos forneles viexos (viejos ga.) con sus pies de hierro quebrados, que tasaron en cinco pesos ambos.... D005

Yt. dos dos pequeñitos de cobre el uno con un pie menos, que tasaron en dos pesos: se advierte que el del Pie menos es de hierro... D002

Yt. una tinaja grande de Sevilla que està enterrada vajo (baixo ga.) de tierra que no tasaron por no o aver en los términos en que se halla....

Yt. unas Trebedes de hierro, que tasaron en doze R.s... D001...4 (fogareiro pt.)

Yt. un Mortero grande de Piedra con su Mano de Palo q.

Suma ant ${ }^{\mathrm{r}}$

Fólio 4577v.

brado que tasaron en dos pesos... D002

Yt. otro dho mas pequeño con sus manos de Piedra que tasar.n en 2 p.s... D002

Yt. un tastador de hierro para cafeè, que tasaron en dos pesos... D002

Yt. una cantarilla de cobre vieja que tasaron en tres pesos... D003 (vaso pt.) 
Yt. un Mostrador que halla en dha cocina de la Botica de Madera de cedro de tres varas, y media de largo, poco mas de vara de alto, y acho, con dos alazenas vaxas, y quatro cajones en cima de ellas, y à espaldas en su frente diez cajones, y los primeros con sus Tiraderas de Bronze que no tasaron por no ser de su facultad........ (alacena ga.) (armario pt.)

Yt una escalerilla pequeña de cinco escalones, que no tasaron por dha razón..... Yt. un tacho quadrilongo de

Suma ant ${ }^{\mathrm{r}}$ Fólio 4578r.

cobre que tasaron em seis pesos... D006

Yt. un Cajon de Madera de Pino que servia de poner carbono que no tasaron por dha Razon...

Yt. un Almirez grande, de hierro tama no com peso prudente de dos arrobas, que tasaron em treinta pesos... D030

Yt. três espartulas de hierro viejas, que tasaron em quatro R.s tud.s ..D000...4

Yt. un cajon, que sirve para molejon, con uma Piedra de Amolar grande, y outra mas mediana com sus hierras correspondientes, y corrientes, que tasaron ambas com dho Cajon en veinte pesos... D020.

Yt. un cruzero de Madera, que no se tasó por ynutil....

Yt. dos calderas de cobre viejas de calentar Agua, que tasaron em diez R.s... D001... 2

Yt. dos palmatorias de Azafar

Suma ant ${ }^{\mathrm{r}}$

Fólio 4578v.

la uma quebrada, y la otra servible, que tasaron en 4 r.s... D000...4

Yt. um par de tenazas de hierro que tasaron em quatro R.s... D000...4 (tesouras de ferro pt.)

Yt. um usillo de Madera, p.a Prehensa, que no tasaron por no ser de su facultad...

Yt. enel Jardin de dha Botica se halla embutida en la Pared um caldero con su Asa, por el que se despachava Agua à la Barberia, que tasaron em quatro pesos..... D004 (caldeirão pt.)

2 D769... $13 / 4$

En este estado se suspendio esta entrega por no haver mas vienes en la referida Botica, y su cocina, y restar solo los que se hallan enel Almahaen de la ante Botica, que se difirio para òtro dia; cuia tasacion dixeron los Peritos haverla hecho seg. ${ }^{\text {}}$

Fólio 4579r.

su leal saver, y entender, y todo lo htã aqui tomado razon segun y como ba referido, y se entrega de ello el señor Diputado a d. ${ }^{\mathrm{T}}$ Lorenzo Orduña Administrador nombrado, qui em sedio por recivido a su entera satisfaccion y vaxo (baixo) las obligaciones que antecedentemente lleva fhas. Y em este estado dixo el señor $d .{ }^{n}$ Fern. ${ }^{\text {do }}$ Fabro, que reproducia la protexta anteriormente fha. Y lo firmaron por antemi de que dy feeFernando de Arze, y Bustillos= Fernando Fabro = Lorenzo Ynfante== Juan Joseph herrero $=$ Lorenzo de Orduña $=$ Ygnacio Tolosa $=$ Antemi Clem.te Guerrero escrivano publico, y del numero 
en la ciudad de Cordoba, em vinte de Noviembre de

Suma anterior.

Fólio 4579v.

mill setecentos setenta y un años, haciendose passado alas ante Botica em prosecucion de esta entrega, y Remocion se practico por todos los dhos señores Nominados em la forma siguiente

Primeramente diez y seis libras de sebo verde que tasaron a doze R.s libra... D024

Yt. Agua de Verdolagas ocho libras a dos R.s libra... D002

Yt. agua de Borrajas ocho libras a dos R.s libra... D002

Yt. agua de Ynojo ocho libras que tasaron a dos R.s libra... D002

Yt. agua de verdolaga ocho libras que tasaron à dos R.s libra... D002

Yt. agua de Borrja ocho lib.s a dos R.s... D002

Yt. agua de Yerba buena dos...

Suma ant ${ }^{\mathrm{r}}$

Fólio 4580r.

Libras a dos R.s libra... D000...4

Yt. ocho libras de Yd. alo pr.o... D002

Yt. Azeyte Phisosofico dos libras, y una onza, que tasaron à quatro pesos libra... D008...2 (Filosophico vg.)

Yt. Azeyte de Piedra blanca libra y quinze onzas a quatro R.s onza... D012...4

Yt. veinte y siente onzas de azeyte petrolio en três frasquitos, que tasaron à seis reales onza... D020... 2 (petróleo vg.)

Yt. Aceyte Vitriolo una libra em dos frasquitos, que tasaron à quatro reales onza D008

Yt. Azeyte de Subsino veinte y siete onzas, que tasaron à ocho pesos libra, y esta en três frasquitos... D013...4

Yt. espiritu de coclearia ocho onzas que tasaron a tres Reales onza... D003 (coclearea vg.)

Yt. espiritu de Azufres

Fólio 4580v.

Suma anterior.

Media libra, que tasaron à quatro R.s onza... D004

Yt quatro libras de agua fuerte en ocho frasquitos, que tasaron à ocho pesos libra...

D032 (aguafuerte vg.)

Yt espiritu de Cuerno de cierbo media libra, que tasaron à dos R.s onza... D002

Yt. quatro onzas de salte marte que tasaron à ocho R.s onza... D004

Yt. sal de Agenjos tres libras en dos limetas, y diez onzas mas, que tasaron à seis r.s onza... D043...4

Yt. precipitado vlanco, catorce onzas, que tasaron a ocho Reales onza... D014

Yt. flor de menfy, quatro onzas y quatro adarmes que tasaron a doze R.s onza...D006...6

Yt. Goma de Galbano, cinco libras y media que tasaron ........ 
Suma ant ${ }^{\mathrm{r}}$

Fólio 4581r.

à seis pesos libra.... D033

Yt. sal cartatica, diez y siete libras y catorze onzas q.e tasaron à três R.s onza...D107...2 (catartica vg.)

Yt. azeyte de Laurel, seis libras que tasaron à quatro Reales libra... D003

Yt. extracto unipero quatro libras, que tasaron à seis pesos libra... D024 (junipero vg.)

Yt. Nitro purificado siete libras que tasaron à seis pesos libra... D042

Yt. Polbos azules dos libras, q.e tasaron a dos pesos libra... D004

Yt. marfl dos liras, y uma onza, que tasaron três pesos cada libra.... D006... 1 1⁄2 (marfil vg.)

Yt higado de antimonio quatro libras, que tasaron à ocho R.s libra... D004

Yt. antimonio doze libras y media, que tasaron qua ..........

Suma ant

Fólio 4581v.

tro pesos libra.... D050

Yt. agua de canela uma libra y seis onzas, que tasaron à catorze pesos libra... D019...2

Yt. azafran de Castilla, una libra q. ${ }^{\mathrm{e}}$ tasaron em doze p. ${ }^{\mathrm{s}}$..D012

Yt. Pulpa de casia tres libras y quatro onzas, que tasaron a quatro pesos libra.. D013

Yt. Diacordio fracastorio uma libra, y nueve onzas que tasaron à quatro pesos libra. D006...2

(Diascordio fracastreo vg.)

Yt. unguento Amarillo quatro libras y m.a que tasaron à quatro R.s libra... D002... 2

Yt. sal de tartaro, dos libras y diez onzas, que tasaron à tres R.s, onza... D015...6

Yt. arcano duplicado una libra, y dos onzas que tasaron à dos R.s onza...D004...4

Yt. azeyte de Almendras ......................

Suma ant ${ }^{\mathrm{r}}$.

Fólio 4582r.

Dulzes cinco libras, que tasar.n à doze R.s libra... D007...4

Yt. Ynguento de Zacarias dos libras, y quatro onzas, que tasaron a ocho R.s libra...

D002...2

Yt. agua de Genciana comp. ${ }^{\text {ta }}$ cinco libras que tasaron à quatro pesos libra...D020

Yt. Nuez noscada Azeyte, doce onzas, que tasaron a tres pesos, y m.o onza... D024

Yt. siete onzas de mandibulas del pez llamado lucio, que tasaron à quatro R.s onza... D003... $4^{228}$

Yt. cuerno de cierbo candinado una y m.a libra, que tasaron a dos pesos libra... D003 (calcinado vg.)

Yt. m.a onza de Polvos de Unicornio, que tasaron en tres pesos la m.a onza... D003 (pós de unicórnio pt.)

Yt. cuerno de cierbo crudo diez onzas, que tasaron ...................

${ }^{228}$ É o nome comumente dado aos peixes do gênero Esox, família Esocidae. São oriundos da América do Norte e Europa Ocidental. 
Fólio 4582v.

Suma ant ${ }^{\mathrm{r}} \ldots \ldots \ldots \ldots \ldots \ldots \ldots$

en dos pesos todo.... D002

Dientes de Jabali cinco y m. ${ }^{\text {a }}$ onzas, que tasaron en tres p. ${ }^{\mathrm{s}}$ t. ${ }^{\mathrm{a}} . . . \mathrm{D} 003$

Yt. Azeyte de Patas m.a libra, que tasaron en ocho r.s... D001 (de pata pt.)

Yt. Uma libra de Ynguento de azahar, que por Ynutil se $\mathrm{m}^{\text {do }}$ arrojar

3D393... $5 \frac{1 / 4}{4}$

En este estado por ser tarde se suspendio esta entrega, y remocion cuia tasacion dixeron los Peritos haverla hecho à su Leal sav. ${ }^{\mathrm{r}}$ y entender, y todo lo hasta aquí tomado razon se hizo entrega de ello a dho Administrador d. ${ }^{\mathrm{n}}$ Lorenzo Orduña, vaxo las mismas obligaciones antezedentes Y el dho señor d. ${ }^{\mathrm{n}}$ Fernando Fabro dixo que reproducia la protexta que tiene hecha. Y lo firmaron todos los dho Señores por ante mi

Suma $\mathrm{B}^{\text {ta }}$

Fólio 4583r.

de que doi fee $=$ Fernando de Arce y Bustillos $=$ Fernando Fabro $=$ Lorenzo Ynfante $=$ Lorenzo de Orduña $=$ Juan de Yseph $($ Joseph $)$ herrero $=$ Ygnacio tolosa $=$ Antemi Clemente Guerrero escriv. ${ }^{\circ}$ publico, y del Numero _ _ _ en veinte y uno de dho mês y año, em prosecucion de la entrega, y Remocion prevenida los dhos señores se trasladaron à la Ante Botica referida, y se prosiguio em la forma siguiente _ _

Primeramente espiritu de vino recificado nueve libras, y diez onzas q.e tasaron em un frasco en seis pesos... D006

Yt. tamarindos uma Petaca con peso de quatro arrobas y diez y siete libras, que tasaron à seis R.s libra... D087

Suma ant ${ }^{\mathrm{r}}$

Fólio 4583v.

Yt. veinte Redomas ${ }^{229}$ de vidrio grandes que tasaron à três p.s cada uma... D060

Yt treze orcitas ${ }^{230}$ grandes de Losa de Sevilla, que tasaron a dos pesos cada uma... D026 Yt. veinte y quatro orzas, y tarras de todos calibres, chico y grande, que tasaron a tres r.s cada uno.... D009

Yt. seis frascos grandes de Christ.l que tasaron a diez y ocho R.s cada uno... D013...4 Yt. uma frasqueira grande del Marques con diez y ocho frascos que tasaron em veinte y siete pesos... D027

Yt. Cinco frascos sueltos del Marques, que tasaron à diez R.s cada uno... D006...2

Yt. quatro frascos de vidrio medianos de medida, el uno

Fólio 4584r.

Suma ant ${ }^{\mathrm{r}}$

8 lime.tas chic.s y grand.s a 2 R.s cada uma... D002

quebrado que tasaron en quatro R.s, cada uno...D002 231

229 “vasilia de vidrio ancha de abajo, que va angostándose hacia la boca.” (Picatoste, 1887: 892).

230 “vasija de barro que sirve para conservas.” (Ibíd: 773). 
Yt. uma Frasquera Portuguesa con diez frascos, que tasaron em siete pesos y médio... D007..4

Yt. Yt. veinte vidrios de Christal de terzera classe que ban referidos, que tasaron à ocho R.s cada uma... D020

Yt. dos Basos, y una Copa de Christal grande, que tasaron à ocho r.s cada pieza...D003

Yt. siete vidritos de todos calibres, que tasaron à R.s... D000...7

Yt. un frasco grande del Marques, que tasaron en diez R.s... D001...2

Yt. doze frascos dhos del Marq.s quebrados, y remendados que se hallan en uma frasqueira vieja, que no lo tasaron p.r ynservibles........

Suma $\mathrm{B}^{\mathrm{ta}}$.

Fólio 4584v.

Yt. un quadro com la adbocaz.n de Nra (nuestra) Señora viejo, de vara y quarta de Alto, una vara de ancho, con su marco Pintado, y dorado sucio, que tasaron en cinco pesos... D005

Yt. un Botiquin ${ }^{232}$ de suela ${ }^{233}$ pequeno com veinte Botlecitos chiquitos de madera pintados de verde, que tasaron en seis pesos... D006

Yt. quatro Barriles de carga, com arcos de Hierro, que tasaron à veinte R.s... D010 Yt. un salterio ${ }^{234}$ de poco mas de tres quartas de largo, que tasaron en seis pesos... D006 Yt. onze Basos de estaño nuebos pequenos, que tasaron à quatro R.s cada uno... D005...4

Yt. tres escudillas ${ }^{235}$ de lo mismo nuevas, q.e tasaron à quatro R.s, cada uma... D001..4

Suma antezed. ${ }^{\text {te }}$

Fólio 4585r.

Yt. un embudo grande viejo, que tasaron em dos r.s... D000...2 (funil pt.)

Yt. doze Botijas vidriadas estrechitas, y grandes, q. ${ }^{\mathrm{e}}$ tasaron à dos R. ${ }^{\mathrm{s}}$ cada uma... D003

Yt. tres Chocolateras de cobre grandes, que tasaron a dos pesos cada uma... D006

Yt. dos Calderas viejas medianas, que tasaron à peso cada una... D002

Yt. dos Sartenes de hierr grandes que tasaron à diez R.s cada uno... D002...4 (panelas

pt.)

Yt. cinco tachos, medianos, y pequenos de metal amarillo remendados, que tasaron à quatro pesos cada uno... D020

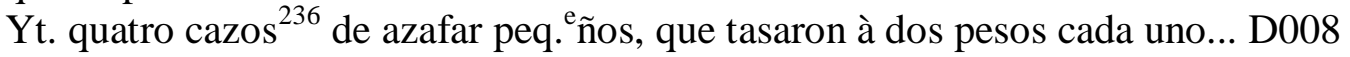

Yt. uma caxa de vara, y quarta de largo, dos tercias de

Fólio 4585v.

Suma anterior

alto, y ancho, que no tasaron por no ser de su facultad...

Yt. outra dha Nueva de cerca de vara y quarta de largo cerca de dos tercias de Alto, y ancho sin cerradura, ni llabe, que no tasaron por dha razon.....

\footnotetext{
${ }^{231}$ Essa linha deve ser da página anterior, no entanto, mantivemos a ordem como aparece no documento.

232 “cajón pequeno con medicinas para transportarle.” (Picatoste, 1887: 173).

233 Acreditamos tratar-see de "el cuero de bueyes curtido.” (Ibíd: 969).

234 “el libro de los salmos.” (Ibíd: 937).

235 “vasija ancha en que se sirve el caldo ó la sopa.” (Ibíd: 468).

236 “vasija semiesférica, por lo común de azófar, con mango de hierro” (Ibid: 227).
} 
Yt. otra dha de poco mas de vara de largo, dos tercias de alto, y ancho, vieja, que no tasaron por dha razon....

Yt. outra arca viexa quebrada de vara y quarta de largo, y de ancho, y alto media vara, q.e no tasaron por dha razon....

Yt. un estante de Madera com seis varas de largo, vara y tres quartos de alto, com ciento y treze cajones de todos calibres, que no tasaron por la razon antes dha...

Yt. una tina desarmada, q.e no tasaron por dha razon....

Suma $B^{\text {ta }} \ldots$. 3D741... $4 \frac{1}{1 / 4}$

Fólio 4586r.

En este estado haviendose concluído todo lo que se hallo em la ante Botica se reserbo pas.r al Almahazen de ella, y los dhos Tasadores dixeron haver hecho esta tasacion a seu leal saver, y entender, y todo lo hasta aqui tomado raz. ${ }^{\mathrm{n}}$ se recivio de ello el Conthen. ${ }^{\text {do }}$ Adm. ${ }^{\mathrm{r}}$ (administrador) vaxo (baixo) las mismas òbligaciones que antezeden en cuia Vxõ dijo el señor D. ${ }^{\mathrm{n}}$ Fernando Fabro, que reproducia en hmã la protexta anteriormente deducida. Y lo firmaron los dhos señores, por Ante mi de que doy fee $=$ Fernando de Arze y Bustillos= Fernando Fabro= Lorenzo Ynfante $=$ Lorenzo de Orduña $=$ Juan Jph (Joseph) herrero $=$ Yg. ${ }^{0}$ Tolosa $=$ Ante mi Clemente Guerrero

\section{Suma $\mathrm{B}^{\text {ta }}$}

Fólio 4586v.

escrivano pp. ${ }^{\mathrm{co}} \mathrm{y}$ del Num. ${ }^{\circ}$ em la ciudad de Cordoba em veinte y dos dho Mes, y año los dhos señores em prosecuz. ${ }^{\mathrm{n}}$ de esta entrega, y remocion se trasladaron al Almahazen dha Botica, y en el se prosiguio esta entrega con su tasacion em la forma siguiente _ - -

Primeram.te Jalapa siete libras, y m.a que tasaron à seis pesos libra... D045

Yt. Goma de Almacigas dos libras, y m.a que tasaron à seis pesos Libra... D015

Yt. Goma copal dos libras, q.e tasaron à seis pesos libra... D012

Yt. vitriolo vlanco tres libras y tres onzas, que tasaron a doze R. ${ }^{s}$ libra..D004...61/4

Yt. castoreo dos libras, y una onza, que tasaron a ocho.......................

Suma $\mathrm{B}^{\text {ta }}$

Fólio 4587r.

pesos libra.... D016...4

Yt. Goma de enebro quatro libras, que tasaron à seis pesos libra... D024

Yt. Alcanfor dos libras y seis onzas, que tasaron à seis reales onza... D028...4

Yt. Goma amoniaco, cinco libras, y die zonzas que tasaron à seis pesos libra... D033...6

Yt. tucia quatro libras y doze onzas, que tasaron à seis pesos libra... D028...4 (tutia vg.)

Yt. Goma de Vedelio, uma libra y catorze onzas, que tasaron à seis pesos onza... D180

Yt. opoponaco dos libras, y die zonzas, que tasaron a seis pesos libra... D015...6

Yt. Antimonio, veinte y quatro libras, que tasaron à quatro pesos libra... D096

Yt. Galvano, cinco libras, y seis onzas, que tasaron a seis

Suma ant ${ }^{\mathrm{r}}$

Fólio 4587v.

pesos libra... D032...2 
Yt. cardenillo, veinte y quatro libras, que tasaron à quatro pesos libra... D096 Yt. sal Amoniaco, veinte y tres libras, y catorze onzas que tasaron à seis pesos libra D0143... 2

Yt. Goma araviga, veinte y tres libras,, y onze onzas que tasaron à seis pesos libra... D142...1 (arábica vg.)

Yt. cremor tartaro $^{237}$, diez y siete libras que tasaron à siete pesos libras... D119

Yt. volo armenico, cinco libras y onze onzas, que tasaron a dos pesos libra... D011...3 (bolo armênico vg.)

Yt. minio quatro libras, y quinze onzas, que tasar.n a dos pesos libra... D009...7

Yt. Goma de Mirra, dos libras, y catorze onzas, q.e tasaron à seis pesos libra... D017...2

Yt. tres libras, y onze onzas .....

\section{Suma $\mathrm{B}^{\mathrm{ta}}$}

Fólio 4588r.

de Raiz de china, que tasar.n à tres pesos libra... D011... 1/2

Yt. Mandibulas de Pez lucio dos libras, y treze onzas, que tasaron à ocho pesos libra... D022... 4

Yt. escamonea, uma libra y doze onzas, que tasaron a seis pesos libra, diez com quat. ${ }^{\text {ro }} . . . \mathrm{D} 010 \ldots 4$

Yt. libra, y treze onzas, de cardamomo, que tasar.n a dos pesos libra... D003...5

Yt. quinze libras, y doze onzas de triaca magna, que tasaron à quatro pesos libra en bruto... D063

Yt. enula Campana, dos libras, y quinze onzas, que tasaron a quatro, pesos lib.a D011... 6

Yt. dientes de Jabali, dos libras, y doze onzas que tasar.n à nueve pesos libra...D024... 6

Yt. calamo aromatico, doze onzas, que tasaron á quatro R.s onza... D006

Suma $B^{\text {ta }}$

Fólio 4588v.

Yt. raiz de Galanga, dos lib.s y catorze onzas, que tasar.n à ocho pesos libra, veinte y tres pesos... D023 (galanja vg.)

Yt. esila, ibra y m.a que tasaron a quatro R.s libra... D000...6

Yt. vistorta una libra y doze onzas que tasaron à doze R.s libra... D002..5 (bistorta vg.)

Yt. raiz de siperos largos una libra, y die zonzas que tasaron a doze R.s onza... D039

Yt. raiz de Angelica, uma libra, y doze onzas, que tasaron à seis pesos libra... D010...4

Flor de Masias libra y m.a que tasaron à treinta y dos pesos libra... D048

Yt. raiz de emperatoria una libra, que tasaron en dos pesos... D002

Yt. una libra y treze onzas de suelda, consuelda, que tasaron a doze R.s libra... D002...5 $3 / 4$

Suma $B^{\text {ta }}$

Fólio 4589r.

Yt. enula campana, onze onzas que tasaron à razon de tres pesos libra... D002... 1/2

${ }^{237}$ Creme de tártaro [Bitartarato de potássio $\mathrm{KC}_{4} \mathrm{H}_{5} \mathrm{O}_{6}$ ]. 
Yt. Dauco cretino, uma libra, y doze onzas que tasaron à doze R.s libra... D002...5

Yt. una libra, y treze onzas de emplasto de Ranas simple que tasaron à dos pesos l.a... D003...5

Yt. Gutagamba doze libras y dos onzas, que tasaron à seis pesos libra... D072...6

Yt. Goma de Limon, quinze onzas y m.a que tasaron a seis pesos libra... D005... 6

Yt. cardenillo cinco libras y quinze onzas que tasaron à quatro pesos libra.... D023...6

Yt. Madre de Perla, cinco libras, y catorze onzas, q.e tasaron à seis R.s libra... D004... 3 $1 / 4$

Yt. uña de la Gran Vestia libra, y quatro onzas em bruto, y neto seis onzas, que tasaron a peso onza... D006

\section{Suma $\mathrm{B}^{\mathrm{ta}}$}

Fólio 4589v.

Yt. sandalo rubio dos libras, y media, a dos pesos libra... D005

Yt. tarage, una libra, que tasaron em seis r.s ... D000...6

Yt. cinco onzas de esponja que tasaron en un peso... D001

Yt. Goma Ysica, veinte y seis libras, y doze onzas netas que tasaron à seis pesos

lib.a...D160...4

Yt. veinte y quatro libras netas de dha Ysica, que tasar.n à seis pesos libra... D144

Yt. de dha Ysica doze libras que tasaron à seis pesos lib.a.. D072

Yt. siete libras y m.a de Ysica que tasaron à seis pesos l.a... D045

Yt. trementina, treinta y quatro libras, y una onza que tasaron à tres pesos lib.a...

D102... 5 1/2

Yt. onze libras Netas de triaca magna, que tasaron à quatro pesos libra... D044

Yt. Balsamo Copahiva, siete libras, y m.a que tasaron

Suma $B^{\text {ta }}$

Fólio 4590r.

a dos pesos libra... D015

$5 \mathrm{D} 804 \ldots 5 \mathrm{1} / 2$

Y en este estado por ser tarde se cerrõ esta entrega, y remoz.n para proseguirla òtro dia, $\mathrm{y}$ todos los dhos efectos Dixeron los Peritos haver tasado à su leal saver y entender, y de todos ellos se dio por recivido el Administrador Nombrado d. ${ }^{n}$ Lorenzo de Orduña, vaxo (baixo) las òbligaciones q. ${ }^{\mathrm{e}}$ antezeden. en cuio estado dijo el señor $\mathrm{d}$. ${ }^{\mathrm{n}}$ Fernando Fabro que reproducia la protexta que tiene hecha, y los firmaron los dhos señores de que doy fee $=$ Fern. ${ }^{\text {do }}$ de Arze y Bustillos $=$ Fernando Fabro $=$ Lorenzo Ynfante $=$ Lorenzo de Orduña $=$ Juan Joseph herrero $=$ Ig ${ }^{\circ}$ Tolosa $=$ Ante mi Clemente Guerrero, escriv ${ }^{0}$ publico, y del Numero _ _ _ en la ciudad de Cord. ${ }^{\text {a }}$ en treinta dias del mes de Noviembre

Suma $\mathrm{B}^{\text {ta }}$

Fólio 4590v.

de mil setecientos setenta, y un años, em prosecucion de la entrega, y remocion prevenida (la que no se prosiguio htã (hasta) el presente à causa de òtros assuntos que òcurrieron de temporalidades, em vrõ de orden Superior de la Jt. ${ }^{\mathrm{e}}$ Junta Provinz. ${ }^{1}$ (provincial) ) y se prosiguio en la fmã (forma) siguiente.. 
Yt. tres libras de azafran de castilla que tasaron a doze pesos libra... D036

Yd. espelma de Ballena seis libras neto, que tasaron à dos pesos libra... D012

Yd. mitridrato quatro libras onze onzas que tasaron à seis pesos libra neto... D028...1

(Mirtridato vg.)

Yt. unguento de Altanita seis libras neto, que tasaron à dos pesos libra... D012

Yt. Alcanfor cinco libras neto que tasaron a doze pesos lib.a... D060

Yt. Borax, siete libras y siete ..............................

Suma Anterior

Fólio 4591r.

onzas neto, que tasaron à dos pesos libra... D014...7

Yt. coral rubio nueve libras neto, que tasaron a dos pesos libra... D018

Yt. tusia seis libras, y seis onz. ${ }^{\mathrm{s}}$ Neto que tasaron à seis pesos libra...D038...2

Yt. ojos de Cangrejos ocho libras y die zonzas, que tasaron à seis pesos libra....

D051...3

Yt. linaza cinco libras y nueve onzas neto, que tasaron à cinco R.s libra.... D003... 3 3/4

Yt. temo tártaro catorze libras que tasaron à siete pesos libra. D098

Yt. Goma de olivano treze libras neto que tasaron à seis pesos libra... D078

Yt. tártaro crudo, catorze lib.s y doze onzas neto, que tasar.n à dos onzas neto,, que tasar.n à dos pesos libra... D029...4

Yt. Goma de enebro seis libras y media neto, que tasaron

Fólio 4591v.

Suma Ant. ${ }^{\mathrm{r}}$

à seis pesos libra.... D039

Yt. Goma azafetida dos libras y doze onzas Neto que tasaron à seis p.s libra.... D016...4

Yt. piedra de matitis siete libras y m. ${ }^{a}$ neto, que tasar. ${ }^{\mathrm{n}}$ à tres pesos libra...D022...4

Yt. escarmonea, tres libras, y doze onzas neto, que tasaron à seis pesos libra.... D022...4 (escamonea vg.)

Yt. castoreo de Rusia quatro libras, y siete onzas, que tasaron à ocho pesos libra neto... D035... 4

Yt. Piedra lipis ocho libras, y media neto, que tasaron à tres pesos libra... D025...4

Yt. vitriolo vlanco nueve livras, y seis onzas Neto, q.e tasaron a doze R.s lib.a... D014... 1/2

Yt. yeso mate, una libra neto, que tasaron em seis r.s... D000...6 ${ }^{238}$

\section{Suma $\mathrm{B}^{\text {ta }}$}

Fólio 4592r.

Yt. goma de limon siete lib.s que tasaron seis pesos lib.a neto... D042

Yt. flor de Azufre treze llibras y media neto, que tasaron à quatro pesos libra... D054

Yt. Ysica, una libra, y diez onzas neto, que tasaron à seis pesos libra... D009...6

Yt. raiz de Galanga, tres libras neto, que tasaron à ocho pes.s libra... D024

${ }^{238}$ Yeso é o "sulfato de cal”; gesso comum. 
Yt. tierra sigilada ruvia, veinte libras y die zonzas neto que tasaron á tres pesos l.a... D061...7

Yt. ruibarbo diez y seis libras y treze onzas neto, que tasaron a cinco pesos libra... D084... 1/2

Yt. ambar, catorze onzas, q.e tasaron à seis pesos onza neto... D084

Yt. ruibarbo ya pasado, cinco libras, y quatro onzas neto que tasaron a dos pesos lib.a... D010...4 ${ }^{239}$

Yt. mechoacan, doze libras y......

Suma ant. ${ }^{\mathrm{r}}$

Fólio 4592v.

media neto, que tasaron à dos pesos libra... D025

Yt. eleboro negro, tres libras y seis onzas neto, que tasaron à tres pesos libra... D010...1

Yt. estoraque tres libras, y onze onzas que tasaron a seis pesos libra... D022...1

Yt. almasiga, tres libras neto, q.e tasaron à seis pesos libra... D018

Yt. coralina cinco libras, y onza onzas Neto, que tasaron a dos pesos libra... D011...3

Yt. Litargirio de oro diez y nueve libras neto, que tasaron a dos pesos libra...D038

Yd. oropimente nueve libras y catorze onzas neto, que tasaron a quatro pesos libra... D039...4

Yd. coloquintidas dos libras neto, que tasaron à quatro pes.s libra... D008

Yt. simiente de Alexandria una libra, y diez onzas neto.................

Suma Ant. ${ }^{\mathrm{r}}$

Fólio 4593r.

que tasaron a dos pesos libra... D003...2 $2^{240}$

Yt. simiente de Auco unr.l ... D000...1 (dauco vg.)

Yt. cantueso nueve onzas que tasaron a razon de dos pesos l.a... D001...1 [contueso murciano Thymus moroderi ou o contueso menor Lavandula stoechas]

Yt. Raiz de sinsifito onze lib.s y m.a neto, que tasaron a doze r.s libra... D017

Yt. sal cartatica veinte y quatro libras, que tasaron à quatro pesos libra. Por no hallarse purificada como la antezedente... D096 (sal catártica vg.)

Yt. marfil, quatro libras doze onzas, que tasaron à tres pesos libra... D014...2

Yt. Cuerno de cierbo, siete libras y doze onzas, que tasaron a doze R.s libra...

D011...5

$7 \mathrm{D} 158 \ldots 41 / 4$

En este estado por ser tarde se suspendio esta entrega, y remocion para proseguirla otro dia, y los dhos Tasadores dixeron haver hecho esta Tasacion a su Leal saber y entender y todo lo-...

Fólio 4593v.

\footnotetext{
${ }^{239} \mathrm{O}$ "ya pasado" sugere que o inventariante considerou a planta inadequada para utilização, apesar disso, ela foi taxada.

240 Não encontramos maiores informações sobre esta semente, apenas referências à ela em: Palacios, 1730: 686.
} 


\section{Suma $\mathrm{B}^{\text {ta }}$}

htã (hasta) aqui tomado razon se recivio de ello el conthenidos Adm. ${ }^{\mathrm{r}}$ (administrador) vaxo (baixo) las mismas obligaciones que antezeden en cuia vrd. (verdade) dixo el señor d. ${ }^{\mathrm{n}}$ Fern. ${ }^{\mathrm{do}}$ Fabro que reproducia en fma (forma) la protexta ant. ${ }^{\mathrm{r}}$ mente deducioa, y lo firmaron los dhos Señores, por ante mi el pres.te escrivano de que doy fee $=$ Fernando de Arze, y Bustillos = Fernando Fabro = Lorenzo de Orduña= Juan Joseph herrero= Yg.o Tolosa= Ante mi Clemente Guerrero, escriv.o publico y del Numero _ _ en la ciudad de Cordoba, en primero de Diziembre de mill setecientos setenta, y un años, em prosecucion de la entrega i promocion prevenida los dhos Señores

Fólio 4594r.

Suma $B^{\text {ta }}$

se trasladaron a el Almahacen de dha Botica, y se procedio en la fmã (forma) sig.te (seguinte) _ _-

Primeram. ${ }^{\text {te }}$ Azogue treze lib. ${ }^{\mathrm{s}}$ neto, q. ${ }^{\mathrm{e}}$ tasaron à ocho R.s libra...D013

Yt. Nitro cinq.ta y quatro libras neto, que tasaron à quatro R.s libra.. D027

Yt. sasafras tres libras y quatro onz.s q.e tasaron a doze R.s libra (Zasafras vg.)

Yt. palo santo, tres @ y ocho libras que tasaron à doze r.s libra... D124...4

Yt. azufre ocho @ 19 li.s neto que tasaron à 4 r.s l.a... D109...4

Yt. Anis dos@y quinze libras neto que tasar.n a 2 p.s @... D005...111/2

Yt. Alumbre de Castilla 7 @ 16 libras neto, que tasaron à 12 r.s libra... D286...4

Yt.pez rubia $3 @$ y 20 1/2 lib.s que tasaron a 8 p.s@... D030...2

Suma $B^{\text {ta }}$

Fólio 4594v.

Yt. mecoacan 23 1 1/2 libras que tasaron a dos pesos libra... D047 (mechoacán vg.)

Yt. seda de Santiago 10 l.s 4 onz.s que tasaron à 2 r.s libra...D002...41/2

Yt. Polipodio 15 onzas que tasaron en 4 r.s...D000...4

Yt. una porcion de Culantrillo que tasaron en 4r.s ... D000 ...4

Yt. una porcion de ruda en um peso todo... D001

Yt. Aliv.s de Canehalagria que tasaron à 4r.s libra... D002

Yt. raiz de Altea $31 \frac{1}{2}$ libras neto, que tasaron a $2 \frac{1}{2} 2$ r.s l.a D001... 3/4 (althea vg.)

Yt. Ypericon 4 onzas que tasaron en 4 R.s... D000...4 (hipericon vg.)

Yt. un poco de Romero en quatro R.s... D000...4

Yt. flor de azahar 6 l.s que tasaron a 3 r.s por estar un poco pasada... D002...2

Yt. flor de cardo santo $1 \frac{1 / 2}{2}$ l.a neto que tasaron a tres R.s ........

Suma ant. ${ }^{\mathrm{r}}$

Fólio 4595r.

libra... D000.. 4 1/2

Yt. doradilla 4 l.s neto que tasaron à 2 r.s l.a... D001

Yt. flor de Mansanilla 2 l.s que tasaron a 2 r.s l.a... D000...4

Yt. salvia que tasaron en D002...2 (salvia)

Yt. flor de violeta onze lib. ${ }^{\mathrm{s}}$ neto, que tasaron a $12 \mathrm{r}^{\mathrm{s}}{ }^{\mathrm{s}}$ libra..D016...4 
Yt. Aluzema 3 l.s y 6 onzas q.e tasaron à 2 r.s libra... D000...6 3/4

7D836... $71 / 4$

Y en este estado por ser tarde se suspendio esta entrega y remocion, para proseguirla otro dia, y los dhos Tasadores dixeron haver hecho esta Tasacion a su leal saber, y entender, y todo lo htã aquí tomado Razon se recivio de ello el conthen. ${ }^{\text {do }}$

Administrador vaxo las mismas òbligaciones que antezeden en cuia vrd (verdade) dixo el señor d. ${ }^{n}$ Fernando Frabro que reproducia en fmã (forma)

Suma ant. ${ }^{\mathrm{r}}$

Fólio 4595v.

la protexta anteriorm.te deducida y lo firmaron dhos señores por ante mi el pres.te escrivano de que doy fee $=$ Fernando de Arze, y Bustillos $=$ Fernando Fabro $=$ Lorenzo Ynfante $=$ Lorenzo de Orduña $=$ Juan Joseph herrero $=$ Yg.o tolosa $=$ Ante mi clemente Guerrero escriv.o publico de Numero _ _ _ en dos dias del mes de Diz.e de dho año se prosiguio esta entrega, y remocion en la fmã (forma) siguiente

Primeram.te 6 l.s 14 onza.s de cera amarilla virgen de s.n tiago, que tasaron a p.o l.a... D006...7 (cera amarela)

Yt. 16 frascos de Christal grandes vacios que a 18 r.s cada uno... D036

Yt. 3 dhos um poco mas medianos que tasaron à 12 r.s... D004...4

Suma ant. ${ }^{\mathrm{r}}$.

Fólio 4596r.

Yt. 13 dhos yd del mismo prec. ${ }^{0}$ (precio)... D019...4

Yt. 79 dhos mas medianos que tasaron à 8 r.s cada uno... D079

Yt. nueve limetas de Christ.l de cuello largo que tasaron à 18 r.s cada una... D020...2

Yt. 28 frascos de vidrio ord.s que tasaron à 6 r.s cada uno... D021

Yt. 12 Botecitos de vidrio, q.e tasaron a 8 r.s cada uno... D012

Yt. 33 Redomas de vidrio que distintas elaves, que tasar.n unas con òtra à 8 r.s... D033

Yt. 4 limetas de Vidrio q.e tasaron à 2 r.s cada una... D001

Yt. 2 Alambiques grandes de Vidrio que tasaron à 10 p.s cada uno... D020.

Yt. 1 dho pequeño la Boca q. brada, que tasaron en 3 p.s... D003

Yt. una Horta de Vidrio que tasaron en 7 p.s... D007

Yt. dos recipientes de vidrio q.e tasaron a 4 p.s cada uno... D008

Suma $\mathrm{B}^{\mathrm{ta}}$.

Fólio 4596v.

Yt. 14 cavezas de Alambiq.e de vidrio, que tasaron a 4 p.s cada una... D056

Yt. dos limetas grandes de Damas Yuanas de vidrio que tasaron en 6 pesos ambas... D006

Yt. 34 Botes de Losa, que tasaron à 6 R.s cada uno... D025...4

Yt. 13 Botecillos de Losa, y Barro, que tasaron à 3 r.s... D004...7

Yt. siete chrisoles de todos tamaños à 9 r.s unos con otros... D004...3

Yt. 214 Botes grandes de madera entre viexos (viejos), y nuevos, que tasaron a 4 R.s cada uno... D107

Yt. 109 dhos chicos que tasaron a 2 r.s cada uno... D027...2

Yt. un Alambique pequeño de cobre que tasaron en D012

Yt. una plancha de fierro, q.e tasaron en 1 p.s... D004 (Se refere a ferro de passar) 
Yt. orzas de Barro de

Suma $\mathrm{B}^{\mathrm{ta}}$

Fólio 4597r.

la tierra servidas a R.s cada una... D003...4

Yt. 33 talegas de crudo en q.e se hallan las yerbas medicinales, que tasaron a R.s...

D004...1 (sacos pt.)

Yt. 9 Botes de estaño tasados en 6 R.s... D000...6

Muebles de Alm. ${ }^{\text {zn }}$ :

Primeram.te una Papelerita de madera de dos Tercias de largo, una de Alto, con quatro cajones pintados con cerradura, y sin llave, q.e no tasaron por no tener Yntelig. ${ }^{\text {a }}$

(inteligência)... D

Yt. otra Papelerita vieja sin tapa, con quatro gavetas que no tasaron por dha raz.n... D

Yd. Dos dhas pequeñas, que no tasaron por la misma razon... D

Yt. dos cajones grandes de Pino que no tasaron

Suma ant. ${ }^{\mathrm{r}}$

Fólio 4597v.

por dha causa....... D

Yt. 3 arcas viexas, 2 grandes y una mediana, que no tasaron por dha razon... D

Yt. una tabla de quarto y m.a varas de largo, 3 q.s (quarto) de ancho que no tasaron por

la misma causa... D

Yt. dos Puertas con sus varios vidrios correspondientes a la Botica que no tasaron por

dha razon..... D

Yt. otras dos Puertas sin vidrios como las anteriores que no tasaron por la misma razon... D

Yt, un instante de Zedro de dos varas de alto, y 4 de largo que no tasaron por lo dho...D

Yt. seis cajones corridos de madera de Zedro nuebos en una pieza que tampoco ta

Suma ant. ${ }^{\mathrm{r}}$

Fólio 4598r.

saron, los quales se componen de cerca de 12 var.s de largo..... D

Yt. una arca de vara, y quarta de largo, y 1 terc. ${ }^{\text {a }}$ (tercia) de ancho, con cerradura, y sin

llabe que tampoco tasaron...

D

Yt. una valanza grande de metal con su cruz de hierro, y marco de 16 libras, q.e tasaron en 32 p.s. D032

Yt. otras dhas pequeña amarrila con marco de 4 libras que le faltan tres pesitas que tasaron en 6 p.s. D006

Yt. una arca de madera de mas de vara de largo, dos tercias de alto, lo mismo de ancho, con cerradura, y sin llave viela, que perteneze a la Rebotica la qual no se taso por falta de intelg.a... $\mathrm{D}$

Suma ant. ${ }^{\mathrm{r}}$

Fólio 4598v.

Yt. 39 hierros chicos, y grandes des de cirujia ynservibles que se tasaron en 20 p.s... D020 
Libros pertenez.tes à la Botica.

Prim. ${ }^{\text {a }}$ m. ${ }^{\text {te }} 14$ libros de folio, y uno enquarto ma. ${ }^{\text {or }}$ de var. ${ }^{\text {s }}$ farmacospeas que tasaron a ocho pesos cada uno... D120

Yt. 15 libros en folio medicinales de varios autores que tasaron a 8 p.s cada uno... D120

Yt. 15 libro de quarto ma.or de cirujia, y Medicina de distintos autores q.e tasaron à tres pesos.... D045.

Yt. 30 libros de aquarto ma.r y mas chicos en lengua Alemana de varios autores, que no se entienden los que no se tasaron, por falta de Ynteligencia.... D

Fólio 4599r.

Suma ant. ${ }^{\mathrm{r}}$

Yt. un libro manuscrito de quentas particulares q.e llevava el P.e (padre) Boticario con algunas foxas escritas...

8D706... $3 \frac{11 / 4}{2}$

En este estado se dio raz.n por el señor d. ${ }^{\mathrm{n}}$ Fernando Fabro, no haver mas vienes que pertenezcan à la Botica y su Almahazen, y todos los htã aqui tomado razon se hizo cargo de ellos d. ${ }^{\mathrm{n}}$ Lorenzo Orduña como Adm. ${ }^{\mathrm{r}}$ nombrado para este efecto vaxo las òbligaciones antez. ${ }^{\text {tes }}$ cuia tasaron dixeron los Peritos haver hecho asu leal saver, y entender en cuia vrd. y bista la referida entrega y tasacion de la Botica, y su Almahazen dixo el señor D. ${ }^{\mathrm{n}}$ Fernando

Fólio 4599v.

Fabro, por si, y en nré (nombre) de d. ${ }^{\mathrm{n}}$ Lorenzo Ynfante, que reproducia la protexta que tiene hecha en el principio de esta entrega, y que requeria, y requirio al señor d. ${ }^{n}$ Fern. ${ }^{\text {do }}$ de Arze, Juez nombrado por los señores de la Junta municipal para que se sirva su mrd mandar que con citacion suia, y de dho Botic.o d.n Lorenzo Ynfante se sumen las Partidas en que estan tasardos los referidos medicamentos con separacion de los muebles, y demas especies que estan tasados en esta entrega à fin de venir en conocimiento del estado y valor en que dan tasados los dhos Medicamentos entregados, y que ha

Fólio 4600r.

si mismo Se sirva mandar a mi el presente Escrivano sele de testimonio y entrega de esta entrega de la Botica y en vista de lo expuesto por el señor d. ${ }^{\mathrm{n}}$ Fernando Fabro dixo el señor d. ${ }^{\mathrm{n}}$ Fern. ${ }^{\text {do }}$ Arze, Juez Nombrado para este efecto que se prozeda seg. ${ }^{\mathrm{n}}$ (segundo) ya mo lo expone, y pide el citado señor d.n Farnando Fabro, y lo firmaron los dhos señores por ante mi el presente escrivano de que doy fee $=$ Fernando de Arze y Bustillos $=$ Fern.${ }^{\text {do }}$ Fabro $=$ Lorenzo Ynfante $=$ Lorenzo Orduña $=$ Juan Jph $($ Joseph $)$ herrero $=$ Ygnacio Tolosa $=$ Antemi Clemente Guerrero escrivano p. ${ }^{\mathrm{co}}$ y del Numero _ _

Fólio 4600v. en la ciudad de Cord. ${ }^{a}$ en quatro de Diciembre, de mill setecientos setenta y un a. ${ }^{\mathrm{s}}$ (assi) estando en Acuerdo los señores de esta muy Yt. ${ }^{\mathrm{e}}$ Junta Municipal de temporalidades se tubo presentes las Diligencias practicadas de la Botica y en su vista, y lo enxp. ${ }^{\text {to }}$ por los tasadores y del Carg. ${ }^{\text {to }}$ maior $d .{ }^{\mathrm{n}}$ Fernado Fabro- mandaron se haga la tasacion de lo que no se halla tasado, y para ello Nombraron ad. ${ }^{\mathrm{n}}$ (administrador) Juan de Alberro, y d. ${ }^{\mathrm{n}}$ 
Antonio Gonzales, que haciendo el Juramento de fidelidad por ante el s. ${ }^{\tilde{n}}$ Presidente prozedan a dha tasacion, con citacion de dho señor d. ${ }^{\mathrm{n}}$ Fernando Fabro

Fólio 4601r.

y a el arreglo de las esumas con separacion de Botica y demas que pide. Y lo firmaron dhos señores ante mi el presente escrivano de que doy fee $=$ Teran $=$ Sarmiento $=$ Gilledo $=$ Montenegro $=$ Ante mi Guerrero. escrivano pp. ${ }^{\text {co }}{ }_{-}{ }_{-}$en dho dia. Yo elth. ${ }^{\mathrm{e}}$ de Alguacil ma.r Portero de la Junta municipal por ocupacio del escrivano de dha Junta hize saber el decreto que antezede a el Sargento ma.r d. ${ }^{\mathrm{n}}$ Fern.do Fabro, y le cite para lo en el conthenido $\mathrm{Y}$ para que conste lo pongo por diligencia = Soto en cinco dias de dho mes y año, yo el then. ${ }^{\text {te }}$ (Tenente) Alguacil ma. ${ }^{\mathrm{r}}$ y Portero de la Junta

Fólio 4601v.

Municipal hize saber el decreto que entezede a d. ${ }^{\mathrm{n}}$ Juan de Alberro para lo en el conthen. ${ }^{\text {do }}$ y para que conste lo pongo por diligencia = Soto en dho dia, Yo el th. ${ }^{\mathrm{e}}$ de Alguaciol ma. ${ }^{\mathrm{r}}$ y Portero de la Junta Municipal hize saber el antezedente $\mathrm{D} .^{\text {to }}$ de tasador à d. ${ }^{\mathrm{n}}$ Antonio Gonzalez. Y para que conste lo pongo por diligencia $=$ Soto _ en la ciudad de Cod. ${ }^{\mathrm{a}}$ en Seis de Diciembre de mill Setencientos Setenta y un a. ${ }^{\mathrm{s}}$ (assi) comparecieron en esta sala donde reside la R. ${ }^{\text {l }}$ (Real) Junta Municipal, d. ${ }^{\mathrm{n}}$ Juan de Alberro, y d. ${ }^{\mathrm{n}}$ Antonio Gonzales, de quienes el señor Presidente

Fólio 4602r.

de ella por ante mi el presente escrivano les recivio juramento, el que hicieron y celebraron por Dios nrõ (nuestro) Señor, y una señal de cruz según drõ, vaxo del qual prometieron desar fiel y legalm. ${ }^{\text {te }}$ el oficio de tasadores de los vienes que aparecen, no tasados por los Botanistas en este Ymbentario a todo su leal sav. ${ }^{\mathrm{r}}$ (saber) y entender, como hasi mismo a el arreglo de lo que se manda en el auto de quatro del que corre que antezede, Y lo fimõ (firmon) el q. ${ }^{\mathrm{e}}$ supo con dho Señor Presid. ${ }^{\text {te }}$ y por dho d. ${ }^{\mathrm{n}}$ Antonio Gonzalez, el theniente de Alguacil ma. ${ }^{\mathrm{r}}$ d. ${ }^{\mathrm{n}}$ Man. ${ }^{\mathrm{l}}$ de Soto, por ante mi

Fólio $4602 \mathrm{v}$.

de que doy fee $=$ Cayethano teran, y quebedo $=$ A rruego de d. ${ }^{\mathrm{n}}$ Antonio Gonz. ${ }^{\mathrm{z}}$

$\left(\right.$ Gonzalez) Manuel de Soto $=$ Juan del Alberro $=$ Ante mi Clem. ${ }^{\text {te }}$ Guerrero escrivano pp. ${ }^{\mathrm{co}} \mathrm{y}$ del numero

Yo el escriv. ${ }^{\circ}$ hize entrega de estos autos a los Tasadores nombrados para el efecto conthenido, y lo firme Guerrero escrivano publico

Los tasadores Nombrados à efecto del Conthenido en el auto provehido por los Señores de la Yt. ${ }^{\mathrm{e}}$ Junta municipal costha (RG) de quatro de Diciembre del año prox. ${ }^{\text {mo }}$ pasado de Setecientos Setenta y uno, que corre al folio setenta y nueve en conformidad delo en el pre-

Fólio 4603r.

venido, Pasamos à hazer la tasacion de los vienes conthenidos sin abaluo (avalúo ga.) (avaliação pt.), y à la suma y separacion de los efectos medicinales, y de mas vienes muebles que se hallan ya tasados, y con asistencia del Sargento ma. ${ }^{\mathrm{r}}$ de Ynfanteria d. ${ }^{\mathrm{n}}$ Fernando Fabro, procedimos al reconocimiento, y Abalico (relativo a avaliação) en la fmã siguiente

Primeram.te reconoci un cuerpo de estanteria alto que sirve en la Botica pintado de azul encarnado y dorado, y en el remate una cormisa (cornija) en la misma conformidad con 
quatro laminas de marco abaladas. Pintadas, y doradas segun y como consta del Ymbentario

de foxas 43 tasamos en quatrcientos pesos... D400. (fojas ga.)

Fólio 4603v.

Yt. reconocido el Segundo Cpõ que se halla ser del color de la madera con cinco orden. ${ }^{\mathrm{s}}$ de caxones, que componen el numero de 272 gabetas inclusive la Cajoneria del pie que se halla ser obra prolixa de bueltas, tasamos en ochocientos ang. ${ }^{\text {ta }}$ pesos... D850.

Yt. dos cenefas (cenephas vg.) de buelta doradas, que estan sné la Puerta de entrada y la ventana de la calle con sus Barillas de hierro y cortinas de Sarasa usadas, que tasamos en 40 p.s... D040.

Yt. una repisa ${ }^{241}$ pequeña dorada, que tasamos en dos pesos D002

Yt. un Mostrador de dos var.s de largo, una de alto, y ancho con siete caxones al

Suma $\mathrm{B}^{\mathrm{ta}}$

Fólio 4604r.

frente, y uno al respaldo con cerradura y llave que tasam.s en ochenta pesos...D080 Yt. otro dho pequeño que se halla al pie de la ventana para el pie de la ventana para el despacho a la calle, q.e tasamos en consideraz.n de su obra en quar. ${ }^{\text {ta }}$ (quarenta) pesos... D040.

Yt. dos Pilares de Nogal torneados arrimados al mostrador del despacho, que tasamos en cinco pesos... D005

Yt. un Banquito de pino viejo que tasamos en seis R.s... D000... 6

Yt. una caja de pino de vara y quarta de largo usada con su aldabon, que tasamos en veinte R.s... D002... 4

Yt. una Banquilla de dos pies de sentar piedras de moler que tasamos en Seis R.s... D000...6

Yt. una prehensa con su

Fólio 4604v.

Suma $\mathrm{B}^{\text {ta }}$

Barra y golilla ${ }^{242}$ de hierro de sacar Azeites en buiola en la Pared, que tasamos en veinte pesos... D020.

Yt. una Tinaja grande Sevilla vidriada, que tasaron mas en catorze pesos... D014.

Yt. un Mostrador en la truy Botica, segun y como consta de Ymbentàrio, que tasam.s en quarenta pesos... D040.

Yt. una escalerita pequena que tasamos en doze R.s.... D001...4

Yt. un Cajon de Pino, que tasamos en doze R.s ... D001...4

Yt. un cruzero de madera que tasamos en quatro r.s... D000...4

Yt. un usillo (GA husillo= fuso) de madera para Prehensa, que tasamos en dos pesos... D002

Yt. una caxa de vara, y quarta de largo, con cerra

Fólio 4605r.

Suma $\mathrm{B}^{\mathrm{ta}}$

dura y sin llave que tasaron en 8 pesos..... D008

\footnotetext{
241 “espécie de ménsula para sostener algún busto, vaso ú outro adorno.” (Picatoste, 1887: 908).

242 “adorno de cartón forrado de tafetán, etc., que hoy usan los togados.” (Ibíd: 547).
} 
Yt. otra dha nueva sin cerradura ni llave, que tasamos en 3 p.s 4 R.s .... D003...4

Yt. otra dha de poco mas de vara de largo con cerradura sin llabe, que tasamos en 6 p.s... D006

Yt. una arca viexa quebrada que tasamos en 12 r.s.... D001...4

Yt. un estante de 6 var.s de largo con 113 cajones, que tasamos en 130 pesos... D130.

Yt. una Papelerita de madera, con cerradura y sin llave que tasamos en quatro P.

...D004

Yt otra viexa sin tapa que tasamos en tres pesos... D003.

Yt. dhas pequeñas que tasam.s à dos pesos cada una... D004.

Yt. dos cajones grandes de Pino que tasamos sin tapa à peso cada uno... D002

Yt. tres arcas viejas, dos gran

Fólio 4605v.

$$
\mathrm{B}^{\mathrm{ta}} \ldots \ldots \ldots \ldots . . . . .
$$

des y una mediana, que tasamos en doze pesos... D012

Yt. una tabla de $4 \frac{1}{1} 2$ varas q.e tasaron en 3 p.s 4 r.s... D003...4

Yt. dos Puertas con sus vidrios que corresponden à las rinconeras ${ }^{243}$ de la Botica, que tasaron en ocho pesos... D008.

Yt. otras dos Puertas sin vidrios, que tasamos en 3 p.s... D003

Yt. un estante de cedro de dos varas de alto que tasamos en 16 p.s... D016

Yt. 6 caxones corridos de madera de cedro nuebos, que tasamos a 10 p.s cada uno... D060.

Yt. una arca de vara, y quarta viexa, que tasamos en ocho R.s... D001.

Yt. tres libros de lengua Alemana, en quarto, que no tasamos por falta de intelig.a D

Yt. una arca de madera

Suma $\mathrm{B}^{\text {ta }}$

Fólio 4606r.

de vara de largo dos tercias de alto, que pertenece a la rebotica, que tasamos en 9 p.s.... D009

Y respecto de no hallarse mas vienes muebles que tasar, quedo concluida esta tasacion la que emos hecho según nrõ (nuestro) leal sav. ${ }^{r}$ y entender, vaxo del xuram. ${ }^{\text {to }}$ (juramiento) que tenemos hecho. Cuia Tasaz. ${ }^{\mathrm{n}}$ según de muestra importa la cant. ${ }^{\mathrm{d}}$ (cantidad) de un mill setez. ${ }^{\mathrm{s}}$ Setenta y cinco pesos por lo respectivo à los vienes muebles que se nos mandaron Tasar que unida a la de ocho mill setez. ${ }^{\mathrm{s}}$ seis pesos tres, y quartillo $\mathrm{R} .{ }^{\mathrm{s}}$, que consta importar la tasacion que hicieron los Medicos d.n Ig. ${ }^{\circ}$ tolosa y d. ${ }^{\mathrm{n}} \mathrm{Juan}$ Joseph herrero asciende el valor total de la Botica à diez mill quatro cientos

Fólio 4606v. ochenta y nueve pesos tres y quartillo R. ${ }^{\mathrm{s}}$ de que se dieron por Satisthos (satisfechos) el Sarg. ${ }^{\text {to }}$ ma. ${ }^{\mathrm{r}}$ d. ${ }^{\mathrm{n}}$ Fernando Fabro, y el Boticario d. ${ }^{\mathrm{n}}$ Lorenzo Ynfante quienes Lo firmaron, y por no saber firmar el carpintero d. ${ }^{\mathrm{n}}$ Antonio Gonzalez, lo hizo a su ruego uno de los Tgos (testigos) que se hallaron presentes, que lo fueron d. ${ }^{\mathrm{n}}$ Mariano Vazquez, y d. ${ }^{\mathrm{n}}$ Thomas Lopez, en esta Cui. ${ }^{\mathrm{d}}$ de Cordoba en veinte y dos dias del mes de febrero,

243 “mesita triangular que se coloca en los rincones.” (Ibíd: 922). 
de mill setez.s Setenta y don (ilegível) Juan de Alberro = Fernando Fabro = Lorenzo Ynfante $=$ Arruego de d. ${ }^{\mathrm{n}}$ Antonio Gonz.z i por tgõ (testigo) Mariano Vazquez en la ciudad de Cor.d en veinte y tres dias del mes de Febrero de mill setez. ${ }^{\mathrm{s}}$ setenta y dos años Yo d. " Juan Alberro, en

Fólio 4607r.

presencia del Sargento ma. ${ }^{\mathrm{r}}$ de Ynfanteria d. ${ }^{\mathrm{n}}$ Fernando Fabro y de d. ${ }^{\mathrm{n}}$ Lorenzo Ynfante Boticario, en vrd (verdad) de la comision a mí conferida por los señores dela Jt. Junta municipal, precedi à entre sacar de los antezedentes Ymbentarios, y tasacion el valor de todos los muebles ex. ${ }^{\text {te }}$ de la Botica que constan en estos autos señalando cada partida al margen con una estrella como demuestran todas ellas, y examinadas con todas prolixiadas suman, y montan la cantidad de tres mill seiscientos ochenta y quatro pesos, tres R. ${ }^{\mathrm{s}}$ en cuia conformidad el valor liquido de los Medicamentos es el de seis mill òchenta cinco pesos, un quartillo de $\mathrm{P} .{ }^{\mathrm{s}}$ con lo que y ebaquada (evacuada ga.) esta diligencia, de buelvo los autos origin. ${ }^{\mathrm{s}}$

Fólio 4607v.

dhos señores de la muy Yt. ${ }^{\mathrm{e}}$ Junta municipal, y haviendo procedido solo de por mi à esta liquidaz. ${ }^{\mathrm{n}}$ por no saber ller el expresado d.n Antonio Gonzalez, lo firmaron con migo (comigo) los dhos señores d. ${ }^{\mathrm{n}}$ Fernando Fabro, y d. ${ }^{\mathrm{n}}$ Lorenzo Ynfante, i por ante tgõs (testigos) por òcupacion del unico escrivano en las mismas temporalidades $=$ Juan de Alberro $=$ Fernando Fabro $=$ Lorenzo Ynfante $=$ Tgõ Juan Baup. ${ }^{\text {ta }}$ (Bautista) Prieto $=$ Tgõ Mariano Vazquez

en la ciudad de cord. ${ }^{\mathrm{a}}$ en cinco de Marzo, de mill setez. ${ }^{\mathrm{s}}$ setenta y dos años estando en Junta los Señores que al presente la componen por las causas que se hallan acordadas se tudo pres. ${ }^{\text {te }}$ esta Tasacion, y mandaron q. ${ }^{\mathrm{e}}$ respecto de Harver falecido d. ${ }^{\mathrm{n}}$ Lorenzo orduña, y tener-

Fólio 4608r.

nombrado por acuerdo de este dia por Depositário de la Botica, y mueble Conthenidos a d. ${ }^{\mathrm{n}}$ Thomas Lopez Fernãnz (Fernandez) el Adm. ${ }^{\mathrm{r}}$ del colégio d. ${ }^{\mathrm{n}}$ Juan de Alberro, con el presente Css. ${ }^{\text {no }}$ à la Remocion de todos ellos entregando elos a el expresado d. ${ }^{\text {n }}$ Thomas, con arreglo à los Ymbentarios, y llamando Partida por Partida, y de lo q. ${ }^{\mathrm{e}}$ pudiese faltar se formara lista con intervez. ${ }^{\mathrm{n}}$ de d. ${ }^{\mathrm{n}}$ Yg. ${ }^{0}$ Tolosa facultativo, y Botanista, laq. (la qual) se agregara à estos Autos para prozeder contra los Vienes del finado, y fho corra todo env. ${ }^{\text {ta }}$ (vista) al Defensor Fiscal de temporalidades para que exponga lo que hallase por conve. ${ }^{\text {te }}$ (conveniente) y hasi se ara saver à unos y otros, y al Albazea, y viuda de dho Difunto Orduña, y lo

Fólio 4608v.

firmaron dhos Señores, por ante mi de que doy fee $=$ Teran $=$ Barzena $=$ Guerrero ass. ${ }^{\text {no }}$ pp. ${ }^{\mathrm{co}}$ en seis dias de dho mes, y año yo el th. ${ }^{\mathrm{e}}$ (tenente) de Alguacil ma. ${ }^{\mathrm{r}}$ y Portero de la Junta Municipal hize saber el auto que antezede a d. ${ }^{\mathrm{n}}$ Thomas Lopez, quien quedo enterado de su contexto y para que conste lo firme = Soto- en dho dia yo el th. ${ }^{\text {e de }} \mathrm{Alg}{ }^{.1}$ ma. ${ }^{r}$ u Portero de la Junta Municipal, hize saver el auto q. ${ }^{\mathrm{e}}$ antezede al Adm. ${ }^{\mathrm{r}}$ del colegio d. ${ }^{\mathrm{n}}$ Juan de Alberro- y para que conste lo firme = SotoYncontinenti, yo el th. ${ }^{\mathrm{e}}$ de Alguacil ma. ${ }^{\mathrm{r}}$ y Portero de la Junta Municipal, hize saver el auto que antezede ad. ${ }^{\mathrm{n}}$ Yg. ${ }^{\mathrm{o}}$ Tolosa, quien quedo enterado de su contexto. y 
Fólio 4609r.

para que conste lo firme

Soto

en la ciudad de Cod. ${ }^{a}$ en seis de dho mes, y año el Adm. ${ }^{r}$ del Colegio d. ${ }^{n}$ Juan de Alberro con d. ${ }^{\mathrm{n}}$ Thomas Lopez Fr'z (Fernandez) y assistencia de mi el presente escrivano, en conformidad del Decreto antezedente, theniendo presente los Autos de remocion de la Botica practicada que se deposito en d. ${ }^{\mathrm{n}}$ Lorenzo de orduña al pres. ${ }^{\text {te }}$ difunto, y de nuevo se mandaremo ver por dha causa en dho d. ${ }^{n}$ Thomas Lopez, quien hallandose presente haviendose principiado dha Remocion y llamandose Partida por Partida según consta de sus Ymbentarios se encontro estar todo con confré (conforme) a dhos Ymbentarios, de que quedo

Fólio 4609v.

satisfho (satisfecho) el referido d. ${ }^{\mathrm{n}}$ Thomas Lopez. Y en esta vrd (verdad) el dho d. ${ }^{\mathrm{n}}$ Juan de Alberro nombrado le hizo entrega de todo ello según y como se expresa, quien sedio por reciv. ${ }^{\text {do }}$ (recivido) à su entera satisfaccion y detenerla prontos a la disposicion de esta Junta municipal ò de otra Competente sin ocurrir con parte, ni el todo de ella a Persona alguna sin expreso mandato de dha Yt. ${ }^{\mathrm{e}}$ Junta, y en esta atencion no haviendo havido Falla alguna se omitio la concurrenz. ${ }^{a}$ de d. ${ }^{n}$ Yg. ${ }^{0}$ Tolosa Botanista nombrado. en cuia vrd (verdad) el exprado d. ${ }^{\mathrm{n}}$ Thomas Lopez dixo, que no se obligava a nada de aquello que tiene

Fólio 4610r.

Coruccíon ni mermas por ser estos unos casos Fortuytos à que ninguno se puede òbligar y en esta atencion se de por libre à d. ${ }^{\mathrm{a}}$ Maria Rosa Lopez su hija, y esposa de dho d. ${ }^{\mathrm{n}}$ Lorenzo de Orduña difunto respecto à haverse hecho cargo de dha Botica, y sus muebles el conthenido d. ${ }^{\mathrm{n}}$ Thomas Lopez, y lo firmaron con dho adm. ${ }^{\mathrm{r}}$ d. ${ }^{\mathrm{n}} \mathrm{Juan}$ de Alberro, por ante mi el presente escrivano de que doy fee $=$ Juan de Alberro $=$ Thomas Lopez Fernãnz $=$ Ante mi clemente Guerrero escrivano pp. ${ }^{\mathrm{co}} \mathrm{y}$ del Num ${ }^{0}{ }_{-}$ Yo el escrivano en conform. ${ }^{\mathrm{d}}$ de lo acordado por los señores de esta Jt. ${ }^{\mathrm{e}}$ Junta Municipal en que ordenan dhos Señores se satisfagan las costas causa

Fólio 4610v.

das a los Comisionados nombrados para la remocion de los vienes secuestrados a los

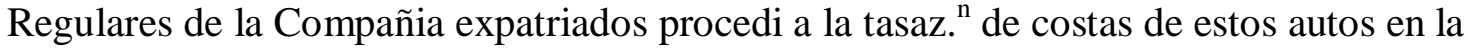
forma siguiente

Primeram. ${ }^{\text {te }} \mathrm{a} \mathrm{d} .{ }^{\mathrm{n}}$ Fernando de Arze, y Bustillos, comisionado que fue para la remocion de la Botica, por siete dias de ocupacion a quatro pesos dia entero. Y quatro medio dias a dos pesos.... D036.

Yt. a d. ${ }^{\mathrm{n}}$ Juan de Alberro por la tasacion y liquidaz. ${ }^{\text {n } q u e ~ d e ~ o r n ̃ ~(o r d e n o u) ~ d e ~ d h o s ~}$ señores hizo, se le asignan doze ep. ${ }^{\mathrm{s}}$ que se regulan por su travaxo (trabajo ga.)...D012 Yt. à el mro de Carpintero d. ${ }^{\mathrm{n}}$ Antonio Gonz. ${ }^{\mathrm{z}}$ hasi mismo Tasador Nombrado para los Trastes de

Fólio 4611r. madera de dha Botica sus estantes, y mostradores se le regula por su Trabajo...D008 Por esta Tasacion que deveran abonar las partes tres pesos, Demanera que según pareze importa esta tasacion Cinquenta y seis pesos (Salvo hierro) la que tengo hecha arreglada 
al R. ${ }^{l}$ Aranzel Practica, y costumbre de esta cuidad, y en su conform. ${ }^{\mathrm{d}}$ la presentò à los Señores de dha Yt. ${ }^{\mathrm{e}}$ Junta para q. ${ }^{\mathrm{e}}$ en su v. ${ }^{\text {ta }}$ provean sus Señorias lo que fuese de su agrado, y lo firmè en cord. ${ }^{\mathrm{a}}$ a diez y ocho de Marzo de mill setez. ${ }^{\mathrm{s}}$ setenta y dos sa. ${ }^{\mathrm{s}}$ Clemente Guerrero ess. (escrivano) publico, y del num. ${ }^{\circ}{ }_{-}$Cord. $^{\text {a }}$ quatro de Abril de

Fólio 4611v.

mill setez. ${ }^{\mathrm{s}}$ Setenta y dos; $\mathrm{v} .{ }^{\text {ta }}$ la tasacion antezedente se à prueva por ser hecha conforme al R. ${ }^{l}$ Aranzel respecto a que por acuerdo cebrado en Junta Completa el dia veinte de Sep. ${ }^{e}$ (septiembre) del año prox. ${ }^{\text {mo }}$ pasado, se mando pagar a todos los Ynteresados el travaxo impendido por cada uno en ser. ${ }^{0}$ de las Temporalidades: Librese à favor de los Sugetos nominados en dha Tasacion la cant. ${ }^{\mathrm{d}}$ que a cada uno corresponde, dexando $\mathrm{R}^{\mathrm{uo}}$ de dho libram. ${ }^{\text {to }}$ cada uno, y asi se anote por el escriv. ${ }^{\circ}$ De que hasi lo proveyeron y firmaron los Señores de que al presente se compone este Jt. ${ }^{\mathrm{e}}$ Junta Municipal de que doy fee $=$ Teran $=$ Bar

Fólio 4612r. zena $=$ Ante mi Guerrero escrivano publico $=$ Nota $=$ se entregò a d. ${ }^{\mathrm{n}}$ Juan de Alberro libramiento de que no lo recivio de doze pesos que pareze le pertenecen de esta tasacion junto con otras que le tocaron. Y para que conste se anota = Guerrero esc. ${ }^{\text {no }}$ publico -

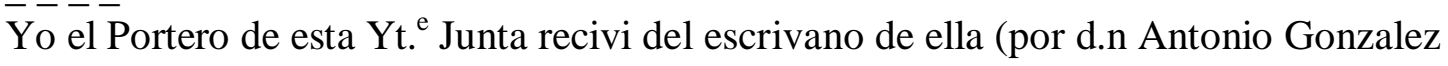
Maestro de carpinteria, y tasador nombrado) un libramiento de cantidad de ocho pesos dado por el señor Presidente de esta Junta por el Travaxo que impendio, que por no saber firmar dho Gonzalez me rogo lo hiciese por el = Guerrero Manuel de Bto _ Nota: Se advierte que el Libram. ${ }^{\text {to }}$ que se dice haverseles entregado

Fólio 4612v.

a d. ${ }^{\mathrm{n}}$ Juan de Alberro de cantidad de doce pesos no lo admitio por decir no corresponder al travaxo que impendio hasi en la tasacion de muebles, y liquidacion de Sumas de las drogas de Botica como de todo lo demas que se hallarà practico. Y para que conste en todo tiempo se anota Guerrero escrivano pp. ${ }^{\mathrm{co}}$

Señores ${ }^{244}$ muy Yt. ${ }^{\mathrm{e}}$ Junta Municipal Dr. Juan Asensio de la concepcion del Sagrado Orñ (Ordem) Belehermitica, y Presidente de esta nueva fundacion Hospitalaria puesto a los Pies de sus Señorias con el devido acatamiento dize que es llegado a su noticia que en las colecciones de las Providencias Tomadas por S. M. (Su Magestad) para la ocupacion de los vienes

Fólio 4613r.

de las Temporalidades de los Jesuytas espatriados se halla una cedula en que S. M. se sirve mandar se apliquen las Boticas a los Hospitales, y casas de Misericordia por lo qual no parezera extraño que por parte de los Pobres enfermos de esta Cui. ${ }^{\mathrm{d}}$ se haga instanz. ${ }^{\text {a }}$ a que se consiga este favor hecho por la R. ${ }^{\text {l }}$ piedad, aun antes de tratado del

\footnotetext{
${ }^{244}$ No inventário de 1771-1772, do lado esquerdo da palavra Señores, encontramos a seguinte nota, escrita com letra diferente daquela do restante do texto:

"Pedim.to (pedimiento) ocl (ver) Preci

d.te oclos (ver) PP. Bethe

lemitas $=$ “
} 
repartimiento de dhos vienes pues es constante que atendiendo a la R. ${ }^{1}$ vonluntad al socorro de la mas urgente necesidad de sus Pobres vasallos, que estos vienen por lo comun son tan contingente quanto la asistencia de su corta duraz.n en el estado de poder servir, que em pocos dias seven reduciolos muchos simples y compuestos a ningun provecho, por la

Fólio 4613v.

facilidad de su corruccion causas que sin duda se tubieron presentes por la R. ${ }^{l}$ Piedad para no esperar el orden de las demas aplicaciones, cuia dificultad no tubo presente el Procurador Gral (geral) de la ciudad para ceñir su dictamen en la determinacion de las casas del Noviciado al orñ (Ordem) que se prescrive a las Juntas Generales y subalternas mandadas crear para el repartimiento, pues es constante que de agoardar a estas creaciones en ese interin hera preciso perderse muchos vienes, que disponiendo de ellos en tiempo oportuno se pudieran Lograr, y no lloraser tal vez ynutilm. ${ }^{\text {te }}$ perdidos, por cuias Razones sin duda acordo esta Junta

Fólio 4614r.

Municipal se aplicase la Botica a este hospital por ser la unica casa de misericordia que existe en esta cuidad, y vasta Provincia, con el cargo de que los Botes, medicinas y demas vienes que pertenezen a la Botica se tasen y que entregado à este hospital de todos ellos por la tasacion que se hiciese que en caso de que la Junta Gral de Repartimientos hallase dificultad en aplicarla à este hospital en este caso se obligase a bolver à aquellos Simples que se huvieren recivido, o de mas muebles de Botica seg. ${ }^{\mathrm{n}} \mathrm{y}$ conforme se recivieron y en su defecto el equivalente em plata por la tasacion no est. ${ }^{\text {do }}$ separado este Hospital de recevir la Botica con esta obligaz. ${ }^{\mathrm{n}}$

Fólio 4614v.

pareze obligada esta Y. ${ }^{\mathrm{e}}$ Junta a no Ynobar en lo ya acordado hasi por las razones espuestas como por no oponerse a esta Resolucion en manera alguna a lo que S. M. previene haverse resuelto por V. S. el que se entregase a este Hospital la casa del Noviciado con esta misma condicion y calidad fue sin duda por que de esta resolucion se sigue el veneficio y seguridad de los vienes que se entregan, evitando por este medio su total ruina, como experimentò en la que padecio esta causa desde el tiempo del extrañamiento htã el presente, y que en caso de querer conservar como htã aqui hera como preciso fuese en aumento el perruicio militar do las mismas razones, y aun

Fólio 4615r.

mas poderosas en orñ a la Botica pueses preciso que en el corto tiempo que ha corrido de la remocion de ella se hallen ya disminuidos y corrompidos algunos simples, $\mathrm{y}$ compuestos de pronto despacho y sin fruto. la tasacion que de ellos se hizo aumentandose cada dia mas este perruicio, quanto fuese la demora de ponerlo en uso estas razones le parecio preciso à este Hospital traerlas presentes a la alta comprehez. ${ }^{\text {n }}$ delos para que no sedifiera por mas tpõ (tiempo) la entrega, por resultar de su demora emperr.o de los R.s haverse aun en caso de que no se deva dar al Hospital, pues ademas desde que se empezaron a remober las estancias, y esclabor de ellas con expecial cuidado se an curado en este Hospital los esclabos de S. M. que Dios Guarde

Fólio 4615v. 
que a el an venido, como hasi mismo despachado las recetas que para ellos sean dado fuera del Hospital, y assi mismo ministrado los Medicamentos que sean pedido para dhas estnz. ${ }^{\mathrm{s}}$ aun sin recibir el veneficio que solicitava esta provre fundacion, ni pedir por ello paga alguna, por esta razon no deveran los señores de la Y. ${ }^{\mathrm{e}}$ Junta recelar que en adelante con igual cuidado se les ministren los Medicam. ${ }^{\text {tos }}$ a los Esclabos que quedan el el serv. ${ }^{\circ}$ de S. M. y la caridad de servirlos en el hospital esprè (esperan) que a el vengan, por cuia razon no se podra decir que la Botica se ha preciso conserbarla en administraz. ${ }^{\mathrm{n}}$ para remedio de los esclabos, que quedasen à falta de facultativos y fiadores para à segurar el valor de ella, y sus Contingencias

Fólio 4616r. es otro escollo en que es preciso reporela $\mathrm{Y}^{\text {tre }}$ Junta, pues no solo pide la administracion de Botica todos estos seguros, sino que se necesita facultad R. ${ }^{1}$ para abrirla, y administrarla de la que absolutam. ${ }^{\text {te }}$ se careze, sin que la tenga òtra persona fuera de mi sagrada orñ, y este hospital, y como el que administrase Botica devesen facultativo aprovado por tal, y con expresa liz. a por lo delicado de su manejo no conciliando estas $\mathrm{R}^{\mathrm{s}}$ disposiciones con las que quedan para el repartim. ${ }^{\text {to }} \mathrm{y}$ no hallando violencia, para conciliarlas con la pretens.n que se hace pues quando no estubiera tan clara y manifiesta la voluntad de nrõ (nuestro) monarca, y por consiguiente tan manifiesta la necesidad de los Pobres de este hospital, pues el corto prãl

Fólio 4616v.

q. ${ }^{\mathrm{e}}$ se asigno por el M. ${ }^{\mathrm{mo}}$ s. $^{\mathrm{r}} \mathrm{d}^{\mathrm{n}}{ }^{\mathrm{P}}{ }^{\mathrm{n}}{ }^{\mathrm{n}}$ Diego salguero de cabrera, aun se halla sin libre uso, y el nobeno y medio mal satisfho (satisfecho), y la corta renta del hospital viejo de santa eulalla tan desninuida que no llega a doscientos pesos al año, por cuia raz. ${ }^{n}$ los Blehemitas, a cuio cuidado se sirvio S. M. poner los Pobres Enfermos, lloravan continuam. ${ }^{\text {te }}$ srè ellos por no poderlos asistir con el amor, y amplitud que les previene su Ynstituto y con el qual no cumpliran sien esta ocasión se desentendieran del vafor Caridad que nrõ monarca desea se verifique en sus Pobres vasallos, y expecialm. ${ }^{\text {te }}$ en los Nrãles de los Lugares donde son las adquisiones que se mandan repartir a las Yglesias, y siendo las primeras colugnas de los Templos los Pobres enfermos espera

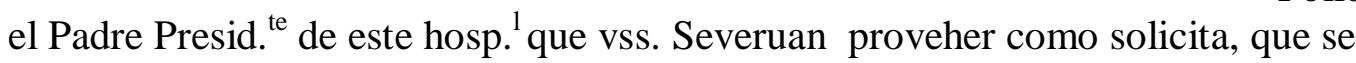
Fólio 4617r. entregue la Botica con el cargo que està acordado por resultar de aqui habien de la causa publica, con el socorro de los miseros enfermos y en seguridad de estos viernes en caso de no haverse de aplicar como se pretende, por lo qual ass, pude y suplica se sirva proveer como aqui se contiene, que es favor que espera recibir de la poderosa mano de vga $=$ Yr. Juan Asenio de la concepz. ${ }^{\mathrm{n}}$ cord. ${ }^{\mathrm{a}} \mathrm{y}$ diz. ${ }^{\mathrm{e}}$ veinte y tres de mil setecientos, setenta y uno. Porpres. ${ }^{\text {da }}$ y para proveer corra en v. ${ }^{\text {ta }}$ al defensor Fiscal, y con lo que dizese autos. Hasi lo proveyeron y lo firmaron los señores de esta Y. ${ }^{\text {te }}$ Junta municipal de temporalidades por ante mi el presente ess. ${ }^{\text {no }}$ de que doy fee $=$ Teran $=d .{ }^{\mathrm{n}}$ Sarmto $=$ Barzena $=$ Montenegro $=$

Fólio 4617v.

Ante mi Guerrero escrivano publico

en dho dia, yo el escrivano di env. ${ }^{\text {ta }}$ este expediente al defensor fiscal de temporalidades Y lo firme Guerrero escrivano $\mathrm{pp}^{\text {co }}{ }_{---}$ 
Señores de la Junta Municipal el defensor fiscal env. ${ }^{\text {ta }}$ de la pretension del R. ${ }^{\text {mo }}$ Padre Fr. Juan Asensio de la concepz. ${ }^{\mathrm{n}}$ Presidente de esta nueva fundaz.n de Hospitalidad dize, que aunq. ${ }^{\mathrm{e}}$ esta Junta Municipal no es Junta de aplicaciones pero las drogas y demas utensilios de Botica que el Suplicante pretende son vienes aplicables, y de los Comprehendidos en el Predicamento de vacantes por los Pios destinos a que los tiene aplicados la R. ${ }^{\text {l }}$ piedad seg. ${ }^{n}$ se expresa en las R. ${ }^{\mathrm{s}}$ Pragmaticas conthenidas en la coleccion grãl, y siendo uno de los pios establecimientos la subsistencia

Fólio 4618r.

de los Hospitales por el fomento que en ellos logran los miserables enfermos, a cuio

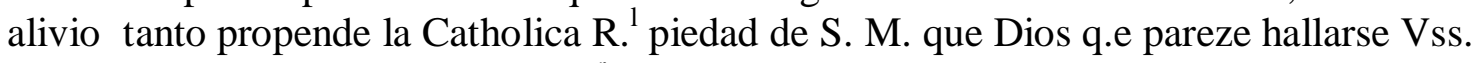
En la precion de aderir a la pretens. ${ }^{\mathrm{r}}$ de Suplicante pues ademas de que con esta resolucion no se perxudica (prejudica ga.) la privativa xurisdicion de las Junta de aplicaciones se livertan aquellos muebles de las contingencias, y perdidas à que por su naturaleza estan expuestos pero siempre convendra que recivido el suplicante de la dha Botica que dè con el grava mende subministrar los remedios a los esclabos de temporalidades y asistir à sus curaciones sim perjuicio del prãl que reciviese durante la resolucion de la Junta Superior de aplicaciones, que es quanto a veneficio de la Re

Fólio 4618v.

publica, y para el Cumplim. ${ }^{\text {to }}$ de las Piadosas R. ${ }^{\mathrm{s}}$, intenciones debe el defensor exponer. Cord. ${ }^{\text {a }}$ y Marzo veinte y tres, de mill setez. ${ }^{\mathrm{s}}$ setenta y dos $=$ Juan Tiburcio del ordoñes =

Cord. $^{\bar{a}}$ quatro de Abril de mill setecientos setenta y dos. Por respondido Autos. hasi lo proveyeron mandaron, y firmar. ${ }^{\mathrm{n}}$ los Señores de que al presente componen la y. ${ }^{\mathrm{e}}$ Junta municip. ${ }^{1}$ de que doy fee $=$ Teran $=$ Barzena $=$ Ante mi Guerrero escrivano publico $\mathrm{Y}$ vistos con el Ymbentario, remocion y tasacion de la Botica que fue delos regulares expatriados y que su tasacion hasi de simples y drogas con los estantes y demas aperos pertenecientes à ella in portan la cant. ${ }^{d}$ de diez mill quatrocientos ochenta y un pesos tres y quartillo R. ${ }^{\mathrm{s}}$ la

Fólio 4619r.

representar. ${ }^{\mathrm{n}}$ hecha por el Rmo Padre Yr. Juan Asensio de la concepcion lo respondido por el defensor fiscal a la v. ${ }^{\text {ta }}$ que se le dio, el acuerdo de Veinte de febrero, del año pasado de setez. Setenta y uno, celebrado en Junta completa, con asistenz. ${ }^{\text {a }}$ del Jt. ${ }^{\text {mo }}$ señor obispo que fue de esta Prv. ${ }^{\mathrm{a}} \mathrm{d} .^{\mathrm{r}}{ }^{\mathrm{d}} .^{\mathrm{n}}$ Manuel Aba Y Llana, en que se resolvio se hicie se la entrega de dha Botica, sus muebles y omènaxes (homenagens) al expresado R. ${ }^{\text {do }}$ Padre, como a Presidente del Hospicio de Bethemitas no haverse executado en tan largo tiempo por aquellos Yndividuos que en consideracion à que se pueden perder su simples y compuestos con las de mas razones que se tubieron presentes, en otro acuerdo de esta fha, y expecialm.te la de no residir facultad para hacer

Fólio 4619v.

aplicación alguna por ser reservada a a Superior junta provincial de Buenos Ayres ò a la que se crease por $\mathrm{S}$. M. se le Notifique al Srè dho $\mathrm{R}^{\text {do }}$ Padre que siempre que de com parecer con su comunidad se conbengan y obliguen los Juros y rentas, a que entregandos elas los. Conthenidos muebles simples compuestos, y drogas los reciviran por el precio de su abaluo (RG), y que los dhos simples compuestos, y drogas los 
pararan em plata sellada cada y quando que S. M. la dha Superior Junta Prov. ${ }^{1}$ à la de aplicaciones se lo mandase y todos los demas muebles los bolveran por la estimacion, $\mathrm{y}$ aprecio que entonzes tuviesen y abonaran hasi mismo en plata la quiebra à diferencia que hubiese, y hasimismo que sin desquento alguno

Fólio 4620r.

estipendo algume curacion ${ }^{245}$ y pondran los medicamentos nezesarios para el auxilio de los esclabos del Ramo de temporalidades se halle por conveniente el que se les de, y entregue por el dho Ymbentario, y tasacion haciendo se el respectivo Ynforme para ello a la referida Junta Superior con Aestim. ${ }^{\circ}$ del Tratado de que se hace mencion deviendose esperar para que se execute su aprovacion, y hasi se les ara saber a dho $\mathrm{R}^{\mathrm{do}}$ Padre, $\mathrm{y}$ a el defensor fiscal $=$ Teran = Barzena: Proveyeron mandaron y firmaron lo desuso los Señores d. ${ }^{\mathrm{n}}$ Cayethano Teran Quebedo, Comisionado y Presidentes de esta Y. ${ }^{\mathrm{e}}$ Junta Municipal de temporalidades, y Juez pribatibo en lo que contencioso de ellas y d. ${ }^{\mathrm{n}}$ Juan Antonio de la Barzena Alferez Rl Prexidon

Fólio 4620v. de cano, y disputado nombrado por el Y. ${ }^{\text {e }}$ cavildo, unicos vocales de que al presente se compone dha Y. ${ }^{\mathrm{e}}$ Junta, por las causas que constan acordadas, en Cord. ${ }^{\mathrm{a}}$ en ocho de Mayo de mill setecientos setenta y dos años, por ante mi de que doy fee $=$ Clemente Guerrero escrivano pp. ${ }^{\mathrm{co}} \mathrm{y}$ del Numero

en dho dia Yo el Portero de la Junta Municipal notifique ò hize saber el auto que antezede al R. ${ }^{\text {do }}$ Padre Presidente fr. Juan Asensio de la concepcion, qui en enterado de su contexto dixo, que esta pronto a cumplir todas las condiciones de el auto entregandos ele la Botica en el dia presente, por que de haver de esperar la aprovaz. ${ }^{\text {n de la Junta }}$ Prov. ${ }^{\mathrm{s}}$ se experimentaran mu

Fólio 4621r. chos perxuicio en la demora ademas de los que puedan haver padecido que no puede òbligar a los Pobres este patente gravam y no efectuandose como pide se le de un testimonio para òcurrir por su mano a la dha Junta Provincial sin que por este se entienda el que sedere de atender a la cura de los esclabos de temporalidades como hta qui, y esto dio por respuesta, y lo firmò conmigo $=$ Fr. Juan Asensio de la Concepz. ${ }^{\mathrm{n}}=$ Manuel de Soto

Cord. ${ }^{\text {a }}$ nueve de Mayo de mill setecientos setenta y dos los s. ${ }^{\text {rer }}$ de la Y. ${ }^{\text {e Junta }}$ Municipal hav. ${ }^{\text {do }}$ visto la respuesta antezedente dada por el R. ${ }^{\text {do }}$ Padre Fr. Juan Asensio de la concepz. ${ }^{\mathrm{n}}$ mandaron se agregase a los autos, $\mathrm{y}$ lo firmaron de que doy fee $=$ Teran $=$ Barzena $=$

Ante mi Guerrero escriv. ${ }^{\circ}$ publico

Fólio 4621v.

Señores de la muy Yt. ${ }^{\mathrm{e}}$ Junta municipal. yr Juan Asensio de la concepcion del Sagrado orn Vetlhemetico, y actual Presidente y Procurador de esta nueva fundacion Hospitalaria, como mas havia lugar en drõ ante V. S. parezco y digo, que ayer ocho del corriente se me hizo saber un auto srè y en razon de la inst. ${ }^{\text {a }}$ que sigo para que se entregue a este Hospital la Botica y sus equipaxe que fue de los regulares de la

\footnotetext{
${ }^{245}$ No documento original, a palavra curacion foi escrita exatamente acima da palavra alguno que se encontra riscada.
} 
Compañia, aconseg. ${ }^{a}$ de ser la unica causa de misericord. ${ }^{a}$ y en donde se socorren, y auxilian a los Pobres con el esmero que el Notorio, suponiendo que la piedad de nrõ Soverano lo tendria avien, segun lo tubo y prescrivio por ordenes circulares para q. hasi se executase

Fólio 4622r.

con todas las demas quese secuestraron en sus dominios adhos Regulares, y asin que de pronto espuse la condicion de q. ${ }^{\mathrm{e}}$ precisamente se me hiciere dha entrega de pronto, y executandose hasi aceptava las demas expresadas en dho auto, Mas como haviendo consultado este grande negocio con mis Compañeros Religiosos, y por consig. ${ }^{\text {te }}$ las dificultades que puedan ofrecerse a VSS. Para condescender a dha condicion, por la que tiene exp. ${ }^{\text {to }}$ en el referido auto, hemos hallado por conveniente, a veneficio de los Pobres, el revocarla, como la revoco en su nrè, y en vrd de ello sean de servir VSS. ha ver por azeptadas en todo, y por todo llanamente todas las que se expresan en el referido auto, y en su vrd. Sean de servir VSS. Simperdida de Apõ

Fólio 4622v.

mandar despachar Testim. ${ }^{\circ}$ de los dos acuerdos que se citan a la Superior Junta Provinz. ${ }^{1}$ haz.do el Ynforme que pide la equidad y justicia en consideraz. ${ }^{\mathrm{n}}$ de las piadosas intenz. ${ }^{\mathrm{s}}$ de S. M. y de lo recomendavle que es por las leyes de mi presentacion, por loq. ${ }^{\mathrm{i}}$ a V.SS. pido y suplico se sirvan de proveer como aqui se contiene, en que reciviran los Pobres Caridad, y just.a y para ello Ha Yr. Juan Asensio de la concepz ${ }^{n}$ en la ciudad de Cord. ${ }^{a}$ en onze dias del mes de Mayo de mill setecientos setenta y dos años ante los señores que al presente componen las $\mathrm{Y}^{\mathrm{e}}$. Junta municipal de temporalidades, se presentò esta peticion por mano del R. ${ }^{\text {do }}$ pe fr. Juan Asensio de la concepz. ${ }^{n}$ superior, y Presidente del Hospicio de Religiosos Betlemitas y los dhos señores haviendo

Fólio 4623r. tenido presente el acuerdo, y auto de ocho del corriente, y lo respondido por dho $\mathrm{R}^{\text {do }}$ Padre em la notificacion que se le hizo con lo nuevamente expuesto em que se conviene à azeytar las condiciones contheniolas en dho auto, dixeron que seguarde y cumpla en todo y por todo, y lo firmaron por ante mi el presente escrivano de que doy fee $=$ Teran $=$ Barzena $=$ Antemi Guerrero escrivano pp. ${ }^{\mathrm{co}}-\ldots---$

en dho dia Yo el Portero de la Junta municipal hice saver el Decreto que antezede al $\mathrm{R} .{ }^{\text {do }}$ Padre Presidente fr. Juan Asensio de la concepicion, quien dixo que se conformava, como lo tiene expuesto, $\mathrm{y}$ lo firmo conmigo $=$ fr. Juan Asensio de la concepcion $=$ Manuel de Soto

en la cuidad de Cord. ${ }^{\bar{a}}$ en veinte y siete de Junio de mil Setez. Setenta y dos años, los señores d. ${ }^{\mathrm{r}}$ d. ${ }^{\mathrm{n}}$ Joseph

Fólio 4623v.

Luis cabral, abogado de la $\mathrm{R}^{\mathrm{l}}$ aud. ${ }^{\mathrm{a}}$ del districto, comissionado, y Presidente de esta municipal Junta de temporalidades, y Juez privatibo srè lo contencioso de ellas, el d. ${ }^{\mathrm{r}} \mathrm{d} .{ }^{\mathrm{n}}$ Joseph Xavier Sarmiento ss. ${ }^{\text {Rio }}$ de la unibersidad de Monserrat cura Reptor de esta s. ${ }^{\text {ta }}$ Yg. ${ }^{\text {a }}$ cathodral, y diputado nuevam. ${ }^{\text {te }}$ nombrado por el señor Provisor Viscario Grãl, y Govern. ${ }^{\text {or }}$ del obispado el Mrè de campo d. ${ }^{n}$ Gregorio de Arrascaetal, Alcalde hord. ${ }^{\circ}$ de primer voto y Diputado nombrado por el Yt. ${ }^{\mathrm{e}}$ cavildo, y d. ${ }^{\mathrm{n}}$ Blas Yoachin de Crisuela, Procurador Grãl estando en su sala de acuerdo el dho señor Prõr Grãl propuso a los 
demas señores de esta Junta, se tuviesen presentes y se reconociesen por su señorías estos autos expecialm.te ${ }^{\text {te }}$ los que contienen la inst. ${ }^{\text {a }}$ hecha por parte de los Padres Betlehemitas

Fólio 4624r. para q. ${ }^{\text {e }}$ se les entregue la Botica interinariam. ${ }^{\text {te }}$ y haviendose trahido a la v. ${ }^{\text {ta }}$ estos dhos autos fueron reconocidas por lo Señores y en su intelig. ${ }^{a}$ represento dho señor Procurador Grãl que uno de los fundamentos propuestos a S. M. por parte del Yt. ${ }^{\text {mo }}$ S. $^{\mathrm{r}}$ d. ${ }^{\mathrm{n}}$ Diego Salguero de Cabrera para la fundacion del Hospital encarg. ${ }^{\text {do }}$ a los Padres Betlehemitas fue entre otros fondos la Botica correspondiente y suficiente para su ministerio como en realidade lo verifico en la que tienen administrando dhos Padres en quienes sea reconocido la mas tirana distribucion de las Medicinas desde que la Botica de temporalidades esta suspensa por hallarse depositada, y enzerrada em cuio tempo am pedido dhos Padres incomparavlem. ${ }^{\text {te }}$ mas caro por dhas medicinas de lo que antes

Fólio 4624v.

las vendian con el perxuicio pp. ${ }^{\mathrm{co}}$ de no querer vender à las Personas que tienen por desafectas, ni providenciar las Prezetas de los Medicos que no sean sus aderidos com gravissimos perjuicios públicos que esta pronto axustificar spre (sempre) que fuese nezesario, notando-se la obrreccion, y subrreccion conq. ${ }^{\mathrm{e}}$ el Padre Presidente de dhos Religiosos afirma en su resp. ${ }^{\text {ta }}$ de foxas (fojas) ochenta y dos, haver assistido a los Esclabos, pertenez. ${ }^{\text {tes }}$ à estas temporalidades en sus enfermidades quando estos corrieron al cuidado de d. ${ }^{\mathrm{n}}$ Lorenzo Ynfante, y de d. ${ }^{\mathrm{n}} \mathrm{Yg} .{ }^{\mathrm{O}}$ Tolosa, sugetos inteligentes en la Medicina que an curado publicamente en esta cuidad con las medicinas de la Botica de temporalidades todo lo qual ynduze uma evid. ${ }^{\text {te }}$ persuasion que si los Citados

Fólio 4625r.

Padres tomasen en si dha Botica tiranizarian al pp. ${ }^{\text {co }}$ revendiendo encareciendo mas i mas las medicinas, y negando estas a los que no contribuien a sus Ydeas, pretendendo tener em subordinacion al vecindario para la condescendiencia de sus fines particulares, y para q. ${ }^{\mathrm{e}}$ se eviten inconven. ${ }^{\text {tes }}$ pp. ${ }^{\text {cos }}$ contradize el Procurador Grãl la pretens. ${ }^{\mathrm{n}}$ de los Religiosos em aquella via que mas huviere lug. ${ }^{\mathrm{r}}$ y em atenz. ${ }^{\mathrm{n}}$ a que la Catholica y R. ${ }^{\mathrm{l}}$ piedad de S. M. encarga la causa pp.ca como ojebro de su real aprecio siendo la yndig. ${ }^{\text {a }}$ a de esta cuidad urgente por no tener de donde se le subministre a sus Avitadores lo preciso p. ${ }^{\mathrm{a}}$ el alivio y curacion de las $n .{ }^{\mathrm{s}}$ enfermidades. Pide dha Cui. ${ }^{\mathrm{d}}$ se administre la Suso dha Botica en los propios Terminos

Fólio 4625v. que antes estava para que todos igualm. ${ }^{\text {te }}$ disfruten este veneficio, y que la propiedad, siendo del Supremo y R. agrado de la R. ${ }^{\mathrm{l}}$ Mag. ${ }^{\mathrm{d}} \mathrm{y}$ de la justificada conmiseracion de la Y. ${ }^{\text {e }}$ Superior Junta Prov'l se le aplique a esta cuidad para los piadosos fines que S. M. delivere, por no tener propios Suficientes $p .{ }^{\mathrm{a}}$ las necessidades pp. ${ }^{\text {cas }}$ en la falta de casa de cavildo, y de carzeles seguras, por cuio defecto continuam. ${ }^{\text {te }}$ hazen fuga los Reos con agravio y escandalo de la vindicta, con òtras mas nezesidades de igual òbligacion, y haviendo fructificado esta dhas cuidad y su jurisdicion las quantiosas temporalidades que se secuestraron a los Padres expulsos pareze que de Xust. ${ }^{a}$ mereze dha cuidad se le subsidie com dha Botica maior. ${ }^{\text {te }}$ 
siendo hasi conforme a las veneficas ydeas de S. M. sin que puedan Embarazarlo las propuestas admitiolas por dhos Religiosos, hasi por que de este modo tanv. " (também) se verificarian como por que se deve atender a el maiorv. ${ }^{\mathrm{n}}$ de dha cuidad, y a evitar los perxuicios públicos a que sin la menor duda se expondria con la experienz. a de lo que lleva representado, y pide dho s. ${ }^{r}$ Procurador Grãl, se le haga asi presente a la Superior Junta Prov. ${ }^{l}$ para los efectos que lleva deducidos em cuia $v .^{\text {ta }}$ acordaron los señores que atendiendo a los fundam. ${ }^{\text {tos }}$ que tiene deducidos el señor Procurador Grãl, a los ynconvenientes que experimentaria el pp. ${ }^{\mathrm{co}}$ em el caso de entregarse la Botica a los Padres Betlehemitas, por las

Fólio 4626v. mismas razones que expone y a que se hallan cerciorados de que dhos Religiosos tienen formalizada supretens. ${ }^{\mathrm{r}}$ ante los señores de la Superior Junta Prov. ${ }^{l}$ de Buenos Ayres, y ultimam. ${ }^{\text {te }}$ à el eminente riesgo de perderse dhos medicamentos, por no haver sugeto de intelig. ${ }^{\text {a }}$ y seguridade que la administre, por quenta de S. M. pues los unicos Botanistas que ay en esta son de ningun abono se remitiese testim. ${ }^{\circ}$ de dho expediente, y este Acuerdo a dha superior Junta acompañandole el correspond. ${ }^{\text {te }}$ ynforme por parte del señor Presidente para que Ynspeccion. ${ }^{\text {do }}$ delivere lo que conzeptuarse mais conveniente a veneficio del publico y seguridade de dhas espécies, y que hasimismo

Fólio 4627r.

se remita los treinta tomos enquarto, y mas medianos escritos en lengua Alemana que no están tasados por falta de Intelig. ${ }^{a}$ haciendose saver igualmente al sargento ma. ${ }^{r}$ d. ${ }^{n}$ Fernando Fabro presente laquenta, y razon jurada que deve aber tomado à d. ${ }^{\mathrm{n}}$ Lorenzo Ynfante del tiempo que tubo em Administraz. ${ }^{\text {n }}$ dha oficina, notificando-se a estes que en el entre tanto no se liquide dha quenta, no salga de estas cuidad, en sus Pies ni en los agenos (ajeno ga.), vaxo la pena de doscientos pesos en que se le declararà incurso por la mas leve contravencion, o desovediencia, y lo firmaron dhos señores ante mi el presente escrivano de que doy fee $=\mathrm{d} .{ }^{\mathrm{r}}$ Joseph Luis Cabral $=\mathrm{d} .{ }^{\mathrm{r}}$ Joseph Xavier Sarm. ${ }^{\text {to }}$

Fólio 4627v.

Gregorio Arras caeta $=$ Blas Joachin de Brisuela = Ante mi Clemente Guerrero, escrivano pp. ${ }^{\text {co }}$ y del Numero $=$

Yo ${ }^{246}$ el ess. ${ }^{\text {No }}$ hize saver el auto antezedente al Sargento ma. ${ }^{\mathrm{r}} \mathrm{d} .{ }^{\mathrm{n}}$ Fernando Fabro, quien quedò enterado de su contexto, $\mathrm{y}$ lo firme $=$

Guerrero $^{247}$, escrivano pp. ${ }^{\mathrm{co}}=$ Yo el escrivano hize saver dho auto à d. ${ }^{\mathrm{n}}$ Lorenzo

Ynfante, quien quedò enterado de su conthen.do y lo firme $=$ Guerrero, escriv. ${ }^{\circ}$

publico $^{248}=$ em m.do me $=$ Alto $=p=$ Libras $=$ ugã $=$ entre renglo mes $=r e=c=c$

curaran $=$ vgã $=$ Testado $=$ alguno $=$

No vale

Concuerda esta copia con los autos oxig. ${ }^{\text {s }}$ de su contexto, à que me refiero, que para efecto de Remitir la pres. ${ }^{\text {te }}$ a la Superior Junta Pronvicial de la cuidad de Buenos Ayres tuve a la vista, com los que las Corregi, y conzerte, està certa, y

\footnotetext{
${ }^{246}$ Do lado esquerdo da palavra "Yo" está a palavra "Dilig. " (diligência).

${ }^{247}$ Do lado esquerdo da palavra "Guerrero" está a palavra "outra \%”.

${ }^{248}$ Do lado esquerdo da palavra "publico" está escrito "fee de erratas".
} 
Fólio 4628r.

verdadeira, à que em lo nez. ${ }^{0}$ a dhos oxig. ${ }^{\mathrm{s}}$ me remito, y de mandato de los señores de esta y. ${ }^{\mathrm{e}}$ Junta Municipal de Temporalidades doy la presentes em cord. ${ }^{\mathrm{a}}$ en tres de Julio de mil setez. ${ }^{\mathrm{s}}$ setenta y dos años; $\mathrm{Y}$ em fee de ello lo signo y firmo $=$

\author{
Em tesíml. de verdade \\ Clemente Guerrero \\ Ess.no pub.co y del Jeuml
}

Drôz al tranz.l

\title{
Rererências Bibliográficas
}

\section{Fontes}

Álvares Alcalá, Francisco (1850), Formulario Universal ó Guia Practica del Medico, del Cirujano y del Farmaceutico, Madrid: Librería de Don Angel Calleja.

Bluteau, Raphael (1712-1728), Vocabulario portuguez \& latino: aulico, anatomico, architectonico, Coimbra: Collegio das Artes da Companhia de Jesus, 8 v. in http://www.brasiliana.usp.br/dicionario/edicao/1

Boy, Jaime (1840), Diccionario teórico, práctico, histórico y geográfico de comercio. Barcelona: Imprenta de Valentin Torras. T. IV.

Colección General de las Providencias hasta aquí tomadas por el Gobierno sobre el extrañamiento y ocupación de Temporalidades de los Regulares de la Compañía que existían en los Domínios de S.M. de España, Indias e islas Filipinas, a consecuencia del Real Decreto de 27 de febrero y Pragmática Sanción de 2 de abril de este año (1767-1784), Cinco Partes o Volúmenes separados, Madrid: Imprenta Real de la Gaceta.

Farmacopea Matritense (1823) Por Cosme Martinez.

Gregorio, Manuel Hernández de (1803), Diccionario Elemental de Farmácia, Botânica y Materia Medica, ó Aplicaciones de los Fundamentos de la Química Moderna á la Farmacia en todos sus ramos [...] Madrid: Imprenta Real.

Nieremberg, Juan Eusebio (1644), Vida del santo padre y gran siervo de Dios el Francisco de Borja, Tercero General de la Compañia de Iesus y antes duque quarto de Gandia. Madri: Por Maria de Quiñones.

Núñez, Miguel Gerónimo Suarez (1780), Memórias instructivas, y curiosas sobre Agricultura, Comercio...Por D. Pedro Marin.

Palacios, Felix (1730), Palestra Pharmaceutica chymico-galenica, Madri: Por Juan de Sierra.

Picatoste, Felipe (1887), Diccionario Popular de la Lengua Castellana, Madrid: Est. Tip. Editorial de G. Estrada, Dr. Fourquet. 
Pinto, J. F. Macedo (1852), Compendio de Veterinaria ou Medicina dos Animaes Domesticos, Coimbra: Na Imprensa da Universidade.

Roma, Fracisco Morato (1753), Luz da Medicina, Pratica Racional e Methodica, Guia de Enfermeyros. Coimbra: Casa de Francisco de Oliveira.

Silva, Antonio Moraes (1813), Diccionario da lingua portugueza - recompilado dos vocabularios impressos ate agora, e nesta segunda edição novamente emendado e muito acrescentado, Por Antonio de Morales Silva, Lisboa: Typographia Lacerdina.

Silveira Pinto, A. A. (1846), Codigo Pharmaceutico Lusitano, Porto: Typographia da Revista.

\section{Infografia}

http://al-quimicos.blogspot.com.br/2007/05/sabes-lo-que-es-el-espritu-de-vino.html Acesso 15/06/13

http://books.google.com.br/books?id=MegBiGZMaYC\&pg=PA154\&lpg=PA154\&dq=e st\%C3\%ADope+mineral\&source=bl\&ots=rxv0VsjVvK\&sig=pzVlBd16PreysCwAJ_I8 ZqKVDFE\&hl=pt\&sa=X\&ei=4I92UZubDKvL0gHzr4DYBw\&redir_esc=y\#v=onepage \&q=est\%C3\%ADope\%20mineral\&f=false Acesso: 24/03/13

http://www.brasiliana.usp.br/dicionario/edicao/1

http://fernandezsendin.blogspot.com.br/2010/10/la-carqueixa-planta-medicinal.html Acesso: 11/05/2013

http://fondosdigitales.us.es/fondos/libros/1300/1/apologia-del-azeite-de-aparicio-a-loscirujanos-desta-ciudad-de-seuilla/ Acesso: 15/04/13.

http://milksci.unizar.es/bioquimica/temas/aditivos/conservantes.html Acesso: 18/04/13

http://portuguese.alibaba.com/product-free/gum-ammoniac-104359202.html Acesso: 31/03/13.

http://super.abril.com.br/ciencia/elementos-morte-446035.shtml Acesso: 21/05/13

http://www.botanical-online.com/medicinalsaguadelcarmen.htm Acesso: 13/05/13

http://www.bristhar.com.ve/tragacanto.html Acesso: 01/06/2013

http://www.cronicadelasmerindades.com/investiga/investigacion181.pdf

Acesso: 13/05/2013.

http://www.gemselect.com/spanish/gem-info/medicinal-gemstones.php Acesso em $11 / 04 / 13$

http://www.hipernatural.com/es/pltsantonico.html Acesso: 04/05/2013

http://www.kremer-pigmente.com/es/medios--aglutinantes-und-colas/aglutinantessolubles-en-disolvente/balsamos-und-ceras/goma-asafetida-500-g-62070.html Acesso: 21/05/13

http://www.linax.com.br/oleos.html Acesso: 02/06/13 
http://www.mast.br/multimidias/botanica/frontend_html/artigos/index-id=111.html Acesso: 26/06/13

http://www.pescaderiascorunesas.es/productos/ficha/?id=87 Acesso: 03/06/13

www.wordreference.com/definicion/euforbio Acesso: 18/04/13

\section{Bibliografía}

Almeida, Carla Berenice Starling de (2009), Medicina mestiça: saberes e práticas curativas nas minas setecentistas, 1. ed. São Paulo: Annablume, v. 1.

Dávila, Joaquín Herrera (2010), El Hospital del Cardenal de Sevilla y el Doctor Hidalgo de Agüero. Visión Histórico Sanitária del Hospital de San Hermenegildo. (1455- 1837), Sevilha: Fundación de Cultura Andaluza.

Furtado, Júnia Ferreira (2005), Barbeiros, cirurgiões e médicos na Minas colonial. Revista do Arquivo Público Mineiro, Belo Horizonte, v. XL, p. 88-105.

Gisbert, Eugenio de Bustos (1986), La Composición Nominal en español, Salamanca: Ediciones Universidad de Salamanca.

Gracia SJ, Joaquín (2006), Los jesuitas en Córdoba - Desde la Colonia hasta la Segunda Guerra Mundial. Tomo I: 1585-1626; Tomo II: 1626-1700, Córdoba: Editora de la Universidad Católica de Córdoba.

Gregorio, Manuel Hernandez de (1803), Diccionario Elemental de Farmácia, Botânica y Materia Medica, ó Aplicaciones de los Fundamentos de la Química Moderna á la Farmacia en todos sus ramos [...] Madrid: Imprenta Real.

Meier, Johannes, “Totus mundus nostra fit habitation”. Jesuitas del território de lengua alemana en la América portuguesa y española. http://www.bn.gov.ar/descargas/pnbc/studios/pnbc_estudio8_ jesuitasalemanes.pdf. [Acesso 08 de fevereiro de 2011].

Ortis Crespo, Fernando (1994), La Cinchona antes y despues del Virreinato del Conde de Cinchon. Caracas: Interciencia, 19(3), p. 130-136.

Page, Carlos; Vera de Flachs, María Cristina (2010), “Textos Clásicos de Medicina en la Botica Jesuítica del Paraguay”, Cuadernos del Instituto Antonio de Nebrija. Madrid, 13 p. 117-135. 